\section{Pacific Northwest}

National Laboratory

Operated by Battelle for the

U.S. Department of Energy

\title{
Critical Mass Laboratory Solutions Precipitation, Calcination, and Moisture Uptake Investigations
}

C.H. Delegard

S.I. Sinkov

B.K. McNamara

S.A. Jones
G.S. Barney

A.J. Schmidt

R.L. Sell

June 2002

Prepared for the U.S. Department of Energy under Contract DE-AC06-76RL01830 


\title{
DISCLAIMER
}

This report was prepared as an account of work sponsored by an agency of the United States Government. Neither the United States Government nor any agency thereof, nor Battelle Memorial Institute, nor any of their employees, makes any warranty, express or implied, or assumes any legal liability or responsibility for the accuracy, completeness, or usefulness of any information, apparatus, product, or process disclosed, or represents that its use would not infringe privately owned rights. Reference herein to any specific commercial product, process, or service by trade name, trademark, manufacturer, or otherwise does not necessarily constitute or imply its endorsement, recommendation, or favoring by the United States Government or any agency thereof, or Battelle Memorial Institute. The views and opinions of authors expressed herein do not necessarily state or reflect those of the United States Government or any agency thereof.

\author{
PACIFIC NORTHWEST NATIONAL LABORATORY \\ operated by \\ BATTELLE \\ for the \\ UNITED STATES DEPARTMENT OF ENERGY \\ under Contract DE-ACO6-76RLO183O
}

Printed in the United States of America
Available to DOE and DOE contractors from the
Office of Scientific and Technical Information,
P.O. Box 62, Oak Ridge, TN 37831-0062;
ph: (865) 576-8401
fax: (865) 576-5728
email: reports@adonis.osti.gov

\author{
Available to the public from the National Technical Information Service, \\ U.S. Department of Commerce, 5285 Port Royal Rd., Springfield, VA 22161 \\ ph: (800) 553-6847 \\ fax: (703) 605-6900 \\ email: orders@ntis.fedworld.gov \\ online ordering: http://www.ntis.gov/ordering.htm
}

This document was printed on recycled paper. 


\section{Critical Mass Laboratory Solutions Precipitation, Calcination, and Moisture Uptake Investigations}
C. H. Delegard
G. S. Barney ${ }^{(\mathrm{a})}$
S. I. Sinkov
A. J. Schmidt
B. K. McNamara
R. L. Sell
S. A. Jones ${ }^{(a)}$

June 2002

Prepared for

the U.S. Department of Energy

under Contract DE-AC06-76RL01830

Pacific Northwest National Laboratory

Richland, Washington 99352

(a) Fluor Hanford, Inc. 


\section{Summary}

Scientists at Pacific Northwest National Laboratory and the Hanford Plutonium Process Support Laboratory of the Plutonium Finishing Plant (PFP) studied flowsheet conditions to selectively precipitate plutonium oxalate from uranium-bearing Critical Mass Laboratory (CML) solutions in the PFP Room 230-C precipitation apparatus and dry, calcine, and package the resulting filtercake. The objective of the processing was to generate a stable plutonium oxide-bearing powder [as judged by loss-on-ignition (LOI) measurements] that can pass the DOE-STD-3013 moisture criterion $(<0.5 \mathrm{wt} \% \mathrm{LOI})$ when produced in the ambient humidity of the remote mechanical C (RMC) line in the PFP. Based on these studies with simulated and genuine CML solutions and various constituent materials, process conditions were recommended under which the product powders can reasonably be expected to pass the moisture criterion when packaged in the RMC line at relative humidity up to $80 \%$. ${ }^{\text {(a) }}$ Furthermore, LOI could monitor product oxide moisture.

The CML solutions are mixtures, in various ratios, of plutonium nitrate and uranium nitrate (of natural and depleted enrichment) in 2-3 M nitric acid with small concentrations of gadolinium nitrate $(0.54 \mathrm{~g} \mathrm{Gd} / \mathrm{L})$ and boric acid $(1.66 \mathrm{~g} \mathrm{~B} / \mathrm{L})$. About half of the total plutonium was present in solution streams in which the uranium concentration was over twice that of the plutonium (Table S.1). Therefore, experimentation focused on these more uranium-rich compositions.

Table S.1. Compositions and Distributions of CML Solution Feed

\begin{tabular}{|c|c|c|c|c|c|}
\hline \multirow{2}{*}{$\begin{array}{c}\text { Atom\% } \% \\
{ }^{240} \mathrm{Pu}\end{array}$} & \multicolumn{2}{|c|}{ Concentration $(\mathrm{g} / \mathrm{L})$} & \multirow{2}{*}{$\begin{array}{l}\text { Pu:U } \\
\text { ratio }\end{array}$} & \multicolumn{2}{|c|}{ wt\% of total } \\
\hline & $\mathbf{P u}$ & $\mathbf{U}$ & & $\mathbf{P u}$ & $\mathbf{U}$ \\
\hline 6.1 & 80.0 & 180.0 & 0.44 & 22 & 41 \\
\hline 6.1 & 77.6 & 178.8 & 0.43 & 29 & 56 \\
\hline 11.86 & 41.2 & 33.6 & 1.23 & 3 & 2 \\
\hline 22.7 & 210.6 & 5.8 & 36.3 & 46 & 1 \\
\hline
\end{tabular}

The following were the general objectives of the laboratory test program that began in October 2001:

- Provide data to the PFP and DOE on oxalate precipitation, calcination, and packaging of CML solution products in the ambient humidity RMC line to support authorization of the planned December 2001 shift to CML solution processing.

- Within this goal, maximize process throughput and minimize worker dose by minimizing process steps and operation time.

- Use existing plant equipment and procedures to the extent possible.

- Minimize the volume of material to be packaged for long-term storage in expensive 3013 containers.

Based on these general objectives, the following specific objectives were pursued:

- Identify precipitation conditions, using solid oxalic acid reagent, that maximize plutonium recovery from CML solution (minimize losses to the filtrate) and minimize uranium contamination (presence of unwanted uranium present in the long-term plutonium product storage container).

(a) Thermal stabilization in the RMC line is administratively controlled so that it does not occur at relative humidity exceeding $60 \%$. 
- Determine the effects of uranium, gadolinium, and boron contaminants on the affinity of the oxide product for water under humid conditions and identify plant operational conditions (humidity and time) that guarantee meeting the $<0.5 \mathrm{wt} \%$ moisture criterion for the product to be held under long-term storage. In particular, determine whether calcined products containing more than $8 \mathrm{wt} \%$ uranium and stored under ambient humidity conditions can meet the $0.5 \mathrm{wt} \%$ moisture criterion.

- Determine the feasibility of using LOI to determine moisture concentrations on calcined oxalate products from the CML feed solutions.

The recommended processing conditions summarized in Table S.2 were adopted by the PFP and are based on small-scale experimental testing. Subsequent experience with full-scale operations suggested only minor adjustments to the proposed parameters. Process parameters that are not listed remained unchanged from practices used to process the plutonium product nitrate solutions by precipitation with oxalic acid and calcination of the product cake.

Table S.2. Recommended Processing Conditions

\begin{tabular}{|c|c|c|}
\hline Process Step & Process Parameter & Condition \\
\hline \multirow[t]{2}{*}{ Feed make-up } & CML concentration & Dilute to $<50 \mathrm{~g} \mathrm{Pu} / \mathrm{L}$ \\
\hline & $\mathrm{HNO}_{3}$ concentration & $\begin{array}{l}\text { Minimize by dilution of CML feed solution with } 0.25 \mathrm{M} \\
\mathrm{HNO}_{3} \text { to } 1-2 \mathrm{M} \text { final acid concentration }\end{array}$ \\
\hline \multirow[t]{2}{*}{ Oxalic acid addition } & Purity and preparation & Reagent-grade, air-dried, and crushed \\
\hline & Quantity & $\begin{array}{l}\text { 2.1-2.3 oxalate:Pu mole ratio; addition above } 2.3 \\
\text { oxalate:Pu mole ratio causes undesired uranyl oxalate } \\
\text { precipitation and lower Pu loading in the product } 3013 \\
\text { vessels }^{\text {(a) }}\end{array}$ \\
\hline Mixing & Time & $30-60$ minutes \\
\hline Filtration & Rinsing & Not required \\
\hline Calcination & $\begin{array}{l}\text { Time between end of } \\
\text { calcination and hermetic } \\
\text { packaging }\end{array}$ & $<3$ days at $<60 \%$ relative humidity \\
\hline $\begin{array}{l}\text { Moisture } \\
\text { measurement }\end{array}$ & wt $\%$ moisture & $\begin{array}{l}\text { Weight measurements before and after two hours of heating } \\
\text { in } 1000^{\circ} \mathrm{C} \text { furnace to measure LOI }\end{array}$ \\
\hline
\end{tabular}

(a) Tests showed that products containing even $100 \mathrm{wt} \% \mathrm{U}_{3} \mathrm{O}_{8}$ satisfy moisture criterion DOE-STD-3013-2000. However, inordinate amounts of uranium increase the required number, handling, and storage costs of 3013 containers and the risk of excessive moisture absorption at extended exposure to humid atmospheres.

The experimental program provided data to the PFP operator and DOE to support authorization of processing the CML solutions and packaging the products in the RMC line using LOI to demonstrate compliance with the DOE-STD-3013 moisture criterion. The timely provision of the test data allowed a smooth transition to processing the CML streams with no plant downtime. The specific recommendations provided to the PFP were applied to the process such that process throughput was increased about three-fold over the original baseline process. As a result, about two months of processing were saved and worker dose was decreased. The process recovered over $99 \%$ of the plutonium while dramatically decreasing the volume of material committed to expensive life-cycle costs in 3013 containers compared with the baseline process.

The proposed operational conditions, properties of the intermediate and final products, and supporting laboratory results are presented in this report. 


\section{Contents}

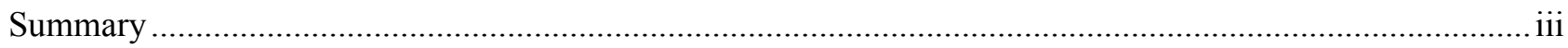

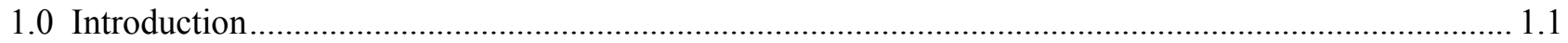

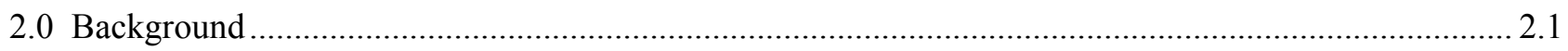

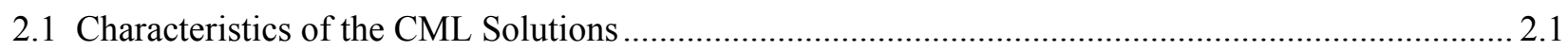

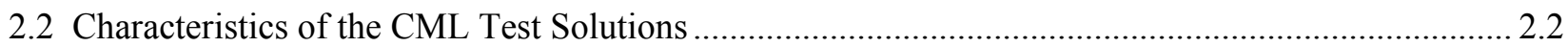

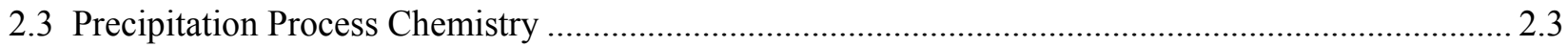

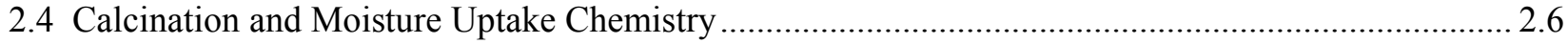

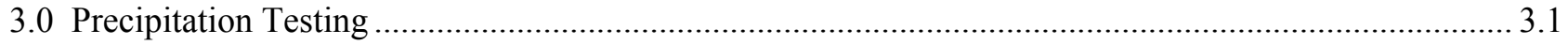

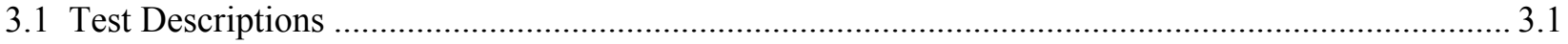

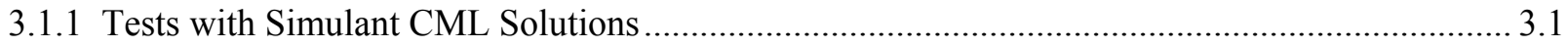

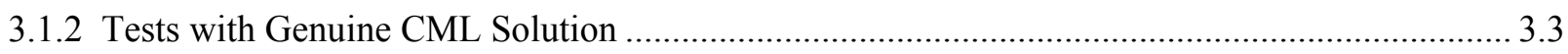

3.2 Results for Small-Scale Tests with Simulant CML Solution.............................................................. 3.4

3.3 Modeling Results from the Precipitation Testing .......................................................................... 3.9

3.4 Results for Small-Scale Tests with Genuine CML Solution.......................................................... 3.10

3.5 Principal Findings from the Precipitation Testing ....................................................................... 3.11

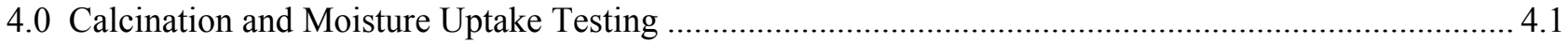

4.1 Calcination and Moisture Uptake Studies of Uranyl Oxalate and Nitrate ........................................ 4.1

4.2 Calcination and Moisture Uptake Studies of the Effects of Boric Acid and Gadolinium................. 4.10

4.3 Tests of the Calcination and Moisture Uptake of Simulated CML Oxalate Precipitate Product....... 4.13

4.4 Tests of the Calcination and Moisture Uptake of Genuine CML Oxalate Precipitate Product.......... 4.16

4.5 Principal Findings from the Calcination and Moisture Uptake Testing......................................... 4.18

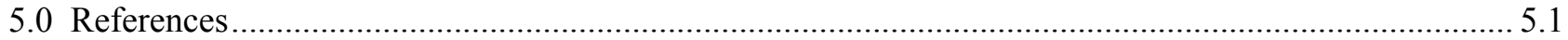




\section{Figures}

1 Absorption Spectrum of Genuine CML Solution Diluted in $3 \mathrm{M} \mathrm{HNO}_{3}$ Compared with $\mathrm{Pu}(\mathrm{IV})$ and $\mathrm{Pu}(\mathrm{VI})$ Spectra in $1 \mathrm{M} \mathrm{HNO}_{3}$

2 Solubilities of $\mathrm{Pu}(\mathrm{IV})$ Oxalate and U(VI) Oxalate in Nitric Acid Solution

3 Absorption Spectra of Simulant Critical Mass Laboratory Solution Precipitation Tests in $2 \mathrm{M} \mathrm{HNO}_{3}$ as a Function of Oxalate:Pu Ratio

4 Absorption Spectra of Oxalate Precipitation Supernatant Solution Before and After

Mn-Catalyzed Oxidation to $\mathrm{Pu}(\mathrm{VI})$ and Oxalate

5 Extent of Uranium, Plutonium, and Americium Precipitation at 90 Minutes as a Function of Oxalate:Pu Ratio in $1.14 \mathrm{M} \mathrm{HNO}_{3}$

6 Extent of Uranium, Plutonium, and Americium Precipitation at 90 Minutes as a Function of Oxalate:Pu Ratio in $2 \mathrm{M} \mathrm{HNO}_{3}$

7 Extent of Uranium, Plutonium, and Americium Precipitation at 90 Minutes as a Function of Oxalate:Pu Ratio in $3 \mathrm{M} \mathrm{HNO}_{3}$

8 Extent of Uranium, Plutonium, and Americium Precipitation at 90 Minutes as a Function of Oxalate:Pu Ratio in Simulant 1.5 $\mathrm{M} \mathrm{HNO}_{3} \mathrm{CML}$ Solution Containing Trace B and Gd

9 Extent of Uranium, Plutonium, and Americium Precipitation as a Function of Oxalate:Pu Ratio in All Simulant CML Solution Tests...

10 Plutonium Concentrations in the Filtrate as a Function of Oxalate:Pu Ratio

11 Americium Concentrations in the Filtrate as a Function of Oxalate:Pu Ratio....

12 Modeled and Observed Extent of Uranium and Plutonium Precipitation as a Function of Oxalate:Pu Ratio in $1.5 \mathrm{M} \mathrm{HNO}_{3}$

13 Extent of Uranium, Plutonium, and Americium Precipitation as a Function of Oxalate:Pu Ratio in All Genuine CML Solution Tests....

14 Infrared Spectrum of $\mathrm{UO}_{2} \mathrm{C}_{2} \mathrm{O}_{4} \cdot 3 \mathrm{H}_{2} \mathrm{O}$ Product.

15 SEM Photomicrographs of $\mathrm{U}_{3} \mathrm{O}_{8}$ Product of Thermal Decomposition of $\mathrm{UO}_{2} \mathrm{C}_{2} \mathrm{O}_{4} \cdot 3 \mathrm{H}_{2} \mathrm{O}$

16 X-Ray Diffraction Scans of Products Taken at Various Depths in $1000^{\circ} \mathrm{C}$ Calcination of $\mathrm{UO}_{2} \mathrm{C}_{2} \mathrm{O}_{4} \cdot 3 \mathrm{H}_{2} \mathrm{O}$ Product in a Crucible

17 Moisture Uptake on $\mathrm{U}_{3} \mathrm{O}_{8}$ Prepared by $1000^{\circ} \mathrm{C}$ Calcination of Uranyl Oxalate as a Function of Humidity and Exposure Time

18 Moisture Uptake at $80 \% \mathrm{RH}$ on $\mathrm{U}_{3} \mathrm{O}_{8}$ Prepared by $650^{\circ} \mathrm{C}$ and $1000^{\circ} \mathrm{C}$ Calcination of Uranyl Nitrate as a Function of Exposure Time

19 Moisture Uptake at $80 \% \mathrm{RH}$ on $\mathrm{U}_{3} \mathrm{O}_{8}$ Prepared by $650^{\circ} \mathrm{C}$ and $1000^{\circ} \mathrm{C}$ Calcination of Uranyl Oxalate as a Function of Exposure Time

20 SEM Photomicrographs of $\mathrm{U}_{3} \mathrm{O}_{8}$ Products of Thermal Decomposition of $\mathrm{UO}_{2}\left(\mathrm{NO}_{3}\right)_{2} \cdot 6 \mathrm{H}_{2} \mathrm{O}$

21 X-Ray Diffraction Scans of Products of $1000^{\circ} \mathrm{C}$ Calcination of $\mathrm{UO}_{2} \mathrm{C}_{2} \mathrm{O}_{4} \cdot 3 \mathrm{H}_{2} \mathrm{O}$ and $650^{\circ} \mathrm{C}$ Calcination of $\mathrm{UO}_{2}\left(\mathrm{NO}_{3}\right)_{2} \cdot 6 \mathrm{H}_{2} \mathrm{O}$ After $400 \mathrm{hr}$ Exposure to $80 \% \mathrm{RH}$ Air.

22 Differential Thermogravimetry of Products of $1000^{\circ} \mathrm{C}$ Calcination of $\mathrm{UO}_{2} \mathrm{C}_{2} \mathrm{O}_{4} \cdot 3 \mathrm{H}_{2} \mathrm{O}$ and $650^{\circ} \mathrm{C}$ Calcination of $\mathrm{UO}_{2}\left(\mathrm{NO}_{3}\right)_{2} \cdot 6 \mathrm{H}_{2} \mathrm{O}$ After $400 \mathrm{hr}$ at $80 \% \mathrm{RH}$

23 Moisture Uptake on Calcined $\mathrm{CeO}_{2}-\mathrm{B}_{2} \mathrm{O}_{3}$ as a Function of Humidity and Exposure Time

24 Moisture Uptake on Calcined $\mathrm{Gd}_{2} \mathrm{O}_{3}$ as a Function of Exposure Time 
$25 \mathrm{X}$-Ray Diffraction Scans of Mixed $\mathrm{Pu} / \mathrm{U}$ Oxides Produced by $1000^{\circ} \mathrm{C}$ Calcination of $\mathrm{PuO}_{2}\left(\mathrm{C}_{2} \mathrm{O}_{4}\right)_{2} \cdot 6 \mathrm{H}_{2} \mathrm{O}$ and 500,700 , and $1000^{\circ} \mathrm{C}$ Calcination of $\mathrm{UO}_{2} \mathrm{C}_{2} \mathrm{O}_{4} \cdot 3 \mathrm{H}_{2} \mathrm{O}$ under Nominal Process Conditions

26 Moisture Uptake on Calcined Simulated CML Product Prepared at 2.25:1 and 2.75:1

Oxalate:Pu Ratio as a Function of Humidity and Exposure Time.....

27 Moisture Uptake on Calcined Simulated CML Product Prepared at 2.25:1 and 2.75:1

Oxalate:Pu Ratio at $80 \%$ RH as a Function of Exposure Time

28 TGA of Genuine Calcined CML Product A 4.17

29 MS Analyses of $\mathrm{H}_{2} \mathrm{O}$ and $\mathrm{CO}_{2}$ from Genuine Calcined CML Product A.

30 MS Analysis of Oxygen from Genuine Calcined CML Product A

\section{Tables}

1 Compositions and Distributions of CML Solution Feed .....................................................................

2 Compositions of Simulant and Genuine CML Test Solutions.......................................................2.2

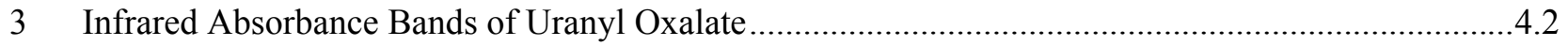

4 Thermal Analysis Results for Uranyl Oxalate Heating in Air .......................................................4.3

5 Plutonium Concentrations, LOI, and TGA/MS for Oxide from Genuine CML Test Solutions .........4.16 


\subsection{Introduction}

The magnesium hydroxide precipitation process began at the Plutonium Finishing Plant (PFP) on the Hanford Site in September 2000 as the initial step to stabilize nitric acid solutions of plutonium by converting them to plutonium oxide. The stabilization satisfies DNFSB 94-1/2000-1 requirements for removing the PFP plutonium inventory in anticipation of plant decommissioning. To overcome process throughput challenges and achieve product quality targets, oxalic acid supplanted magnesium hydroxide as the baseline precipitation process reagent for solution stabilization in July 2001. This decision was based on favorable results from a process test with impure (single-/double-pass filtrate) plutonium solutions also containing iron, sodium, and other metals. The oxalate reagent's selectivity to precipitate the desired plutonium but leave most other metals dissolved (where they could be consigned to waste instead of accompanying the plutonium) was a major advantage over the magnesium hydroxide reagent because solids quantities requiring drying, calcination, and long-term monitored storage were decreased. With magnesium hydroxide, not only plutonium but also undesired multivalent metals (e.g., iron, aluminum, chromium) precipitate, needlessly increasing the processing time and the plutonium product bulk.

From August 2001 to January 2002, only pure plutonium product nitrate solutions, having little other dissolved metal, were processed by oxalate precipitation. After all of the pure product nitrate solutions were stabilized, PFP planned to begin oxalate processing of Critical Mass Laboratory (CML) solutions. The CML solutions contain plutonium with high concentrations of isotopically natural and depleted uranium and low concentrations of boric acid and gadolinium nitrate. To ensure complete plutonium precipitation, initial plans called for addition of enough oxalate to precipitate the plutonium and nearly all of the uranium as well. Because the natural and depleted uranium is of little value, no specific requirement existed for its recovery from solution, stabilization, and storage. Therefore, decreases in processing time, product bulk, radiation dose to workers, and shipping and storage requirements could be realized if uranium were not precipitated with the desired plutonium product. In addition, improved process throughput, PFP utilization, radiological dose, and schedule could be obtained if it could be demonstrated that acceptably low moisture concentrations could be attained by thermal stabilization of plutonium product containing uranium, boron, and gadolinium impurities in the ambient humidity of the remote mechanical line $\mathrm{C}$ (RMC) of the PFP and if the low moisture concentration could be measured by the existing loss-on-ignition (LOI) technique.

Laboratory testing was required to establish processing parameters to minimize uranium precipitation and to verify that acceptably low moisture uptake on the calcined uranium-bearing plutonium oxide product could be achieved to meet the DOE-STD-3013-2000 standards. The following are the general objectives of the laboratory test program, which began in October 2001:

- Provide data to the PFP and DOE on oxalate precipitation, calcination, and packaging in the ambient humidity RMC line to support authorization of the planned December 2001 shift to CML solution processing.

- Within this goal, maximize process throughput and minimize worker dose by minimizing process steps and operation time.

- Use existing plant equipment and procedures to the extent possible.

- Minimize the volume of material to be packaged for long-term storage in expensive 3013 containers. 
Based on these general objectives, the following specific objectives were pursued:

- Using oxalic acid reagent, identify precipitation conditions that maximize plutonium recovery (minimize losses to the filtrate) and minimize uranium contamination (presence of unwanted uranium present in the long-term plutonium product storage container).

- Determine the effects of uranium, gadolinium, and boron contaminants on the affinity of the oxide product for water under humid conditions and identify plant operational conditions (humidity and time) that guarantee meeting the $<0.5 \mathrm{wt} \%$ moisture criterion for the product to be held under longterm storage. In particular, determine whether calcined products containing more than $8 \mathrm{wt} \%$ uranium and stored under ambient humidity conditions could meet the $<0.5 \mathrm{wt} \%$ moisture criterion.

- Determine the feasibility of using LOI to determine moisture concentrations on calcined oxalate products from the CML feed solutions.

The test results described in this report provided the bases for the selection of operating parameters to precipitate plutonium from CML solutions. The results demonstrated that the calcined product prepared according to plant practices (two hours calcination at $1000^{\circ} \mathrm{C}$ ) should exhibit acceptable moisture uptake properties even when handled in the gloveboxes of the PFP RMC line when operations are permitted at less than $60 \%$ relative humidity $(\mathrm{RH})$. It was also shown that moisture concentrations could be measured by LOI.

The laboratory testing with simulated CML solutions was conducted in radiological gloveboxes at the Pacific Northwest National Laboratory (PNNL). Testing with genuine CML solutions was conducted at the Plutonium Process Support Laboratory (PPSL) of the PFP. This work was sponsored by the Nuclear Materials Focus Area (NMFA) and performed in accordance with Technical Task Plan RL31NM11, Rev. 1, Tasks A and C. The Fluor Hanford Technology Management Program provided additional support. The lab work was designed, executed, and reported and plant operating conditions recommended in three months (mid-October 2001 to mid-January 2002), allowing PFP operations to transition smoothly from processing the product nitrate solutions to DOE-approved processing of the CML solutions.

Section 2 of this report describes the CML solutions, CML solution simulants, and the expected oxalate precipitation, calcination, and moisture uptake chemistries. In Section 3, the precipitation testing, results, and proposed operational parameters are described. Tests of oxalate precipitate calcination, product calcine characterization, and moisture uptake of uranium oxide $\left(\mathrm{U}_{3} \mathrm{O}_{8}\right)$, boric acid with cerium oxide (a plutonium oxide surrogate), and calcined uranium-bearing plutonium oxides from CML simulants and genuine CML solutions are described in Section 4 along with the principal findings and expected operational performance for calcination processing in the RMC line. Cited references are listed in Section 5. 


\subsection{Background}

Several aqueous nitric acid solutions of uranium and plutonium were prepared for use at the CML during previous studies of nuclear criticality safety. These CML solutions were stored at the PFP and were part of PFP's plutonium-bearing solutions inventory that needed to be converted to the stable $\mathrm{PuO}_{2}$ form for long-term storage under the DOE-STD-3013-2000 criteria (DOE 2000). The characteristics of the CML solutions and the solutions used in the laboratory testing are described in this section. The oxalate precipitation process, oxalate calcination chemistry, and potential for moisture uptake also are explained.

First, in Section 2.1, the origins and compositions of the uranium-rich CML solution types are considered in light of the relative plutonium and uranium inventories, isotopic compositions, and chemical valences (oxidation states). The nitric acid concentrations and the presence of small but potentially significant concentrations of boron and gadolinium are described in Section 2.2. The precipitation chemistry of tetravalent plutonium oxalate then is explained based on technical literature and plutonium processing plant practices, including current practices at PFP, in Section 2.3. The expected precipitation behaviors of hexavalent uranium, gadolinium, and boric acid in the CML media are discussed in Section 2.4. In particular, the relative solubilities of the plutonium and uranium oxalates are contrasted to illustrate the technical basis for the proposed selective precipitation of the desired plutonium away from the more concentrated but undesired uranium. The drying and calcination behaviors of the expected $\mathrm{Pu}(\mathrm{IV})$ oxalate filtercake with accompanying uranyl oxalate solids, uranyl nitrate solution, gadolinium oxalate solids, and boric acid then are described. The hygroscopicity of the product oxides is considered within this discussion.

\subsection{Characteristics of the CML Solutions}

The compositions and approximate inventory distributions of the CML solutions requiring stabilization are presented in Table 1. About half of the plutonium and $97 \%$ of the uranium mass are found in the two groups composed of weapons-grade $\left(6.1\right.$ atom $\left.\%{ }^{240} \mathrm{Pu}\right)$ material. These two groups also have practically the same solution composition $(\sim 80 \mathrm{~g} \mathrm{Pu} / \mathrm{L}$ and $\sim 180 \mathrm{~g} \mathrm{U} / \mathrm{L})$. The other two solution groups compose the remaining half of the CML solutions' plutonium inventory. They have lower concentrations of uranium relative to the plutonium and therefore should have process behaviors intermediate between pure plutonium product nitrate (for which the plant has extensive current processing experience) and the $\sim 80 \mathrm{~g} \mathrm{Pu} / \mathrm{L}$ and $\sim 180 \mathrm{~g} \mathrm{U} / \mathrm{L}$ materials represented by the first two CML solution groups. For this reason, experimentation focused on the processing properties of the first two groups.

Table 1. Compositions and Distributions of CML Solution Feed

\begin{tabular}{|c|c|c|c|c|c||}
\hline \multirow{2}{*}{$\begin{array}{c}\text { Atom\% } \\
{ }^{240} \mathbf{P u}\end{array}$} & \multicolumn{2}{|c|}{ Concentration (g/L) } & \multirow{2}{*}{$\begin{array}{c}\text { Pu:U } \\
\text { ratio }\end{array}$} & \multicolumn{2}{|c|}{$\begin{array}{c}\text { wt\% of CML } \\
\text { inventory }\end{array}$} \\
\cline { 2 - 3 } \cline { 5 - 6 } & $\mathbf{P u}$ & $\mathbf{U}$ & & $\mathbf{P u}$ & $\mathbf{U}$ \\
\hline 6.1 & 80.0 & 180.0 & 0.44 & 22 & 41 \\
\hline 6.1 & 77.6 & 178.8 & 0.43 & 29 & 56 \\
\hline 11.86 & 41.2 & 33.6 & 1.23 & 3 & 2 \\
\hline 22.7 & 210.6 & 5.8 & 36.3 & 46 & 1 \\
\hline
\end{tabular}


All solutions are in strong $(\sim 2-3 \mathrm{M})$ nitric acid. The CML solutions with $6.1 \%{ }^{240} \mathrm{Pu}$ and $\sim 80 \mathrm{~g} \mathrm{Pu} / \mathrm{L}$ and $\sim 180 \mathrm{~g} \mathrm{U} / \mathrm{L}$ also have present small concentrations of boron and gadolinium, both neutron poisons, at $1.66 \mathrm{~g} \mathrm{~B} / \mathrm{L}$ and $0.54 \mathrm{~g} \mathrm{Gd} / \mathrm{L}$. The solutions with 6.1 and $11.86 \%{ }^{240} \mathrm{Pu}$ contain depleted $\left(0.66\right.$ atom $\left.\%{ }^{235} \mathrm{U}\right)$ uranium.

\subsection{Characteristics of the CML Test Solutions}

Laboratory tests with both simulant and genuine CML feed solutions focused on the first two solution groups given in Table 1 because the concentration of uranium is higher than that of plutonium. Plant criticality safety requirements constrain solution concentration in the precipitation vessel to less than $50 \mathrm{~g}-\mathrm{Pu} / \mathrm{L}$. In addition, precipitates prepared from higher-concentration solutions are difficult to separate from the mother solution. Therefore, the simulant tests were prepared to be dilutions of the nominal $80 \mathrm{~g}$ $\mathrm{Pu} / \mathrm{L}-180 \mathrm{~g} \mathrm{U} / \mathrm{L}$ to the level of $\sim 50 \mathrm{~g} \mathrm{Pu} / \mathrm{L}$ (and consequently $\sim 12 \mathrm{~g} \mathrm{U} / \mathrm{L}$ ). The tests with genuine CML solution were dilutions of an original CML solution prepared using $0.5 \mathrm{M} \mathrm{HNO}_{3}$ or water as the diluent. The compositions of the simulant and genuine CML test solutions (including the concentrations of ${ }^{241} \mathrm{Am}$, the decay product of ${ }^{241} \mathrm{Pu}$ ) are given in Table 2. The genuine CML solution contains $\sim 0.3 \mathrm{~g}{ }^{241} \mathrm{Am} / \mathrm{L}$ or an Am:Pu mass ratio of about 0.0039:1. The tests with simulant CML solution also began with an aged plutonium(IV) nitrate $\left[\mathrm{Pu}\left(\mathrm{NO}_{3}\right)_{4}\right]$ solution (i.e., had ${ }^{241} \mathrm{Am}$ from decay of ${ }^{241} \mathrm{Pu}$ ) that contained a somewhat lower relative concentration of in-grown ${ }^{241} \mathrm{Am}$ (0.0021:1 Am:Pu mass ratio).

Spectrophotometry verified that the plutonium stock used in the simulant tests was exclusively tetravalent. The genuine CML solution used in the lab testing also was measured by absorption spectrophotometry (Figure 1) and showed the expected exclusive existence of the dissolved plutonium as $\mathrm{Pu}(\mathrm{IV})$ with no evidence of $\mathrm{Pu}(\mathrm{VI})$ (strong sharp peak at $831 \mathrm{~nm}$ ) or $\mathrm{Pu}(\mathrm{III})$ (strong peaks at 565 and $595 \mathrm{~nm}$ ). The primary U(VI) spectrum features occur below $460 \mathrm{~nm}$ and are off-scale around 415-420 $\mathrm{nm}$. The CML solution spectrum in Figure 1 is compared with spectra of $\mathrm{Pu}(\mathrm{IV})$ and $\mathrm{Pu}(\mathrm{VI})$ prepared by treatment of $\mathrm{Pu}$ nitrate stock solutions with hydrogen peroxide $\left(\mathrm{H}_{2} \mathrm{O}_{2}\right)$ and potassium permanganate $\left(\mathrm{KMnO}_{4}\right)$, respectively.

Table 2. Compositions of Simulant and Genuine CML Test Solutions

\begin{tabular}{|c|c|c|c|c|c|c|}
\hline \multirow{2}{*}{ Test Solution } & \multicolumn{5}{|c|}{ Concentration (g/L) } & \multirow{2}{*}{$\begin{array}{c}\mathrm{HNO}_{3} \text { Conc } \\
\text { (M) }\end{array}$} \\
\hline & $\mathbf{P u}$ & $\mathbf{U}$ & Am & B & Gd & \\
\hline \multirow{4}{*}{ Simulant CML } & 52.6 & 112 & 0.108 & 0 & 0 & 1.14 \\
\hline & 52.6 & 112 & 0.108 & 0 & 0 & 2.00 \\
\hline & 52.6 & 112 & 0.108 & 0 & 0 & 3.00 \\
\hline & 52.6 & 112 & 0.108 & 1.04 & 0.34 & 1.50 \\
\hline Genuine feed CML & 74.2 & 210 & 0.287 & Unk. $^{(a)}$ & Unk. $^{(a)}$ & 2.48 \\
\hline \multirow{4}{*}{$\begin{array}{l}\text { Dilutions of genuine feed CML } \\
\text { with } 0.5 \mathrm{M} \mathrm{HNO}_{3} \text { or water (see } \\
\text { text) }\end{array}$} & 37.1 & 105 & 0.143 & Unk. $^{(a)}$ & Unk. $^{(a)}$ & 1.49 \\
\hline & 24.7 & 69.8 & 0.096 & Unk. $^{(a)}$ & Unk. $^{(a)}$ & 1.16 \\
\hline & 18.6 & 52.4 & 0.072 & Unk. $^{(a)}$ & Unk. $^{(a)}$ & 1.00 \\
\hline & 50.7 & 96.4 & 0.197 & Unk. $^{(a)}$ & Unk. $^{(a)}$ & 1.33 \\
\hline
\end{tabular}




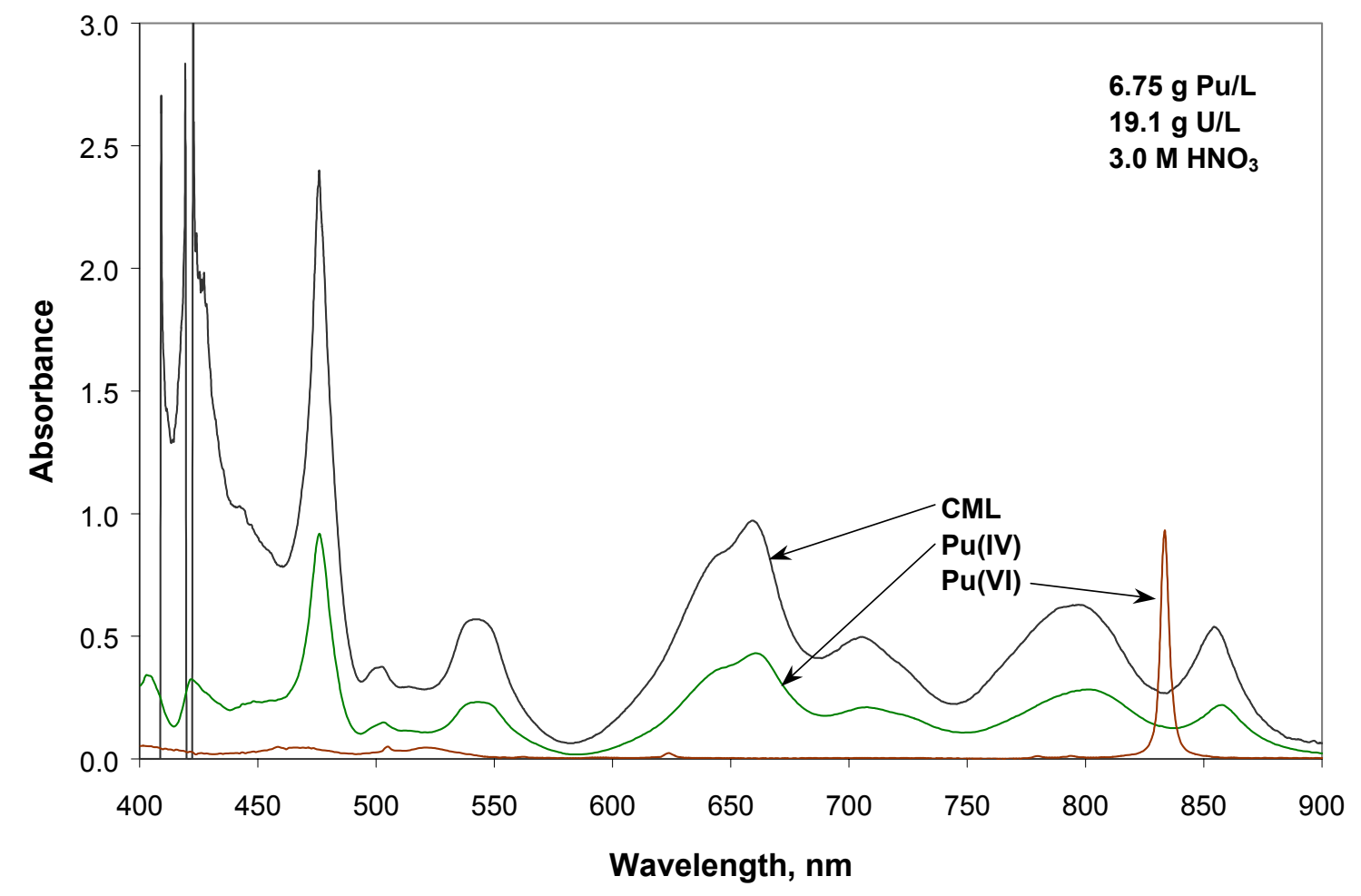

Figure 1. Absorption Spectrum of Genuine CML Solution Diluted in $3 \mathrm{M} \mathrm{HNO}_{3}$ (6.75 g Pu/L; $19.1 \mathrm{~g} \mathrm{U} / \mathrm{L}$ ) Compared with $\mathrm{Pu}(\mathrm{IV})$ and $\mathrm{Pu}(\mathrm{VI})$ Spectra in $1 \mathrm{M} \mathrm{HNO}_{3}$

\subsection{Precipitation Process Chemistry}

Since August 2001, the precipitation of plutonium(IV) oxalate has been used for plutonium-bearing solution stabilization operations in the PFP as the first step in the conversion to plutonium dioxide $\left(\mathrm{PuO}_{2}\right)$ for long-term storage. The technology of $\mathrm{Pu}(\mathrm{IV})$ oxalate precipitation in the purification and preparation of $\mathrm{PuO}_{2}$ is well established, beginning with pioneering work and practice at Hanford and continuing to commercial processes for the preparation of $\mathrm{PuO}_{2}$ (Harmon et al. 1961; Weigel et al. 1986 and references therein; Greintz and Neal 1976). In this section, $\mathrm{Pu}(\mathrm{IV})$ oxalate process chemistry is described briefly in light of the input CML solution composition and the constraints of PFP equipment and practices. Special note is taken of the relatively high solubility of uranium(VI) oxalate compared with $\mathrm{Pu}(\mathrm{IV})$ oxalate and the prospective exploitation of this difference to effect a selective precipitation and separation of plutonium from CML solutions.

In typical plant conditions used to precipitate $\mathrm{Pu}(\mathrm{IV})$ oxalate, hydrogen peroxide is added to the feed solution or precipitation vessel to chemically reduce any plutonium present as the more soluble hexavalent (VI) state to the desired less soluble (IV) state. Both batch and continuous precipitation processes have been used with direct strike (oxalic acid, $\mathrm{H}_{2} \mathrm{C}_{2} \mathrm{O}_{4}$, solution added to plutonium solution), reverse strike (plutonium added to oxalic acid), or concurrent addition of the separate plutonium and oxalic acid streams to a precipitation vessel. Feed solutions range from 5 to $250 \mathrm{~g} \mathrm{Pu} / \mathrm{L}$ in 1 to $5 \mathrm{M} \mathrm{HNO}_{3}$. To aid crystal growth, the precipitation generally is conducted at elevated temperatures (e.g., 40 to $60^{\circ} \mathrm{C}$ ) with oxalic acid 
introduced as a concentrated $(\sim 1 \mathrm{M})$ solution to give 0.1 to $0.2 \mathrm{M}$ excess $\mathrm{H}_{2} \mathrm{C}_{2} \mathrm{O}_{4}$ in the slurry. Oxalic acid concentrations too much in excess of the stoichiometry increase the solubility of plutonium by forming soluble, higher- $\mathrm{Pu}(\mathrm{IV})$ oxalate complexes [e.g., $\mathrm{Pu}\left(\mathrm{C}_{2} \mathrm{O}_{4}\right)_{3}{ }^{2-}$; see Reas 1949]. Digestion times at the elevated temperatures range from about 0.5 to 1 hour before the solids are filtered from solution and the filtercake washed with dilute $(\sim 0.05 \mathrm{M})$ oxalic acid in $\sim 2 \mathrm{M} \mathrm{HNO}_{3}$ to remove interstitial impurities. Filtrates typically are 30 to $60 \mathrm{mg} \mathrm{Pu} / \mathrm{L}$ or $1.2-2.5 \times 10^{-4} \mathrm{M} \mathrm{Pu}$ under process conditions.

The PFP converts plutonium present in concentrated solutions for packaging and storage as $\mathrm{PuO}_{2}$ using the $\mathrm{Pu}(\mathrm{IV})$ oxalate precipitation process. In contrast with typical plutonium oxalate and $\mathrm{PuO}_{2}$ production operations, product purity and crystal quality are of secondary concern in present PFP operations, while higher throughput, lower operator dose, and low plutonium loss to the filtrate remain important. For process simplicity and to conform with existing process equipment (6-inch-diameter glass columns) installed originally for plutonium precipitation using magnesium hydroxide powder reagent, $\mathrm{Pu}(\mathrm{IV})$ oxalate precipitation at PFP is performed by adding oxalic acid crystals (not solution) directly to the plutonium feed solution. The spectrophotometric analysis reported in the previous section confirmed the expectation that water radiolysis (with concomitant generation of hydrogen peroxide during long-term storage of the CML solution) had caused the plutonium to become exclusively tetravalent. Therefore, adjustment of plutonium valence by hydrogen peroxide addition is judged to be unnecessary. The mixture of plutonium feed solution and oxalic acid crystals is stirred by air sparge from the column bottom caused by applying a vacuum to the top of the column. No solution heating (or cooling) is provided in the existing design. After the desired agitation time, the product slurry is drained through a pan filter (a glazed polypropylene felt filter is used) to collect the $\mathrm{Pu}(\mathrm{IV})$ oxalate filtercake. Though the $\mathrm{Pu}(\mathrm{IV})$ oxalate cake may be rinsed with water on the filter pan in case undesirable interstitial contaminants must be removed, rinsing ordinarily can be avoided to decrease dose and process time. The moist slurry is manually scraped into metal boats for subsequent drying on a hotplate and calcination to satisfy DOE-STD-3013 criteria while the filtrates pass through a secondary filter and are analyzed; if of suitably low concentration, they are made alkaline with sodium hydroxide, with sodium nitrite added as a corrosion inhibitor, and discharged to the Hanford underground tank farm waste system.

Each mole of $\mathrm{Pu}(\mathrm{IV})$ nitrate reacts with two moles of oxalic acid and six moles of water to produce one mole of $\mathrm{Pu}(\mathrm{IV})$ oxalate hexahydrate and four moles of nitric acid:

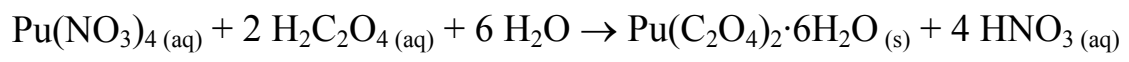

Therefore, the complete precipitation of $50 \mathrm{~g} \mathrm{Pu} / \mathrm{L}(\sim 0.21 \mathrm{M} \mathrm{Pu})$ will increase $\mathrm{HNO}_{3}$ concentration by about $0.84 \mathrm{M}$.

The precipitation of $\mathrm{U}(\mathrm{VI})$ nitrate with oxalic acid proceeds according to the reaction:

$$
\mathrm{UO}_{2}\left(\mathrm{NO}_{3}\right)_{2(\mathrm{aq})}+\mathrm{H}_{2} \mathrm{C}_{2} \mathrm{O}_{4(\mathrm{aq})}+3 \mathrm{H}_{2} \mathrm{O} \rightarrow \mathrm{UO}_{2} \mathrm{C}_{2} \mathrm{O}_{4} \cdot 3 \mathrm{H}_{2} \mathrm{O}_{(\mathrm{s})}+2 \mathrm{HNO}_{3} \text { (aq). }
$$

The solubility of the uranyl oxalate $\left(\mathrm{UO}_{2} \mathrm{C}_{2} \mathrm{O}_{4} \cdot 3 \mathrm{H}_{2} \mathrm{O}\right)$ is about 100 times higher than that of $\mathrm{Pu}(\mathrm{IV})$ oxalate $\left[\mathrm{Pu}\left(\mathrm{C}_{2} \mathrm{O}_{4}\right)_{2} \cdot 6 \mathrm{H}_{2} \mathrm{O}\right]$. For example, at $2 \mathrm{M} \mathrm{HNO}_{3}$, the uranium concentration above a uranyl oxalate precipitate is $\sim 11 \mathrm{~g} / \mathrm{L}$ (based on Chernyaev 1966), while the plutonium concentration above a $\mathrm{Pu}(\mathrm{IV}$ ) oxalate precipitate is $0.128 \mathrm{~g} / \mathrm{L}$ (Mandleberg et al. 1961). The solubilities are compared in Figure 2. 


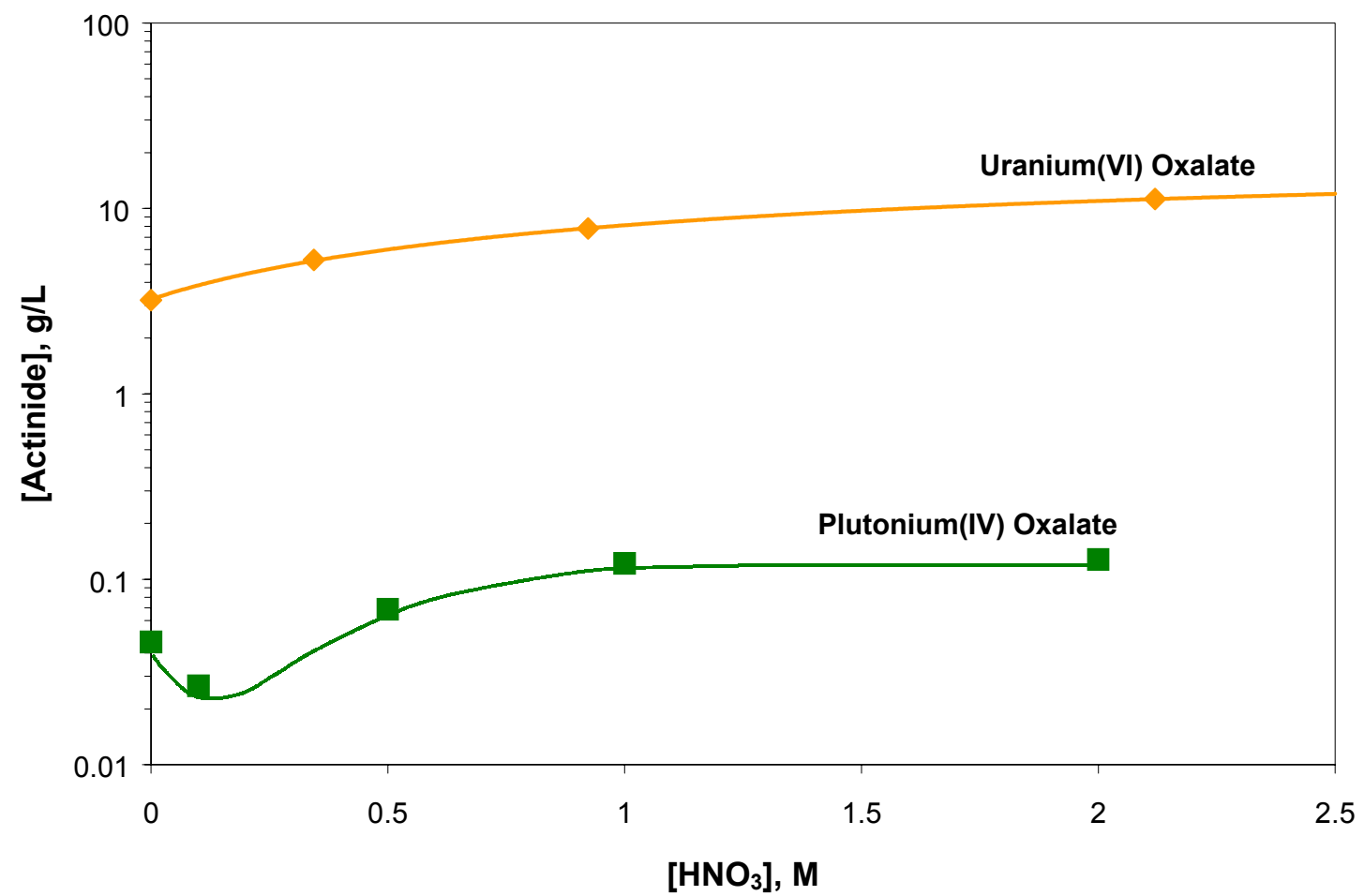

Figure 2. Solubilities of $\mathrm{Pu}(\mathrm{IV})$ Oxalate and U(VI) Oxalate in Nitric Acid Solution (Mandleberg et al. 1961; Chernyaev 1966)

The boric acid $\left(\mathrm{H}_{3} \mathrm{BO}_{3}\right)$ present in the CML solutions is not expected to precipitate with any of the solution components and should only accompany the filtercake as part of the interstitial liquid. Gadolinium is present in the acidic CML solutions at about $0.54 \mathrm{~g} \mathrm{Gd}(\mathrm{III}) / \mathrm{L}(\sim 0.0034 \mathrm{M}$ compared with $\sim 0.33 \mathrm{M} \mathrm{Pu}$ and $\sim 0.76 \mathrm{M} \mathrm{U})$. The solubility of $\mathrm{Gd}(\mathrm{III})$ oxalate $\left[\mathrm{Gd}_{2}\left(\mathrm{C}_{2} \mathrm{O}_{4}\right)_{3} \cdot 10 \mathrm{H}_{2} \mathrm{O}\right]$ is about $0.001 \mathrm{M}$ in $2 \mathrm{M} \mathrm{HNO}_{3}$ and $0.00026 \mathrm{M}$ in $2 \mathrm{M} \mathrm{HNO}_{3} / 0.1 \mathrm{M} \mathrm{H}_{2} \mathrm{C}_{2} \mathrm{O}_{4}$; the solubility increases with increasing $\mathrm{HNO}_{3}$ concentration (Sarver and Brinton 1927). Based on these solubilities, coprecipitation or carrier precipitation of Gd(III) with $\mathrm{Pu}(\mathrm{IV})$ oxalate is likely.

Based on the data shown in Figure 2 and assuming chemical equilibrium is reached, uranyl oxalate should not precipitate to a large extent if the quantity of oxalic acid is limited to that just required to precipitate the less soluble $\mathrm{Pu}(\mathrm{IV})$ oxalate (i.e., just over a 2:1 oxalate:Pu ratio). However, uranium is present in high concentrations in the CML solution, and mass action effects may initially cause unwanted precipitation of uranyl oxalate, even at low oxalate:Pu ratios. Therefore, the precipitation kinetics and relative labilities of the respective plutonium and uranium oxalate precipitates may affect product quality and must be investigated. It also is recognized that uranyl oxalate may precipitate by evaporative concentration during the hotplate heating of the $\mathrm{Pu}(\mathrm{IV})$ oxalate filtercake that contains uranyl nitrate and excess oxalic acid in the interstitial solution. In addition, because of imprecise analytical data and variable process line holdup volumes, knowledge of the plutonium quantity being delivered to the PFP precipitation process vessels may not be accurate enough ( $\pm 5 \%$ relative) to permit selective and complete Pu precipitation with no accompanying uranium precipitation. Therefore, to avoid the inordinate loss of $\mathrm{Pu}$ to the filtrate and the consequential required recycling, process operations might require a stoichiometric overdose of oxalic acid. 
Because these conditions may cause limited uranyl oxalate precipitation, testing must include the preparation and properties of products from super-stoichiometric oxalate:Pu ratios.

In summary, the primary objective of the laboratory precipitation testing was to investigate the relative differences in the solubilities of the $\mathrm{Pu}(\mathrm{IV})$ and $\mathrm{U}(\mathrm{VI})$ oxalates with the objective, ideally, of precipitating the less soluble $\mathrm{Pu}(\mathrm{IV})$ oxalate completely while leaving the more soluble U(VI) oxalate in solution. Examination of the reaction stoichiometries and process conditioning factors suggest that the testing should be done at oxalate:Pu mole ratios ranging from just below the stoichiometric $2: 1$ to higher values. In addition to the oxalate:Pu ratio, the effects of acid concentration and mixing time should be explored using solid oxalic acid addition and reaction at ambient temperatures based on existing PFP precipitation equipment and practices.

\subsection{Calcination and Moisture Uptake Chemistry}

Plutonium oxide produced from solution stabilization efforts at the PFP must satisfy the criteria for long-term storage under DOE-STD-3013-2000 (DOE 2000). For optimum plant utilization, thermal processing should occur in the RMC line, which is subject to the ambient humidity of the PFP. Because the PFP uses evaporative cooling in the hot summer months, $\mathrm{RH}$ of $70 \%$ or more can be reached. However, thermal stabilization operations in the RMC line are administratively controlled so as not to occur if the RH exceeds $60 \%$. Furthermore, a value of $0.2 \mathrm{wt} \%$, ascribed to water, is added to weight losses found by LOI measurement at the PFP. This so-called "LOI bias" of $0.2 \mathrm{wt} \%$ is applied to account for moisture uptake on pure plutonium dioxide occurring during the period from the end of mandated two-hour heating at $1000^{\circ} \mathrm{C}$ until weighing, when the LOI sample was cooled to room temperature. The "LOI bias" value is based on a survey of the technical literature that showed that moisture uptake by pure plutonium dioxide calcined above $900^{\circ} \mathrm{C}$ is less than $0.16 \mathrm{wt} \%$ if exposed to air during cooling at $\mathrm{RH}$ below $72 \%$. ${ }^{(\mathrm{a})}$ The expected behaviors of CML oxalate precipitation constituents during calcination and subsequent moisture uptake of the calcine constituents by exposure to humid air are considered in this section.

Plutonium(IV) oxalate $\left[\mathrm{Pu}\left(\mathrm{C}_{2} \mathrm{O}_{4}\right)_{2} \cdot 6 \mathrm{H}_{2} \mathrm{O}\right]$ is the primary product of the CML solution precipitation step. $\mathrm{The} \mathrm{Pu}(\mathrm{IV})$ oxalate undergoes two dehydration steps by heating before final decomposition to the product $\mathrm{Pu}$ (IV) oxide, $\mathrm{PuO}_{2}$ (Myers 1956). Thus, with heating, $\mathrm{Pu}\left(\mathrm{C}_{2} \mathrm{O}_{4}\right)_{2} \cdot 6 \mathrm{H}_{2} \mathrm{O}$ loses five waters of hydration at about $80^{\circ} \mathrm{C}$ to form $\mathrm{Pu}\left(\mathrm{C}_{2} \mathrm{O}_{4}\right)_{2} \cdot \mathrm{H}_{2} \mathrm{O}$, which then decomposes to $\mathrm{Pu}\left(\mathrm{C}_{2} \mathrm{O}_{4}\right)_{2}$ at $80-150^{\circ} \mathrm{C}$. In this decomposition, the dry $\mathrm{Pu}(\mathrm{IV})$ oxalate produced following dehydration is reduced to $\mathrm{Pu}(\mathrm{III})$ oxalate $\left[\mathrm{Pu}_{2}\left(\mathrm{C}_{2} \mathrm{O}_{4}\right)_{3}\right]$ accompanied by the oxidation of oxalate to form carbon dioxide $\left(\mathrm{CO}_{2}\right)$ :

$$
\mathrm{Pu}\left(\mathrm{C}_{2} \mathrm{O}_{4}\right)_{2} \rightarrow 0.5 \mathrm{Pu}_{2}\left(\mathrm{C}_{2} \mathrm{O}_{4}\right)_{3}+\mathrm{CO}_{2}
$$

The $\mathrm{Pu}(\mathrm{III})$ oxalate ultimately decomposes to $\mathrm{PuO}_{2}$ with the release of $\mathrm{CO}_{2}$ and carbon monoxide (CO):

$$
0.5 \mathrm{Pu}_{2}\left(\mathrm{C}_{2} \mathrm{O}_{4}\right)_{3} \rightarrow \mathrm{PuO}_{2}+\mathrm{CO}_{2}+2 \mathrm{CO}
$$

(a) Barney GS. June 21, 2001. Internal letter 1AC00-PPSL-01-030 to LF Perkins Jr, "Bias Correction for LOI Measurements on Relatively Pure $\mathrm{PuO}_{2}$." Fluor Hanford Incorporated, Richland, WA. 
The decomposition of anhydrous $\mathrm{Pu}(\mathrm{IV})$ oxalate to $\mathrm{Pu}(\mathrm{III})$ oxalate begins at $130-150^{\circ} \mathrm{C}$. In addition to thermal decomposition, the $\mathrm{Pu}(\mathrm{III})$ oxalate reacts rapidly and exothermically with air or oxygen beginning at about 150 to $200^{\circ} \mathrm{C}$ to form $\mathrm{PuO}_{2}$. The cake bed temperature can increase by several hundred degrees because the carbon monoxide produced in the decomposition reaction:

$$
2 \mathrm{CO}+\mathrm{O}_{2} \rightarrow 2 \mathrm{CO}_{2}
$$

burns with oxygen $\left(\mathrm{O}_{2}\right)$. As discussed in the previous section on precipitation reactions, uranyl oxalate $\left(\mathrm{UO}_{2} \mathrm{C}_{2} \mathrm{O}_{4} \cdot 3 \mathrm{H}_{2} \mathrm{O}\right)$ should not precipitate to a large extent in the PFP precipitation reactor if the quantity of oxalic acid is limited to that required to precipitate the less soluble $\mathrm{Pu}(\mathrm{IV})$ oxalate (i.e., around a 2.1-2.3 oxalate:Pu ratio), but higher oxalate ratios may be used in plant processing, and interstitial uranyl nitrate and excess oxalic acid were precipitated during the hotplate heating of the $\mathrm{Pu}(\mathrm{IV})$ oxalate filtercake.

The thermal decomposition of $\mathrm{UO}_{2} \mathrm{C}_{2} \mathrm{O}_{4} \cdot 3 \mathrm{H}_{2} \mathrm{O}$ has been studied both in the presence and absence of oxygen gas or air (e.g., Bressat et al. 1963; Tel et al. 1999). The loss of two waters of hydration occurs above $100^{\circ} \mathrm{C}$, and loss of the third water occurs at about $170^{\circ} \mathrm{C}$. The thermal decomposition of the anhydrous uranyl oxalate occurs at $365^{\circ} \mathrm{C}$ in air (Tel et al. 1999), apparently to form $\mathrm{UO}_{2}$, as judged by the observed $34.52 \%$ weight loss (34.36 wt $\%$ theoretical) in $\sim 20-\mathrm{mg}$ scale thermogravimetric analysis (TGA). Thermal decomposition to $\mathrm{UO}_{2}$ also was observed in vacuum and under nitrogen gas $\left(\mathrm{N}_{2}\right)$ atmosphere in the earlier tests (Bressat et al. 1963). Dehydration occurs at lower temperatures under vacuum than in air; the loss of the first two waters of hydration occurs below $100^{\circ} \mathrm{C}$ and the third begins at about $120^{\circ} \mathrm{C}$. In this earlier study, exothermic decomposition of the anhydrous uranyl oxalate to $\mathrm{UO}_{2}$ in air was observed at $367^{\circ} \mathrm{C}$. However, the $\mathrm{UO}_{2}$ intermediate is transitory and quickly forms $\mathrm{U}_{3} \mathrm{O}_{8}$ with further heating in air.

Uranyl nitrate, dissolved in the interstitial liquid of the filtercake, crystallizes at low temperature to form the hexahydrate salt $\left[\mathrm{UO}_{2}\left(\mathrm{NO}_{3}\right)_{2} \cdot 6 \mathrm{H}_{2} \mathrm{O}\right]$. This salt begins to lose water at $46^{\circ} \mathrm{C}$ (Duval 1963), decomposes in air to reach $\gamma-\mathrm{UO}_{3}$ at about 400 to $600^{\circ} \mathrm{C}$ (Weigel 1986), and converts to $\mathrm{U}_{3} \mathrm{O}_{8}$ above $760^{\circ} \mathrm{C}$ (Brouns and Mills 1955; Duval 1963; Vita et al. 1973).

Pure triuranium octaoxide $\left(\mathrm{U}_{3} \mathrm{O}_{8}\right)$ is the chemical weighing form for uranium formed in gravimetric analyses by ignition of most uranium organic compounds and inorganic salts. Its preparation and stability is discussed in analytical chemistry texts (e.g., Kolthoff et al. 1962 and references therein) and, as described in the previous paragraphs, would be expected to form by calcination of any uranyl nitrate or uranyl oxalate present in the CML product filtercake to temperatures around $800^{\circ} \mathrm{C}$. At temperatures above $\sim 800^{\circ} \mathrm{C}$, some loss of oxygen occurs to produce sub-stoichiometric $\mathrm{U}_{3} \mathrm{O}_{8-\mathrm{x}}$, but cooling in air restores the ideal $\mathrm{U}_{3} \mathrm{O}_{8}$ stoichiometry. Kolthoff and colleagues (1962) recommend ignition at $875 \pm 25^{\circ} \mathrm{C}$ for 16 hours for gravimetric analyses of uranium. They also note that the National Bureau of Standards (now the National Institute of Standards and Technology) recommends ignition of their provisional standard $\mathrm{U}_{3} \mathrm{O}_{8}$ in platinum at $900^{\circ} \mathrm{C}$ for one hour before use because "finely divided $\mathrm{U}_{3} \mathrm{O}_{8}$ slowly absorbs small quantities of water from the atmosphere." Recently, Icenhour and colleagues (2002) have studied weight uptake rates and amounts on $\mathrm{U}_{3} \mathrm{O}_{8}$ [prepared by overnight $650^{\circ} \mathrm{C}$ calcination of uranyl nitrate and identified by X-ray diffractometry (XRD)] under high humidity conditions. Moisture uptakes of $1 \mathrm{wt} \%$ at $70 \% \mathrm{RH}$ were found after about 30 days. Their results are considered in more detail later in this report.

Boric acid would be expected to accompany the $\mathrm{Pu}(\mathrm{IV})$ oxalate precipitate as part of the interstitial liquid. Boric acid thermally decomposes at about $300^{\circ} \mathrm{C}$ to form the vitreous (non-crystalline) boric oxide, 
$\mathrm{B}_{2} \mathrm{O}_{3}$ (Greenwood and Earnshaw 1984). The crystalline form of $\mathrm{B}_{2} \mathrm{O}_{3}$ melts at about $450^{\circ} \mathrm{C}$ but, because it does not boil until about $2250^{\circ} \mathrm{C}$, should remain as a melt with the $\mathrm{PuO}_{2}$ (and accompanying $\mathrm{U}_{3} \mathrm{O}_{8}$ and $\mathrm{Gd}_{2} \mathrm{O}_{3}$ ) product under calcination conditions. No data were found in the technical literature identifying specific compounds of plutonium, boron, and oxygen. Instead, it is expected that $\mathrm{B}_{2} \mathrm{O}_{3}$, known to act as a fluxing agent for chemical analyses to break down refractory materials for subsequent dissolution in aqueous media (Bock 1979), will act as a solvent for the refractory $\mathrm{PuO}_{2}$ to form a borate glass upon cooling. Though pure boric oxide is hygroscopic and may suffer significant moisture uptake on cooling in humid atmospheres, the hygroscopicity of any possible $\mathrm{B}_{2} \mathrm{O}_{3}-\mathrm{PuO}_{2}$ glass and its effect on stabilizing the CML solutions in the humid RMC glovebox line remain to be determined.

Assuming a Pu oxalate filtercake density of $1.9 \mathrm{~g} / \mathrm{mL}$ (as measured in FY 2001 lab studies of vacuum filtration), a Pu density in the cake of $0.37 \mathrm{~g} / \mathrm{mL}$ (also measured in FY 2001 studies), a 0.35 solution volume fraction in the filtercake, and a boron concentration of $1.04 \mathrm{~g} / \mathrm{L},{ }^{(a)}$ the mole ratio of $\mathrm{Pu}: \mathrm{B}$ in the moist filtercake would be about $45: 1$, or a mass ratio of about $1000: 1$. The distribution of $\mathrm{B}_{2} \mathrm{O}_{3}$ on the calcined $\mathrm{PuO}_{2}$ particles at such low ratios is unknown. However, it is possible that the hygroscopicity of $\mathrm{B}_{2} \mathrm{O}_{3}$ would worsen on a gram-by-gram basis because the $\mathrm{B}_{2} \mathrm{O}_{3}$ could form a film on the $\mathrm{PuO}_{2}$ particle surfaces. Under these nominal conditions, if the $\mathrm{B}_{2} \mathrm{O}_{3}$ distributed on the $\mathrm{PuO}_{2}$ surface were to fully rehydrate to form $\mathrm{H}_{3} \mathrm{BO}_{3}$, the water content of the resulting $\mathrm{PuO}_{2}-\mathrm{H}_{3} \mathrm{BO}_{3}$ mixture would be about $0.22 \mathrm{wt} \%$, or about half of the $0.5-\mathrm{wt} \% 3013$ threshold.

Under the same gravimetric and plutonium densities in the filtercake and with the uranium concentration in the supernatant (and interstitial) solution being $112 \mathrm{~g} \mathrm{U} / \mathrm{L}$, the Pu:U mole and mass ratios would be about 9.4:1 in the moist filtercake assuming no uranyl oxalate precipitation. If the moist filtercake then were dried and calcined without rinsing, the plutonium mass fraction in the thermally stabilized solid arising from selective precipitation of $\mathrm{Pu}(\mathrm{IV})$ oxalate (i.e., no uranium oxalate precipitation) and its subsequent calcination would be about $80 \mathrm{wt} \%$ (versus about $88 \mathrm{wt} \%$ for pure $\mathrm{PuO}_{2}$ ). As described above, the interstitial uranyl nitrate solution would dry and calcine to form $\mathrm{U}_{3} \mathrm{O}_{8}$ to give a uranium concentration in the calcine of about $7 \mathrm{wt} \%$ or a $\mathrm{U}_{3} \mathrm{O}_{8}$ concentration of about $10 \mathrm{wt} \%$ in the product calcine oxide.

The Gd(III) oxalate $\left[\mathrm{Gd}_{2}\left(\mathrm{C}_{2} \mathrm{O}_{4}\right)_{3} \cdot 10 \mathrm{H}_{2} \mathrm{O}\right]$ is expected to accompany or coprecipitate with the $\mathrm{Pu}(\mathrm{IV})$ oxalate. With heating, the $\mathrm{Gd}(\mathrm{III})$ oxalate dewaters at about $180^{\circ} \mathrm{C}$ and decomposes to the sesquioxide, $\mathrm{Gd}(\mathrm{III})$ oxide or $\mathrm{Gd}_{2} \mathrm{O}_{3}$, at about $700^{\circ} \mathrm{C}$ in the cubic structure (Gmelin 1974). The cubic structure is stable to about $1200^{\circ} \mathrm{C}$. Highly fired $\mathrm{Gd}(\mathrm{III})$ oxide is not as strongly hygroscopic as the lighter lanthanide oxides. For example, $\mathrm{Gd}_{2} \mathrm{O}_{3}$ fired to $1300^{\circ} \mathrm{C}$ does not react with boiling water (Curtis and Johnson 1957). Over one or more years' exposure to humid air, heavier lanthanide sesquioxides (firing temperature not specified) only incompletely pick up moisture and $\mathrm{CO}_{2}$ and retain the cubic phase (Bernal et al. 1987). If all of the Gd in the CML solution were to precipitate as the oxalate and report to the filtercake, be calcined to $\mathrm{Gd}_{2} \mathrm{O}_{3}$, and subsequently acquire moisture to form $\mathrm{Gd}(\mathrm{OH})_{3}$, the weight uptake of the Gd-bearing $\mathrm{PuO}_{2}$ calcine would be about $0.1 \mathrm{wt} \%$. $^{(\mathrm{b})}$

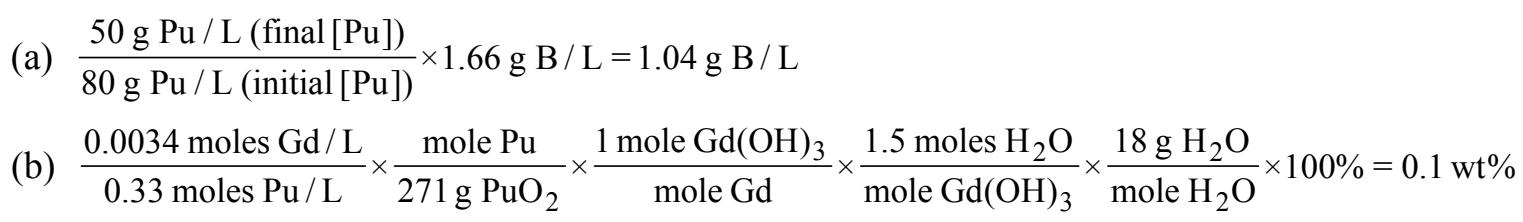


The effects of interstitial liquids containing nitric acid $\left(\mathrm{HNO}_{3}\right)$ and oxalic acid $\left(\mathrm{H}_{2} \mathrm{C}_{2} \mathrm{O}_{4}\right)$ on the drying and especially the calcination of $\mathrm{Pu}(\mathrm{IV})$ oxalate cake and associated U(VI) oxalate/nitrate are not known. Nitric acid and oxalic acid should not affect the oxidation/reduction behaviors of the gadolinium and boron oxides that are expected to remain in their respective highly stable (III) oxidation states. It is postulated that most of the $\mathrm{HNO}_{3}$ solution will evaporate before the $\mathrm{HNO}_{3}$ (a potent oxidant) can participate significantly in the thermochemical decompositions of the $\mathrm{Pu}(\mathrm{IV})$ and $\mathrm{U}(\mathrm{VI})$ oxalates. The $\mathrm{H}_{2} \mathrm{C}_{2} \mathrm{O}_{4}$ is not as volatile as $\mathrm{HNO}_{3}$; heating of the solution would first crystallize the dihydrate, $\mathrm{H}_{2} \mathrm{C}_{2} \mathrm{O}_{4} \cdot 2 \mathrm{H}_{2} \mathrm{O}$, by evaporation of water. The dihydrate then dehydrates at about $102^{\circ} \mathrm{C}$. Anhydrous oxalic acid begins to sublime at $157^{\circ} \mathrm{C}$ and decomposes to $\mathrm{CO}$ and $\mathrm{CO}_{2}$ at about $190^{\circ} \mathrm{C}$. The excess oxalic acid thus might act to inhibit the oxidation of $\mathrm{Pu}$ (III) oxalate or of the intermediate $\mathrm{UO}_{2}$ by blanketing these compounds from contact with $\mathrm{O}_{2}$, but ultimately $\mathrm{PuO}_{2}$ and $\mathrm{U}_{3} \mathrm{O}_{8}$ will form provided sufficient air contact is achieved for the $\mathrm{U}_{3} \mathrm{O}_{8}$. 


\subsection{Precipitation Testing}

The effects of oxalate:Pu ratio, acid concentration (which may be controlled by varying the strength of the acid used to dilute the feed CML solution), and precipitate digestion time on the relative precipitations of $\mathrm{Pu}(\mathrm{IV})$ and $\mathrm{U}(\mathrm{VI})$ oxalate were studied to identify the optimum conditions for process operations. Analyses also showed the behavior of americium(III) during the precipitation. The possible influence of boron and gadolinium on $\mathrm{Pu}(\mathrm{IV}), \mathrm{Am}(\mathrm{III})$, and U(VI) precipitation was investigated. To imitate plant operations, the precipitation testing occurred at room temperature, and the oxalic acid was introduced as the solid. The testing showed that precipitation occurred in the order $\mathrm{Pu}(\mathrm{IV})$ - $\mathrm{Am}(\mathrm{III})$ - U(VI) as the oxalate:Pu ratio increased and that plutonium recoveries improved with lower nitric acid concentrations. Most importantly, at controlled oxalate:Pu ratios, plutonium could be precipitated selectively even in the presence of high uranium concentrations.

\subsection{Test Descriptions}

The precipitation tests with the simulant CML solution were performed at PNNL, and the tests with dilutions of the genuine CML solution were conducted at the Plutonium Process Support Laboratory (PPSL) of the PFP. The precipitation tests and analyses were performed differently in the two laboratories but, as will be seen, the results generally are consistent.

\subsubsection{Tests with Simulant CML Solutions}

The simulant $\mathrm{CML}$ test solutions were prepared using the stock $\mathrm{Pu}(\mathrm{IV})$ nitrate solution, reagent grade uranyl nitrate hexahydrate $\left[\mathrm{UO}_{2}\left(\mathrm{NO}_{3}\right)_{2} \cdot 6 \mathrm{H}_{2} \mathrm{O}\right]$, and reagent grade nitric acid $\left(\mathrm{HNO}_{3}\right)$ to produce the final target compositions shown in Table 2. To prepare the test solution containing boron and gadolinium, reagent grade boric acid $\left(\mathrm{H}_{3} \mathrm{BO}_{3}\right)$ and gadolinium nitrate $\left[\mathrm{Gd}\left(\mathrm{NO}_{3}\right)_{3} \cdot 6 \mathrm{H}_{2} \mathrm{O}\right]$ also were used.

The precipitation tests were conducted using glass "1-dram" ( $\sim 5 \mathrm{~mL}$ total capacity) vials. Each vial contained an $x$-shaped Teflon-coated magnetic stirrer. The appropriate quantity of air-dried oxalic acid dihydrate $\left(\mathrm{H}_{2} \mathrm{C}_{2} \mathrm{O}_{4} \cdot 2 \mathrm{H}_{2} \mathrm{O}\right)$, obtained from the PFP and the same $99.5 \%$ pure reagent material used in oxalate precipitation operations (GFS Chemicals, Inc.), was added to each test vial. The CML simulant tests in 1.14 $\mathrm{M} \mathrm{HNO}_{3}$ were conducted at oxalate:Pu mole ratios of 1.75:1, 2.01:1, 2.19:1, 2.62:1, and 3.50:1 (versus 2.00:1 oxalate:Pu stoichiometry). In all other CML simulant tests (run at 1.50, 2, and $3 \mathrm{M} \mathrm{HNO}_{3}$ ), oxalate:Pu ratios were 2.01:1, 2.25:1, 2.5:1, 2.75:1, and 3:1.

After the weighed portions of dry oxalic acid were added, the vials were placed in the glovebox, $2600 \mu \mathrm{L}$ of the appropriate test solution added, and the oxalic acid/solution mixture was stirred at the highest rate for 30 minutes. The oxalic acid suspended efficiently in the yellow-olive U/Pu solution, and high shear was achieved using this technique. Even with effective mixing, about 1-2 minutes passed until the distinct onset of a latte-colored turbidity indicating $\mathrm{Pu}(\mathrm{IV})$ oxalate precipitation. From that point, the color and granularity of the precipitate slurry did not change visibly with time. However, oxalic acid dissolution and dispersion were noticeably retarded for the tests run in $3 \mathrm{M} \mathrm{HNO}_{3}$. 
After 30 minutes of stirring, the vials were centrifuged for two minutes, a $700-\mu \mathrm{L}$ aliquot of the supernatant solution withdrawn, ${ }^{(a)}$ and the remaining slurry re-agitated using the magnetic stirrer. The mixing was continued another 30 minutes and the sampling process repeated. Another sample was taken in a similar way after an additional 30 minutes' agitation. Samples thus were taken after 30, 60, and 90 minutes of contact. The supernatant aliquots were removed from the glovebox within five minutes of sampling, transferred to an open-face fume hood, and passed through $0.2-\mu \mathrm{m}$ pore size syringe filters to achieve final clarification.

The absorption spectra of the filtered supernatant solutions were measured using a dip-tube fiberoptic spectrometer (Spectral CCD Array, Spectral Instruments Inc., Tucson, AZ), with reference spectra taken using pure nitric acid of the same concentration. Spectra generally were gathered in the 400 to $900 \mathrm{~nm}$ range. The absorbance peaks [505 $\mathrm{nm}$ for $\mathrm{Am}, 660 \mathrm{~nm}$ for $\mathrm{Pu}(\mathrm{IV})$, and the U(VI) shoulder near $460 \mathrm{~nm}$ ] were measured against "valleys" (absorption minima) to determine net absorbance. The absorbance values were converted to concentrations using the Beer-Lambert Law and, where available, published values of molar absorptivity (for Pu and U) (Schmieder and Kuhn 1972). Additional investigations were performed to determine the effects of oxalate on the $\mathrm{U}(\mathrm{VI})$ and $\mathrm{Pu}(\mathrm{IV})$ spectra shapes and intensities and were used in assigning concentration values.

The spectra for the $2 \mathrm{M} \mathrm{HNO}_{3}$ test series, shown for illustration in Figure 3, indicate the decrease in intensity of the absorption peaks as the oxalate:Pu ratio increases.

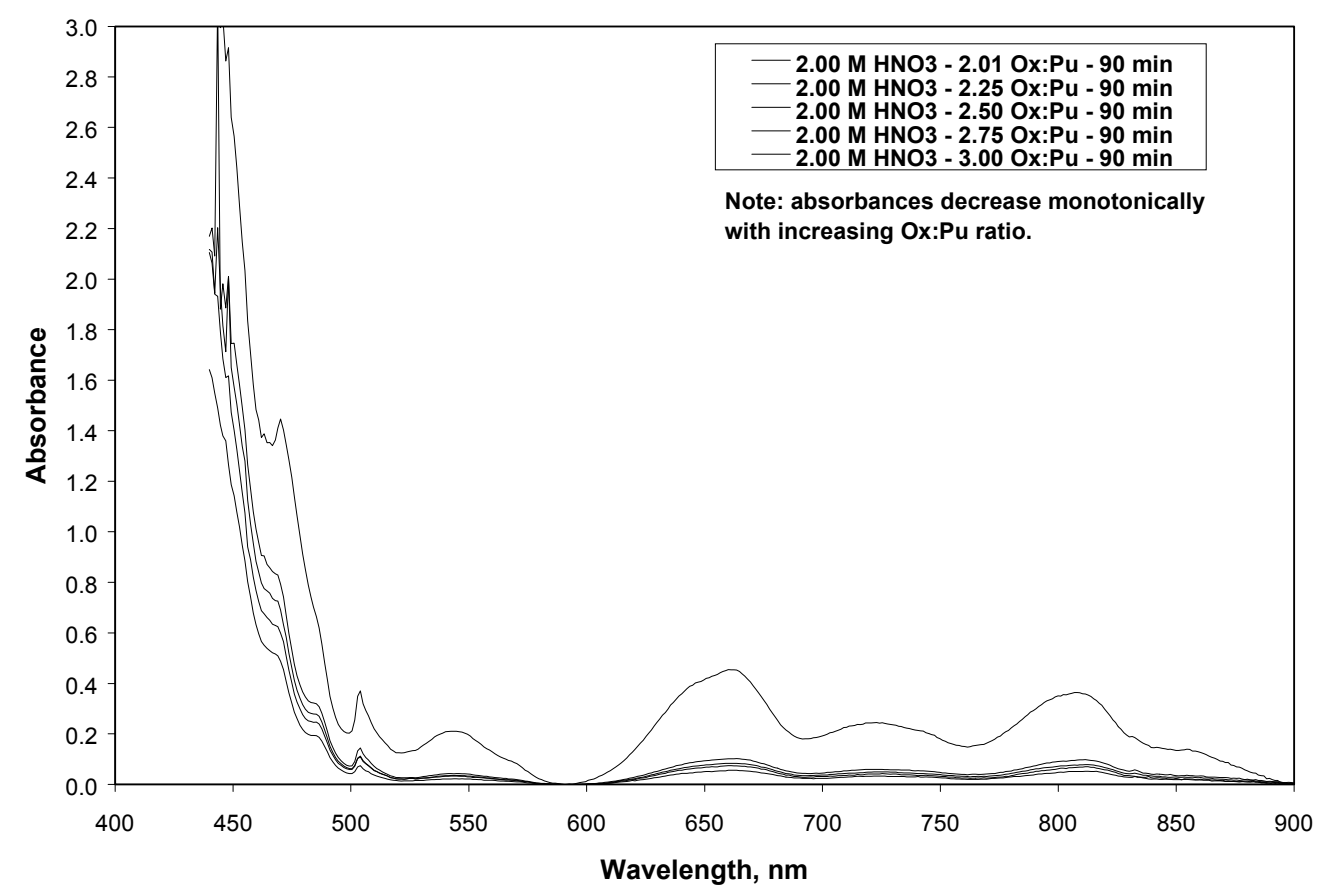

Figure 3. Absorption Spectra of Simulant Critical Mass Laboratory Solution Precipitation Tests in $2 \mathrm{M} \mathrm{HNO}_{3}$ as a Function of Oxalate:Pu Ratio (note: spectra intensities decrease with increasing oxalate:Pu ratio)

(a) In certain tests with higher oxalate:Pu ratios and consequent uranyl oxalate precipitation, the withdrawn solution volumes sometimes were less than $700 \mu \mathrm{L}$ to prevent solids removal. 
Confirmations of $\mathrm{Pu}$ and $\mathrm{Am}$ concentrations in selected solutions were performed by gamma nondestructive analysis. Confirmations of $\mathrm{Pu}$ and $\mathrm{U}$ concentrations in other solutions, treated to destroy oxalate and oxidize all Pu to its hexavalent state, also were performed. By this technique, the spectrophotometric effects caused by oxalate complexation were eliminated and the sensitivity for plutonium analysis increased by using the $\mathrm{Pu}(\mathrm{VI})$ absorption peak at $831 \mathrm{~nm}$ instead of the $\mathrm{Pu}(\mathrm{IV})$ absorption peak at $660 \mathrm{~nm}$. The chemical oxidation to form $\mathrm{Pu}(\mathrm{VI})$ and destroy the oxalate was performed by overnight heating to $\sim 100^{\circ} \mathrm{C}$ of an equal-volume mixture of supernatant test solution and concentrated $(\sim 15.9 \mathrm{M})$ $\mathrm{HNO}_{3}$. These solutions also were made $\sim 0.05 \mathrm{M} \mathrm{Mn}\left(\mathrm{NO}_{3}\right)_{2}$ with the $\mathrm{Mn}(\mathrm{II})$ acting as an oxidation catalyst. After oxidation, the solutions were brought to $\sim 3 \mathrm{M} \mathrm{HNO}_{3}$ by dilution with $0.16 \mathrm{M} \mathrm{HNO}_{3}$ and the absorption spectra measured. Spectra of a test solution before and after this treatment are compared in Figure 4.

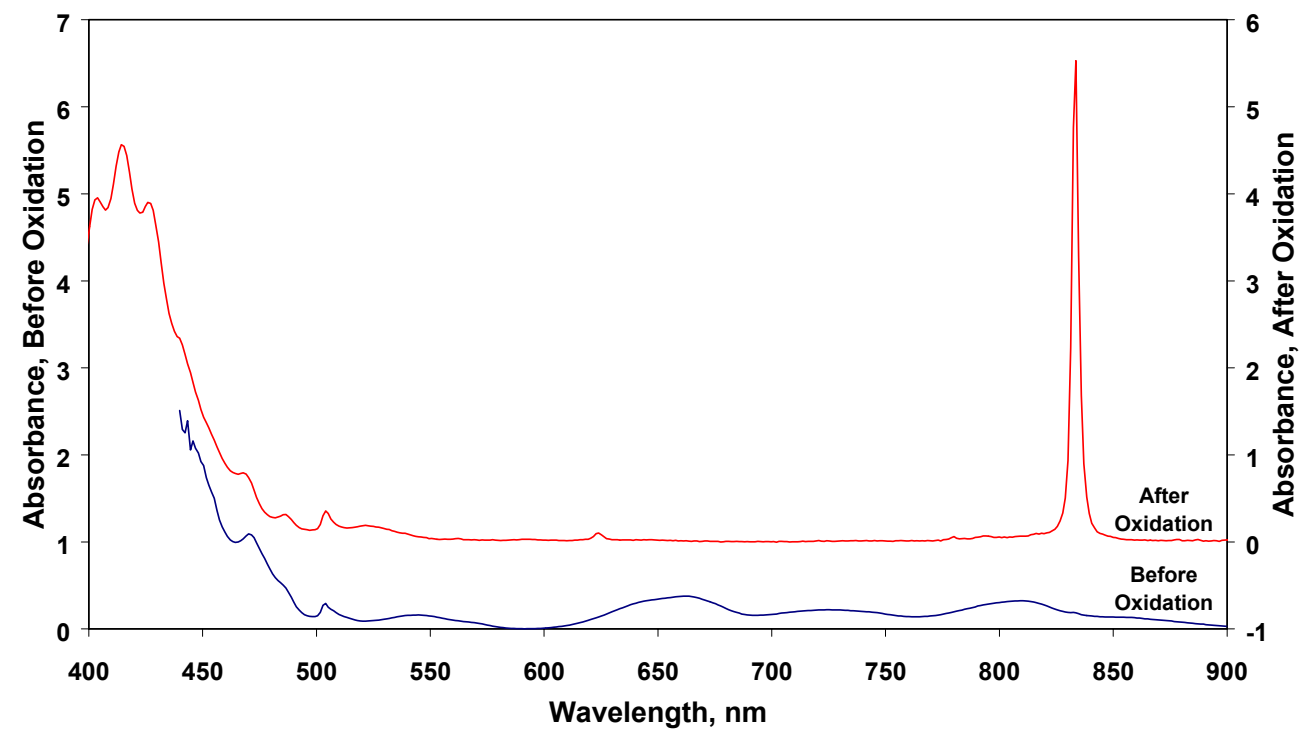

Figure 4. Absorption Spectra of Oxalate Precipitation Supernatant Solution Before and After Mn-Catalyzed Oxidation to $\mathrm{Pu}(\mathrm{VI})$ and Oxalate

\subsubsection{Tests with Genuine CML Solution}

Precipitation tests of dilutions of a genuine CML solution were performed under somewhat different conditions than the tests for the simulant CML solutions. First, dilutions in ratios of 1:1,1:2, and 1:3 in terms of volume CML starting solution and volume of $0.5 \mathrm{M} \mathrm{HNO}_{3}$ diluent were prepared. Other tests having plutonium concentrations near $50 \mathrm{~g} / \mathrm{L}$ and $1.33 \mathrm{M} \mathrm{HNO}_{3}$ were prepared by water dilution of the starting CML solution. Samples $(50 \mathrm{~mL})$ of the selected dilutions were transferred to centrifuge tubes for precipitation testing. As in the simulant tests, the tests with genuine CML solution used the same oxalic acid as used in the plant. The oxalic acid was added as the solid to the 50-mL aliquots at oxalate:Pu ratios ranging from about 1.2:1 to 14:1 (with the higher ratios used for the more diluted CML test solutions). The capped centrifuge tubes were shaken, allowed to stand for at least 30 minutes, shaken again, and then centrifuged. The unfiltered supernatant solutions were collected for analysis. The Pu and Am concentrations were determined by a gamma spectrometric technique. The $U$ concentrations were determined by a time-resolved laser fluorometric technique. 


\subsection{Results for Small-Scale Tests with Simulant CML Solution}

The results of the simulant CML solution precipitation tests conducted at 1.14, 2, and $3 \mathrm{M} \mathrm{HNO}_{3}$ (i.e., those tests without added boron and gadolinium) and 90-minute agitation times are shown in Figures 5, 6, and 7, respectively. For each of these figures, an optimum range of oxalate: $\mathrm{Pu}$ ratio is indicated, usually between about 2.1:1 and 2.3:1, showing where plutonium precipitation is virtually complete without accompanying uranium precipitation. Americium precipitation extent is intermediate between that of plutonium and uranium.

Results of oxalate precipitation tests in $1.5 \mathrm{M} \mathrm{HNO}_{3}$ simulant CML solutions containing boron and gadolinium are shown in Figure 8 for 90 minutes' agitation. Additional points at 2.25:1 and 2.75:1 oxalate:Pu mole ratios were obtained for tests conducted under the same conditions but performed with about five times higher scale and 60 minutes' contact time. These larger-scale tests were used to produce oxalate cakes for thermal treatment and moisture uptake studies but gave filtrate concentrations near those observed for the smaller scale tests.

Again, a window for processing is indicated showing where plutonium precipitation is virtually complete without accompanying uranium precipitation (and again with intermediate americium precipitation). However, this processing window is narrower than in the tests without the boron and gadolinium. The line following plutonium behavior shows "complete" precipitation (i.e., $\mathrm{x}$-axis intercept) at an oxalate:Pu ratio of about 2.1:1. This value is identical to those observed for the three test series without boron and gadolinium (Figures 5, 6, and 7). In contrast, the apparent onset of uranium precipitation occurs at a ratio near 2.2:1 for the tests with boron and gadolinium but at 2.3-2.45:1 for the tests without boron and gadolinium. The narrowing that occurs entirely by decrease of oxalate required for the onset of uranium precipitation suggests that perhaps borate is involved in the uranium oxalate precipitate.

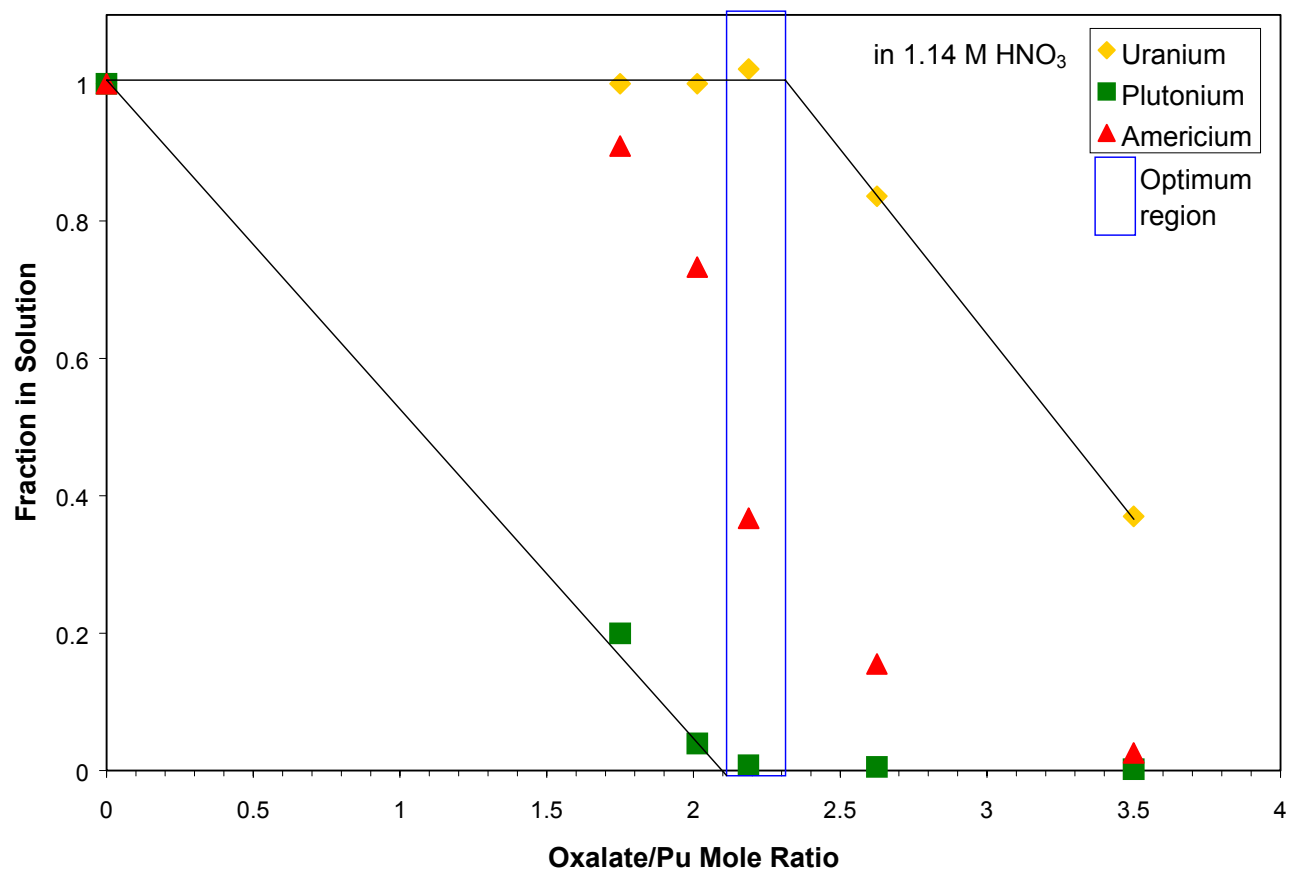

Figure 5. Extent of Uranium, Plutonium, and Americium Precipitation at 90 Minutes as a Function of Oxalate:Pu Ratio in $1.14 \mathrm{M} \mathrm{HNO}_{3}$ 


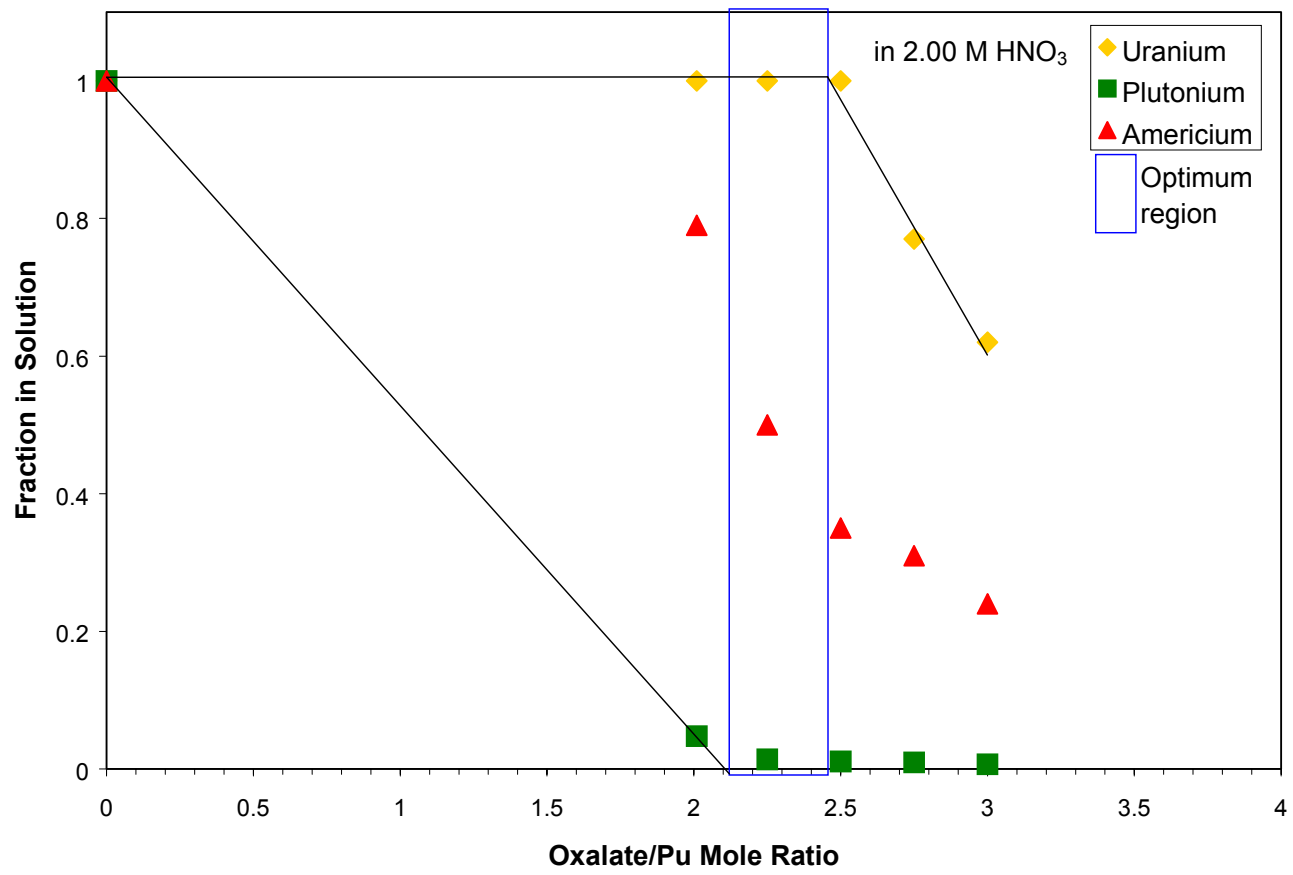

Figure 6. Extent of Uranium, Plutonium, and Americium Precipitation at 90 Minutes as a Function of Oxalate:Pu Ratio in $2 \mathrm{M} \mathrm{HNO}_{3}$

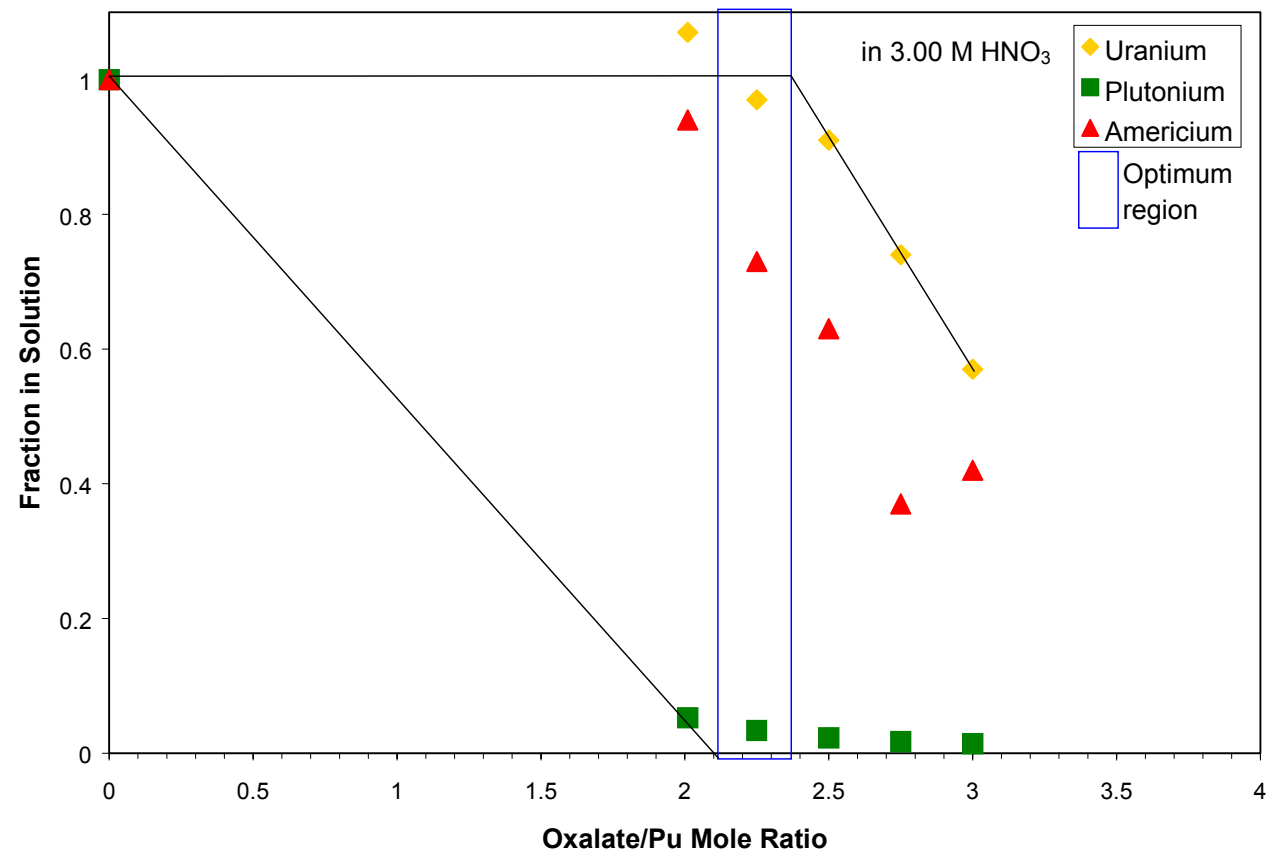

Figure 7. Extent of Uranium, Plutonium, and Americium Precipitation at 90 Minutes as a Function of Oxalate:Pu Ratio in $3 \mathrm{M} \mathrm{HNO}_{3}$ 


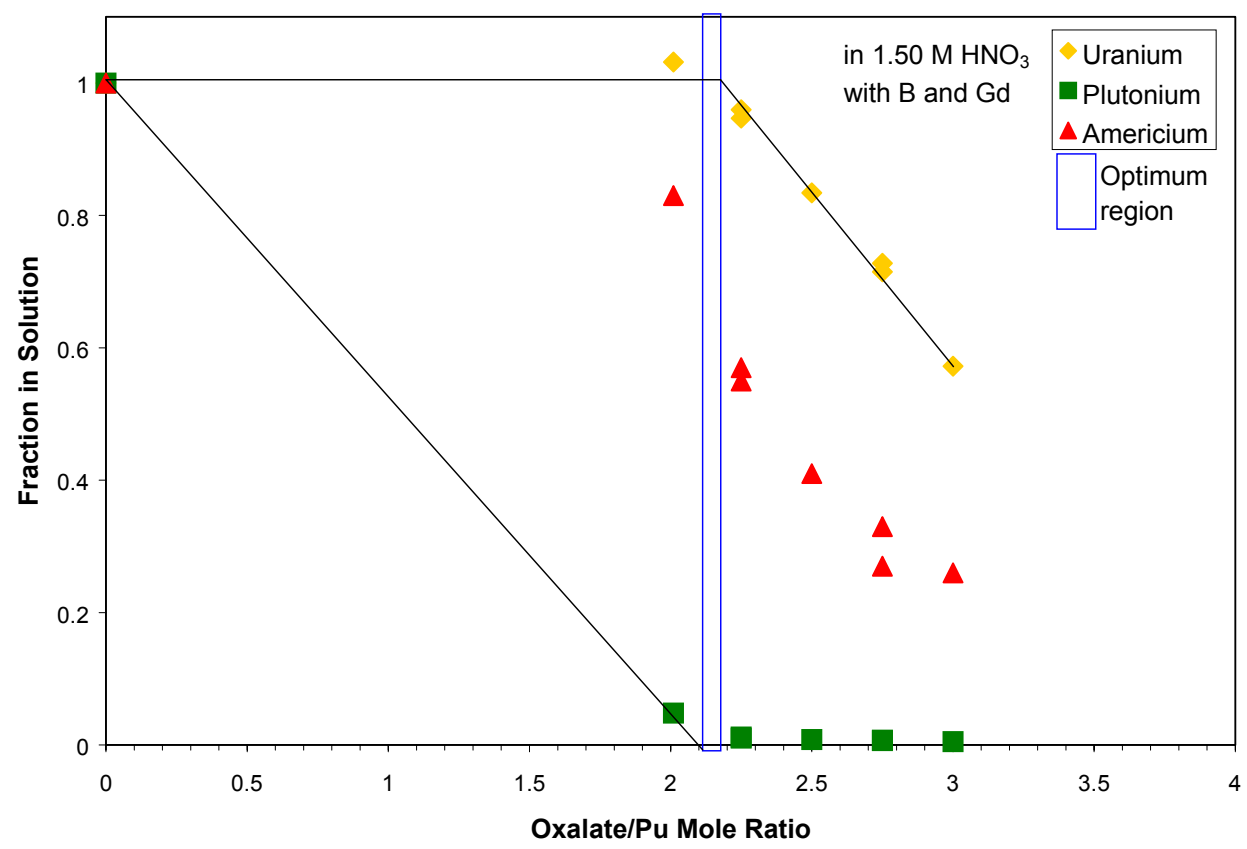

Figure 8. Extent of Uranium, Plutonium, and Americium Precipitation at 90 Minutes as a Function of Oxalate:Pu Ratio in Simulant 1.5 $\mathrm{M} \mathrm{HNO}_{3} \mathrm{CML}$ Solution Containing Trace B and Gd

The concentration data from all simulant CML precipitation tests are plotted in Figure 9. This comparison reiterates the finding that plutonium can be selectively precipitated away from uranium using oxalic acid reagent.

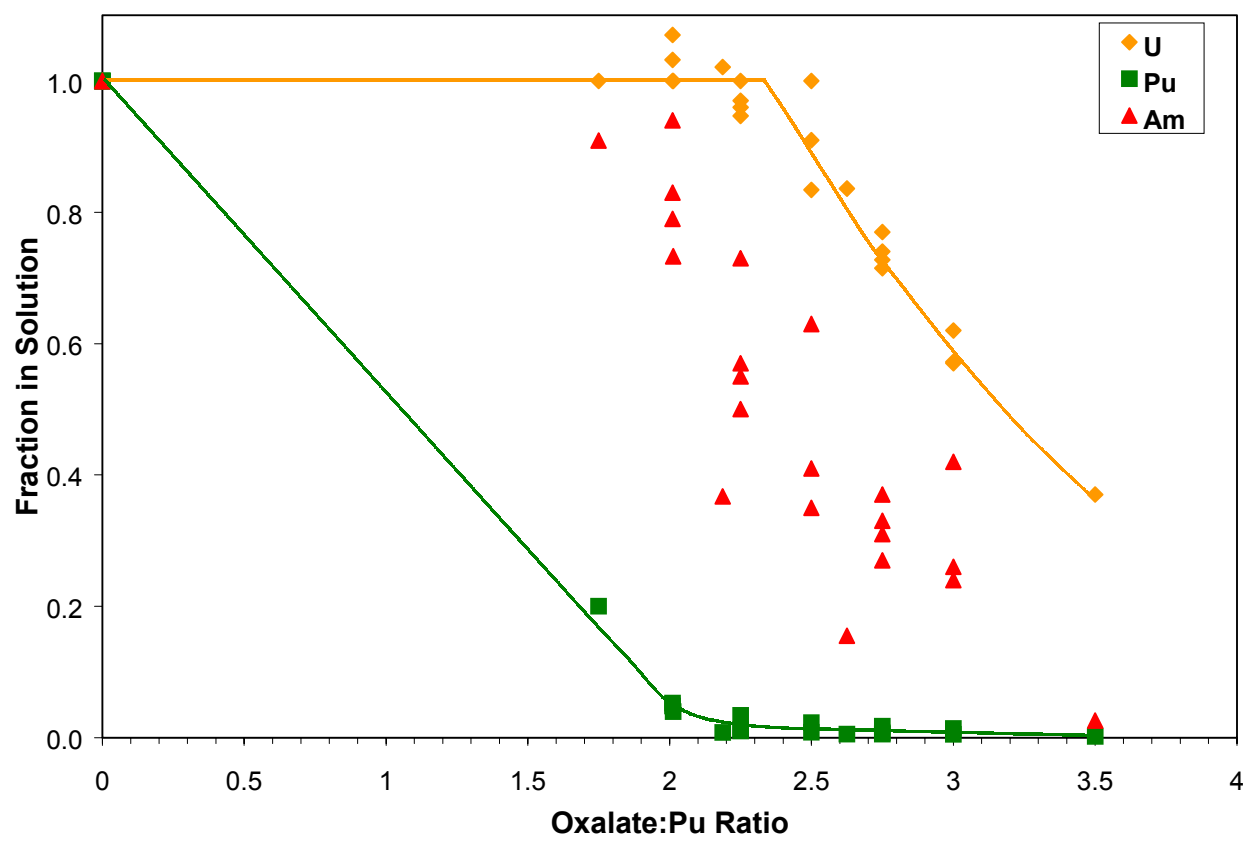

Figure 9. Extent of Uranium, Plutonium, and Americium Precipitation as a Function of Oxalate:Pu Ratio in All Simulant CML Solution Tests 
Also shown in Figure 9 is a slight decontamination of $\mathrm{Pu}(\mathrm{IV})$ from contained in-grown $\mathrm{Am}(\mathrm{III})$ observed at intermediate oxalate:Pu ratios in these batch precipitation tests (e.g., the decontamination factor, $\mathrm{DF} \cong 2$ at 2.25 oxalate:Pu). Limited decontamination of $\mathrm{Pu}$ from $\mathrm{Am}(\mathrm{DF}=1.2)$ was found in batch tests in which the oxalic acid solution was added over a period of time to the Pu nitrate solution (Harmon and Facer 1953). However, no decontamination of Pu from $\mathrm{Am}(\mathrm{DF}=1)$ was observed in prior plant operations performed under continuous precipitation conditions (see, for example, Harmon et al. 1961). It is thought that the difference in $\mathrm{Pu}$ decontamination from Am between the recent batch tests and former plant operations is related to the comparative availabilities of free oxalate in the two processes and the phenomenon of coprecipitation.

Thus, in the former plant operations, separate solution streams of $\mathrm{Pu} / \mathrm{Am}$ and oxalic acid were added concurrently. Under such conditions, the required stoichiometric molar excess of oxalate:Pu $(>2: 1)$ was constantly maintained. In contrast, for the recent batch precipitation testing, the oxalate was added as solid oxalic acid and stoichiometric excess in solution was not attained until the precipitation reactions were near completion. Therefore, in the plant operations, conditions were ideal for carrier precipitation of the trace Am oxalate with the much higher amounts of $\mathrm{Pu}$ oxalate. Oxalate concentrations were sufficiently high at all times to exceed the solubilities of both the Pu oxalate and the Am(III) oxalate. Any trace amount of precipitated Am(III) oxalate or Am(III) sorbed on the forming Pu(IV) oxalate crystals would be carried (captured and occluded) by the vastly superior quantities of precipitating $\mathrm{Pu}(\mathrm{IV})$ oxalate.

In contrast, in the recent batch precipitation testing, the oxalate was released relatively slowly to the solution by dissolution of the oxalic acid. As the oxalate was released to solution, it would precipitate first with the high concentration $\mathrm{Pu}(\mathrm{IV})$ (initially $\sim 50 \mathrm{~g} \mathrm{Pu} / \mathrm{L}$ versus $\sim 0.1 \mathrm{~g} \mathrm{Am} / \mathrm{L}$ ) according to the solubility of $\mathrm{Pu}(\mathrm{IV})$ oxalate. The solubility of the Am(III) oxalate could not be exceeded until much of the $\mathrm{Pu}$ was precipitated and the free oxalate solution concentration could increase. As the Pu concentration decreased to be near that of the $\mathrm{Am}$, it is likely that some coprecipitation occurred, judging by the observed $\mathrm{Pu} / \mathrm{Am}$ precipitation behaviors. The equilibrium solubility of $\mathrm{Pu}(\mathrm{IV})$ oxalate $\left[\mathrm{Pu}\left(\mathrm{C}_{2} \mathrm{O}_{4}\right)_{2} \cdot 6 \mathrm{H}_{2} \mathrm{O}\right.$; Mandleberg et al. 1961] is comparable to or lower than that of $\mathrm{Am}(\mathrm{III})$ oxalate $\left[\mathrm{Am}_{2}\left(\mathrm{C}_{2} \mathrm{O}_{4}\right)_{3} \cdot 10 \mathrm{H}_{2} \mathrm{O}\right.$; Burney and Porter 1967] at nominal end point conditions. For example, at $0.1 \mathrm{M}$ oxalic acid in $2 \mathrm{M} \mathrm{HNO}_{3}$, the solubility of the $\mathrm{Pu}$ salt is $\sim 12 \mathrm{mg} \mathrm{Pu} / \mathrm{L}$, and the Am salt is $\sim 400 \mathrm{mg} \mathrm{Am} / \mathrm{L}$. In $0.1 \mathrm{M}$ oxalic acid in $1 \mathrm{M} \mathrm{HNO}_{3}$, the solubilities are $\sim 20 \mathrm{mg} \mathrm{Pu} / \mathrm{L}$ and $\sim 25 \mathrm{mg} \mathrm{Am} / \mathrm{L}$.

The plutonium concentrations in the filtrate solutions arising from the simulant CML testing are shown in Figure 10. Over the range of conditions studied, the plutonium concentrations decrease with increasing oxalate: $\mathrm{Pu}$ ratio and with decreasing acid concentration. The boron and gadolinium in the tests with $1.5 \mathrm{M}$ $\mathrm{HNO}_{3}$ do not affect these general trends. Based on these findings, it can be recommended that the CML solution be diluted to create $\mathrm{Pu}$ concentrations just below $50 \mathrm{~g} / \mathrm{L}$ to achieve the highest throughput rates while using the lowest possible acid concentration to minimize $\mathrm{Pu}$ losses to the filtrate.

Americium concentrations in the filtrate from the simulant CML tests are plotted in Figure 11. The trends of decreasing Am concentration with increasing oxalate:Pu ratio and decreasing $\mathrm{HNO}_{3}$ concentrations are similar to those observed for $\mathrm{Pu}$, though the $1.5 \mathrm{M} \mathrm{HNO}_{3}$ test series with added $\mathrm{B}$ and $\mathrm{Gd}$ departs slightly from the trend for acid concentration dependence (Am being more soluble) observed in the 1.14, 2 , and $3 \mathrm{M} \mathrm{HNO}_{3}$ tests. 


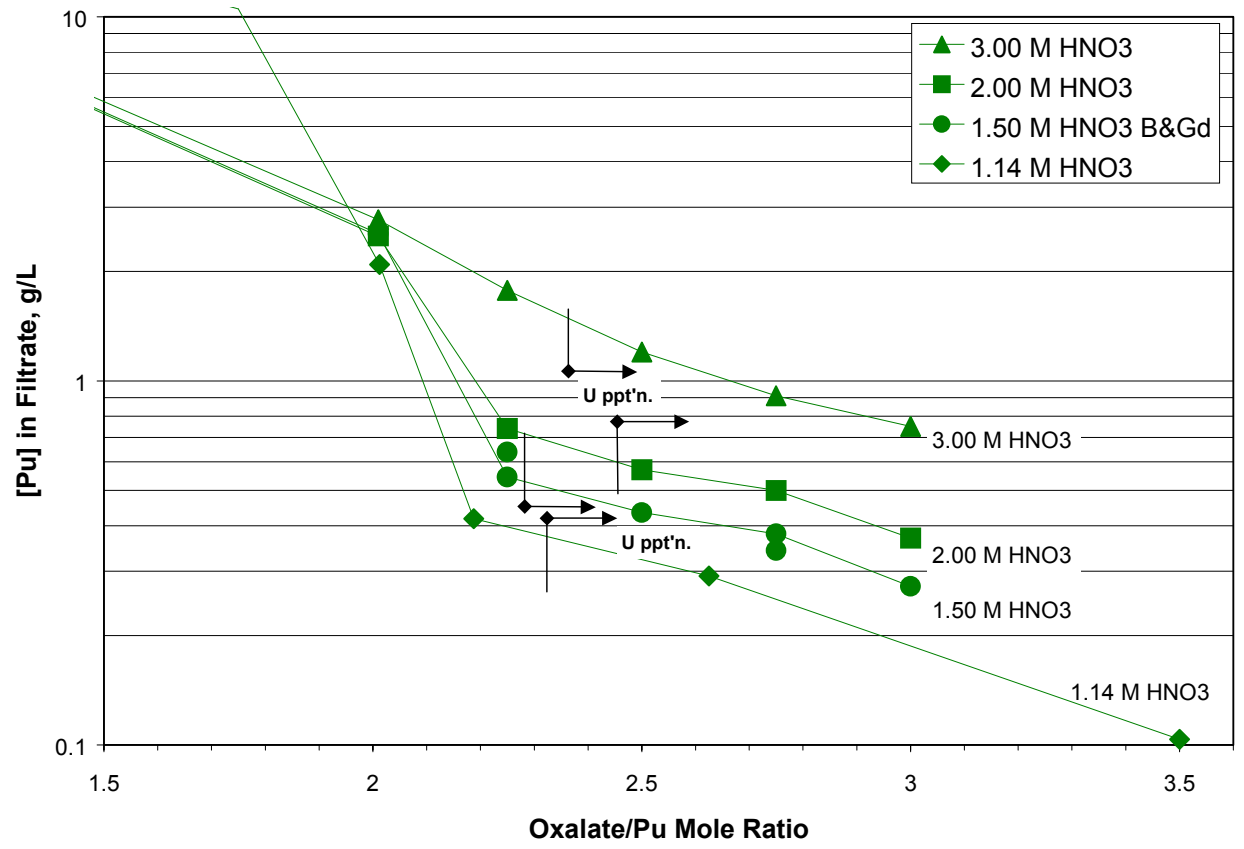

Figure 10. Plutonium Concentrations in the Filtrate as a Function of Oxalate:Pu Ratio

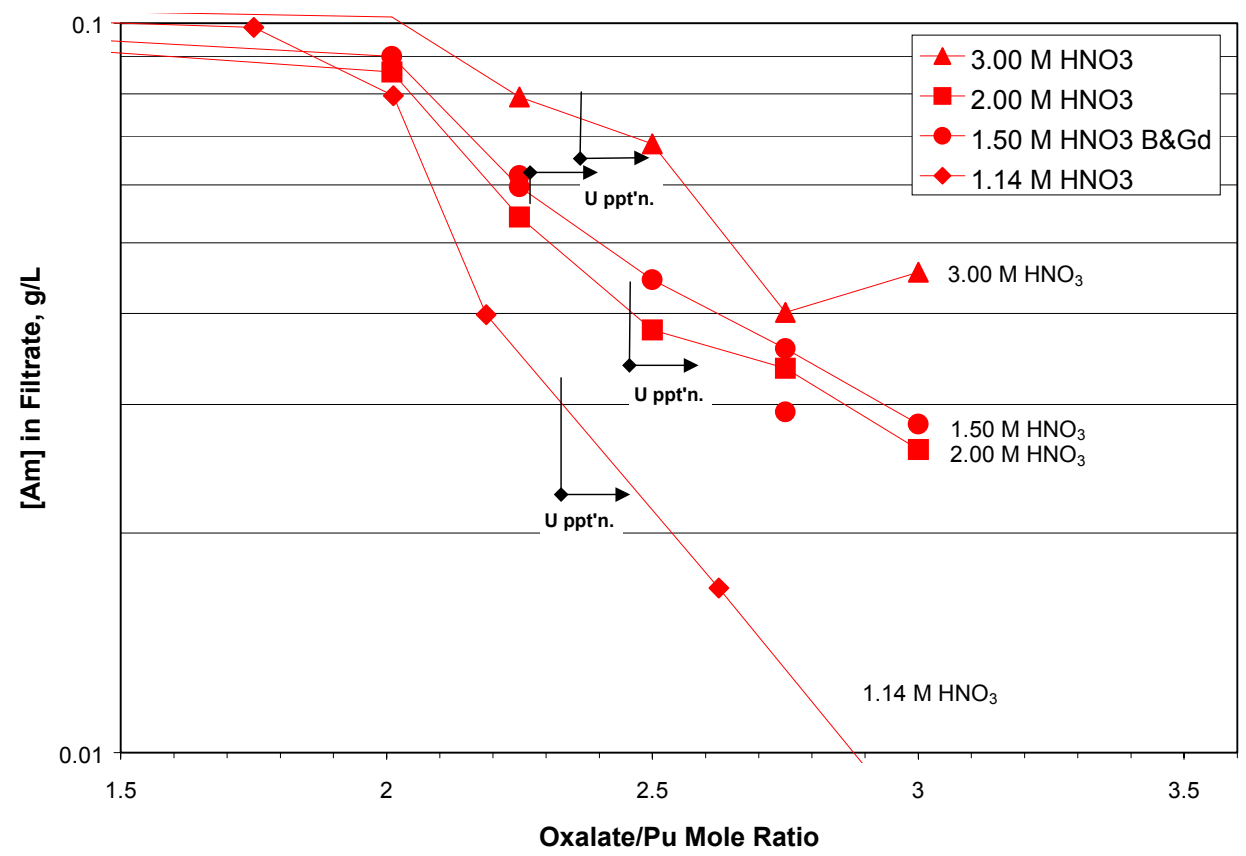

Figure 11. Americium Concentrations in the Filtrate as a Function of Oxalate:Pu Ratio 


\subsection{Modeling Results from the Precipitation Testing}

The complexation and precipitation of $\mathrm{Pu}(\mathrm{IV})$ and $\mathrm{U}(\mathrm{VI})$ with oxalate have been examined in numerous studies. With these data and the appropriate thermodynamic modeling software, characteristics of $\mathrm{Pu}(\mathrm{IV})$ and U(VI) speciation and precipitation from solution by oxalate can be predicted. The latest version of the Hyperquad Simulation and Speciation software (HYSS2) (Protonic Software) was used to generate speciation diagrams for the many species present in the $\mathrm{Pu}(\mathrm{IV}) / \mathrm{U}(\mathrm{VI}) / \mathrm{H}_{2} \mathrm{C}_{2} \mathrm{O}_{4}$ system in $\mathrm{HNO}_{3}$ and to fit the observed experimental results. Because $\mathrm{H}_{2} \mathrm{C}_{2} \mathrm{O}_{4}$ is used to precipitate $\mathrm{Pu}(\mathrm{IV})$, the protons associated with the oxalic acid are released into solution, raising the solution acidity, when the metal-oxalate complexes and precipitates form. As noted previously, the precipitation of $50 \mathrm{~g} \mathrm{Pu} / \mathrm{L}$ will increase $\mathrm{HNO}_{3}$ concentration about $0.84 \mathrm{M}$. Though the HYSS2 software is used to generate speciation diagrams at constant ligand concentration as a function of acidity, it also can determine species at constant acidity with varying ligand concentration, a condition corresponding more closely to the present system. However, the simultaneous variation of the two parameters (acidity and total ligand concentration) is beyond HYSS2 capabilities. Modeling, therefore, was performed presuming a constant $1.5 \mathrm{M} \mathrm{HNO}_{3}$.

The complexation of $\mathrm{U}(\mathrm{VI}), \mathrm{UO}_{2}{ }^{2+}$, with oxalate has been described at $1.0 \mathrm{M}$ ionic strength (Havel 1969) and the formation constants of mono-, di-, and tri-oxalato complexes with $\mathrm{UO}_{2}{ }^{2+}$ judged to be selfconsistent and reliable. Plutonium(IV) forms much stronger complexes with oxalate (Hindman 1954) than does $\mathrm{UO}_{2}{ }^{2+}$ such that mono-, di-, tri-, and even tetra-oxalato complexes are reported. The tetra- complex, however, is observed only at near-neutral $\mathrm{pH}$ with high $\mathrm{C}_{2} \mathrm{O}_{4}{ }^{2-}$ concentrations and is not favored in acidic media where protonation decreases the free ligand concentration substantially.

The reported solubility products $\left(\mathrm{K}_{\mathrm{sp}}\right)$ for $\mathrm{Pu}\left(\mathrm{C}_{2} \mathrm{O}_{4}\right)_{2} \cdot 6 \mathrm{H}_{2} \mathrm{O}$ and $\mathrm{UO}_{2} \mathrm{C}_{2} \mathrm{O}_{4} \cdot 3 \mathrm{H}_{2} \mathrm{O}$ were measured by dissolving crystalline solids in mixtures of nitric and oxalic acids (Gel'man et al. 1962). In plant processing and in the present experiments, however, $\mathrm{Pu}(\mathrm{IV})$ and $\mathrm{U}(\mathrm{VI})$ oxalates would be less crystalline, forming from initially homogeneous solution with little time (1-2 hr) for crystal growth and aging (ripening). Thus, because the approach to equilibrium in crystallization is slower than that in complexation, and the time to crystallization equilibrium inadequate, the solubility products of the solid metaloxalate compounds are more likely to give an incorrect view of the plant process dynamics. For this reason, the $\mathrm{K}_{\mathrm{sp}}$ literature data were used cautiously to model the observed precipitation efficiency of U(VI) and $\mathrm{Pu}(\mathrm{IV})$ by oxalic acid.

Preliminary calculations using the HYSS2 software showed that the literature values of $\mathrm{K}_{\mathrm{sp}}$ led to unrealistically low predicted $\mathrm{Pu}(\mathrm{IV})$ solution concentrations. Contrary to lab findings, the calculations also indicated that $\mathrm{U}(\mathrm{VI})$ oxalate should begin to precipitate immediately upon exceeding the $2: 1$ (oxalate:Pu) $\mathrm{Pu}\left(\mathrm{C}_{2} \mathrm{O}_{4}\right)_{2} \cdot 6 \mathrm{H}_{2} \mathrm{O}$ mole ratio. Therefore, a series of more realistic, gradually increasing approximations of $\mathrm{Pu}\left(\mathrm{C}_{2} \mathrm{O}_{4}\right)_{2} \cdot 6 \mathrm{H}_{2} \mathrm{O}$ and $\mathrm{UO}_{2} \mathrm{C}_{2} \mathrm{O}_{4} \cdot 3 \mathrm{H}_{2} \mathrm{O} \mathrm{K}$ sp were made in simulation calculations to identify the best correspondence between the calculated and observed residual $\mathrm{Pu}(\mathrm{IV})$ and $\mathrm{U}(\mathrm{VI})$ concentrations. The combination of $\mathrm{K}_{\mathrm{sp}}$ of -20.5 and -8 for $\mathrm{Pu}(\mathrm{IV})$ and $\mathrm{U}(\mathrm{VI})$ oxalate, respectively, was found to best describe the measured data.

The modeled results obtained for the precipitation of $0.2 \mathrm{M} \mathrm{Pu}(\mathrm{IV})(47.8 \mathrm{~g} \mathrm{Pu} / \mathrm{L})$ and $0.45 \mathrm{M} \mathrm{U}(\mathrm{VI})$ (107.1 $\mathrm{g} \mathrm{U} / \mathrm{L}$ ) in $1.48 \mathrm{M} \mathrm{HNO}_{3}$ with oxalate as the oxalate:Pu ratio increases are shown in Figure 12. The modeled results are compared with the observations made with the $1.5 \mathrm{M} \mathrm{HNO}_{3}$ test findings and agree 


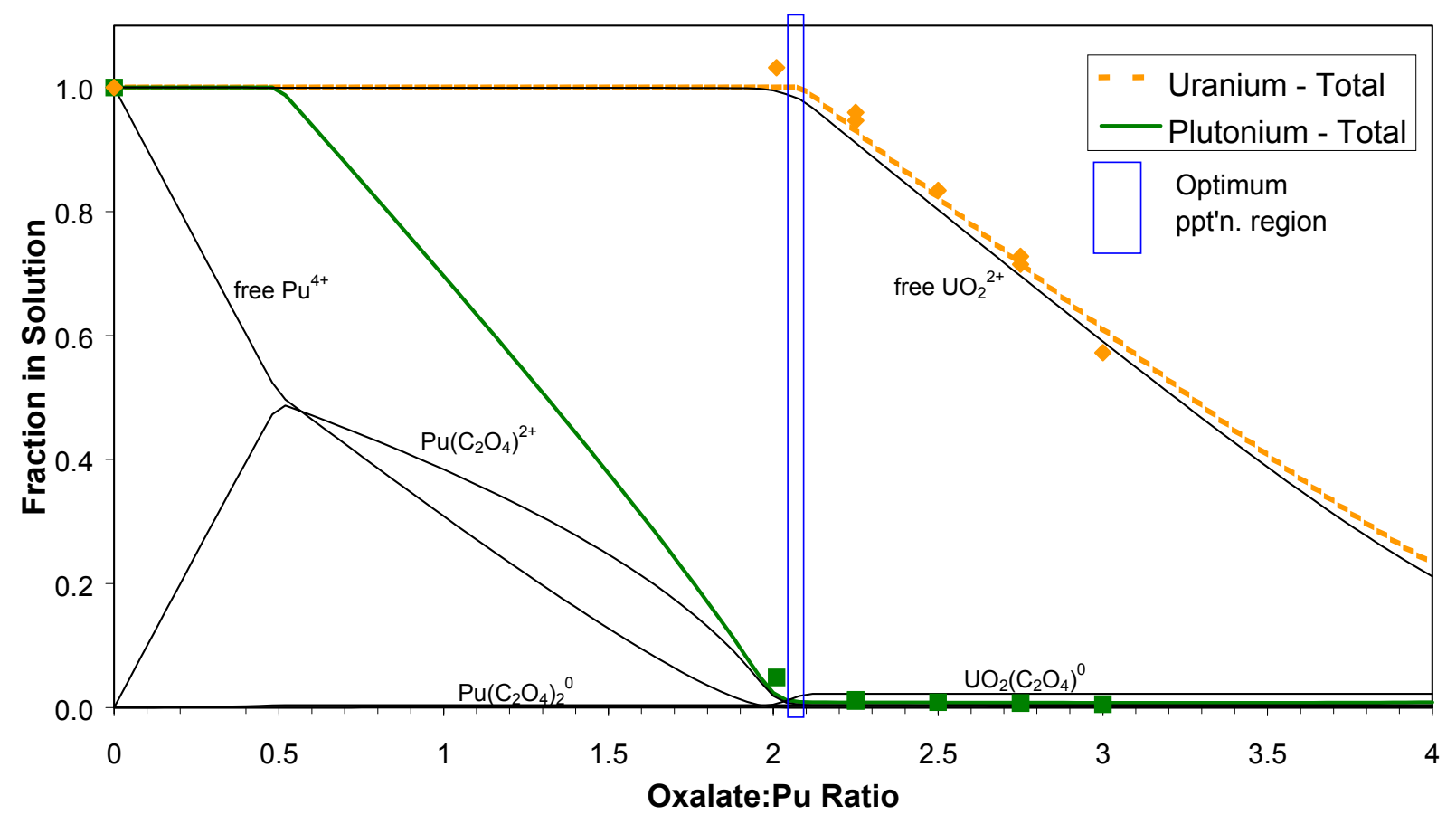

Figure 12. Modeled and Observed Extent of Uranium and Plutonium Precipitation as a Function of Oxalate:Pu Ratio in $1.5 \mathrm{M} \mathrm{HNO}_{3}$

well with measured results. They also indicate that because of formation of the soluble $\mathrm{Pu}\left(\mathrm{C}_{2} \mathrm{O}_{4}\right)^{2+}$ complex plutonium precipitation will not begin until a $0.5: 1$ oxalate: $\mathrm{Pu}$ mole ratio is attained.

\subsection{Results for Small-Scale Tests with Genuine CML Solution}

Tests of oxalate precipitation with various dilutions of genuine CML solution were performed at the PPSL. Results of the tests with the genuine CML solution are plotted in Figure 13 and compared with results of the tests performed with the simulant CML solution. Two of the 27 tests with genuine CML gave anomalously high $\mathrm{U} / \mathrm{Pu} / \mathrm{Am}$ concentrations, and the scatter in the uranium concentrations seems to be high (likely because of the error caused by the multiple dilutions of the concentrated solution required for the highly sensitive laser fluorometric technique). Though the overall trends, particularly for $\mathrm{Pu}$, match the trends observed for the tests with simulant CML solutions, some tests in the 2:1-3:1 oxalate:Pu ratio range have $\sim 20 \% \mathrm{U}$ precipitation and correspondingly high Pu solution concentrations. These findings might be explained by the relatively gentle test agitation that did not allow the uranyl oxalate formed initially under mass action conditions to re-dissolve and yield its oxalate to precipitate the $\mathrm{Pu}$. The agitation shear rate provided by air sparging in the actual plant operations likely lies between the rapid magnetic stirring used in the simulant CML solution tests and the intermittent shaking used in the genuine CML solution tests. 


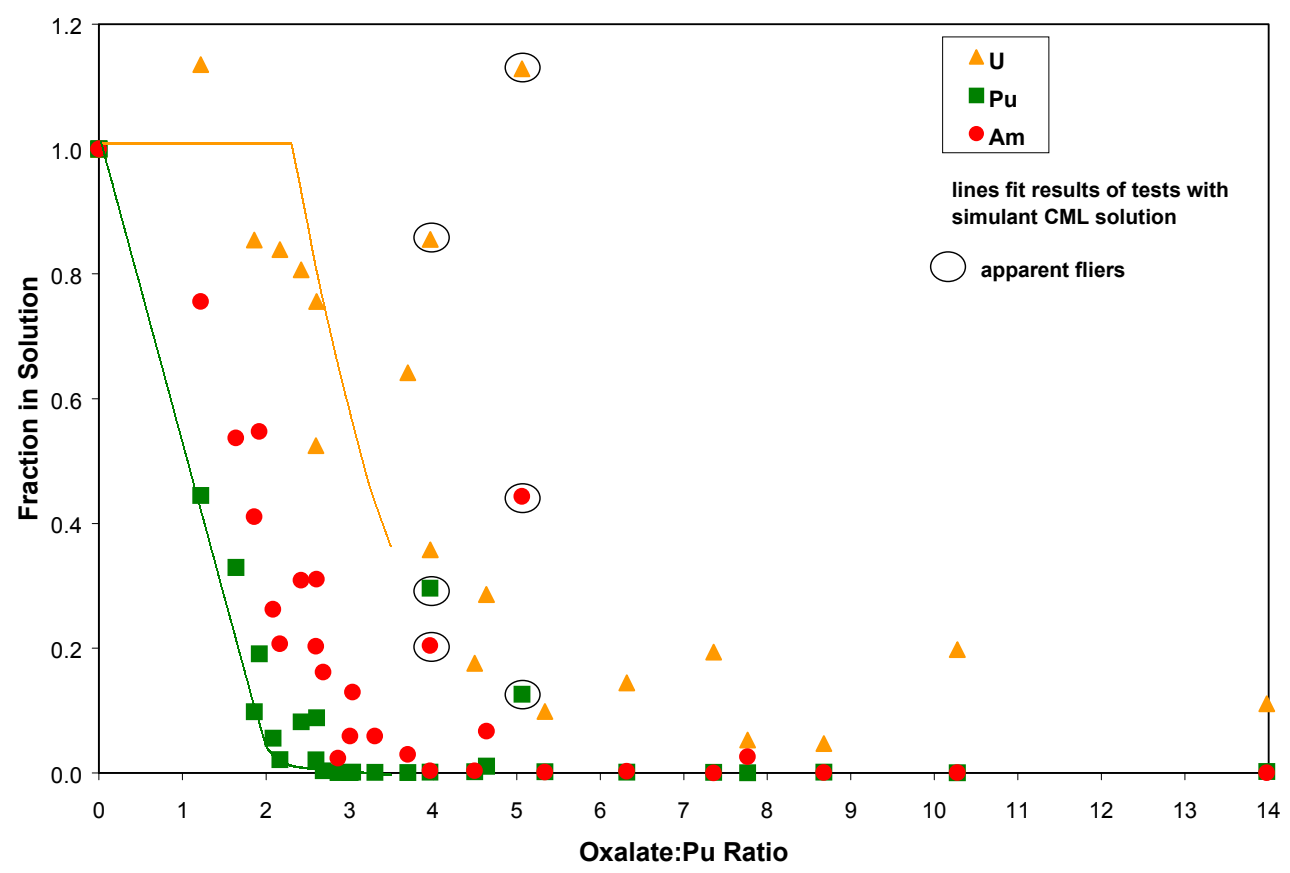

Figure 13. Extent of Uranium, Plutonium, and Americium Precipitation as a Function of Oxalate:Pu Ratio in All Genuine CML Solution Tests

\subsection{Principal Findings from the Precipitation Testing}

The proposed flowsheet conditions can be inferred from the overall precipitation test findings:

- Under proper conditions, plutonium(IV) can be selectively precipitated away from uranium(VI) with oxalic acid. The selective precipitation dramatically decreases the resulting precipitate volume to allow increased process throughput, decreased worker dose, and decreased product bulk for the PFP.

- The ideal oxalate:Pu ratios (with $>98 \% \mathrm{Pu}$ but no $\mathrm{U}$ precipitated) are $\sim 2.1-2.3$ at $1.14 \mathrm{M} \mathrm{HNO}_{3}$, $\sim 2.1-2.4$ at $2 \mathrm{M} \mathrm{HNO}_{3}, \sim 2.1-2.3$ for $3 \mathrm{M} \mathrm{HNO}_{3}$ tests, and $\sim 2.1-2.2$ for the $1.5 \mathrm{M} \mathrm{HNO}_{3}$ tests with added boron and gadolinium.

- In the small-scale simulant CML tests, digestion time (30, 60, 90 minutes) had little effect on the extent of precipitation except that oxalic acid dissolution is noticeably slower and $\mathrm{Pu}$ oxalate precipitation less at 30 minutes in $3 \mathrm{M} \mathrm{HNO}_{3}$. Similar plutonium precipitation behaviors usually were observed in tests with the genuine CML solution using less vigorous agitation and 30-minute digestion times. However, a few instances were observed that suggest this less-vigorous agitation was inadequate to redissolve the initially precipitated uranyl oxalate to release oxalate for plutonium precipitation. Because plant agitation rates likely lie between the two laboratory rates, at least 30 minutes' agitation and perhaps 60 minutes are suggested for initial plant operations. The digest time may be modified based on plant operating experience.

- Plutonium losses to the filtrate (and subsequently to the waste storage tanks) increase with acid concentration; $\mathrm{Pu}$ losses decrease with increasing oxalate:Pu ratio.

- Americium concentrations in the filtrate also increase with acid concentration and decrease with increasing oxalate:Pu ratio.

- The fractional extent of americium precipitation is between those of uranium and plutonium. 
- Limited decontamination of Pu from Am is achieved under batch conditions, but the decontamination decreases with increasing oxalate:Pu ratio.

- Tests with dilutions of genuine CML solution show results similar to those observed for the simulant CML tests.

To achieve the highest process throughput rates, the CML solution should be diluted to create $\mathrm{Pu}$ concentrations just below $50 \mathrm{~g} / \mathrm{L}$ using the lowest-possible acid concentration (e.g., $0.3 \mathrm{M}$ ) to minimize $\mathrm{Pu}$ losses to the filtrate. 


\subsection{Calcination and Moisture Uptake Testing}

The purposes of the calcination and moisture testing are to evaluate the drying, calcination, and calcine moisture uptake behaviors of plutonium-bearing products prepared by oxalate precipitation of the CML solution. The key objective of the testing is to determine the feasibility of stabilizing the solids to meet the DOE-STD-3013 standards in the humid gloveboxes of the PFP RMC line. The following are the technical questions to be answered in the testing:

1. What are the products of calcination of the uranium that accompanies the plutonium oxalate precipitate?

2. How do the uranium calcination products evolve as a function of heating time, temperature, and material scale/amount?

3. What are the moisture uptake properties of the calcined uranium oxide and plutonium/uranium oxide products as a function of water vapor pressure (humidity)?

4. What are the effects of boric oxide $\left(\mathrm{B}_{2} \mathrm{O}_{3}\right)$ and gadolinium oxide $\left(\mathrm{Gd}_{2} \mathrm{O}_{3}\right)$ on moisture uptake by the thermally stabilized solids?

The chemical transformations expected in the drying and calcination of the moist filtercake obtained by oxalic acid precipitation of $\mathrm{Pu}(\mathrm{IV})$ from the $\mathrm{CML}$ solutions have been investigated as a function of the extent of uranium content in the cake and the presence of boric acid and gadolinium nitrate in the interstitial solution.

\subsection{Calcination and Moisture Uptake Studies of Uranyl Oxalate and Nitrate}

Uranyl oxalate and uranyl nitrate will be present in plutonium oxalate filtercakes prepared during the CML solution stabilization operations at the PFP. According to the precipitation testing, the uranyl oxalate trihydrate salt $\left(\mathrm{UO}_{2} \mathrm{C}_{2} \mathrm{O}_{4} \cdot 3 \mathrm{H}_{2} \mathrm{O}\right)$ can precipitate by addition of oxalic acid in excess of the $\sim 2.3: 1$ oxalate: $\mathrm{Pu}$ ratio. Uranyl oxalate also can precipitate by drying of the interstitial liquor in the $\mathrm{Pu}(\mathrm{IV})$ oxalate filtercake. Uranyl nitrate hexahydrate salt $\left[\mathrm{UO}_{2}\left(\mathrm{NO}_{3}\right) \cdot 6 \mathrm{H}_{2} \mathrm{O}\right]$ also is expected to form during drying of the interstitial liquor.

Uranyl oxalate trihydrate was prepared by precipitation of a $2 \mathrm{M}$ aqueous solution of reagent-grade uranyl nitrate with a 1.5 -fold stoichiometric excess $(3 \mathrm{M})$ oxalic acid solution at $70^{\circ} \mathrm{C}$. The bright yellow crystals precipitated immediately upon mixing and were digested with cooling overnight. The crystals were filtered, rinsed with several portions of cold water, and air-dried.

About $1 \mathrm{mg}$ of the air-dried crystals were crushed and blended with $0.1 \mathrm{~g}$ potassium bromide $(\mathrm{KBr})$ and pressed into a pellet for infrared spectrometric analysis. The absorbance spectrum of the pressed pellet, measured in the range 400 to $4000 \mathrm{~cm}^{-1}$ with a Nicolet 500 Fourier-transform infrared (FTIR) spectrometer, is shown in Figure 14. Frequencies of the more prominent absorption bands are listed in Table 3 and compared with band energies and spectral assignments described for reagent $\mathrm{UO}_{2} \mathrm{C}_{2} \mathrm{O}_{4} \cdot 3 \mathrm{H}_{2} \mathrm{O}$ (Ribnikar and Trtica 1998). Two of the three $\mathrm{UO}_{2}{ }^{2+}$ bands are distinguishable at 869 and $946 \mathrm{~cm}^{-1}$ (the third band, at $257 \mathrm{~cm}^{-1}$, is outside the scan range). The broad water bands appear between 3700 and $2800 \mathrm{~cm}^{-1}$, and prominent oxalate peaks appear at about $490,803,1315,1357$, and $1627 \mathrm{~cm}^{-1}$, with intensities and locations near those expected from measurements of reagent $\mathrm{UO}_{2} \mathrm{C}_{2} \mathrm{O}_{4} \cdot 3 \mathrm{H}_{2} \mathrm{O}$. 


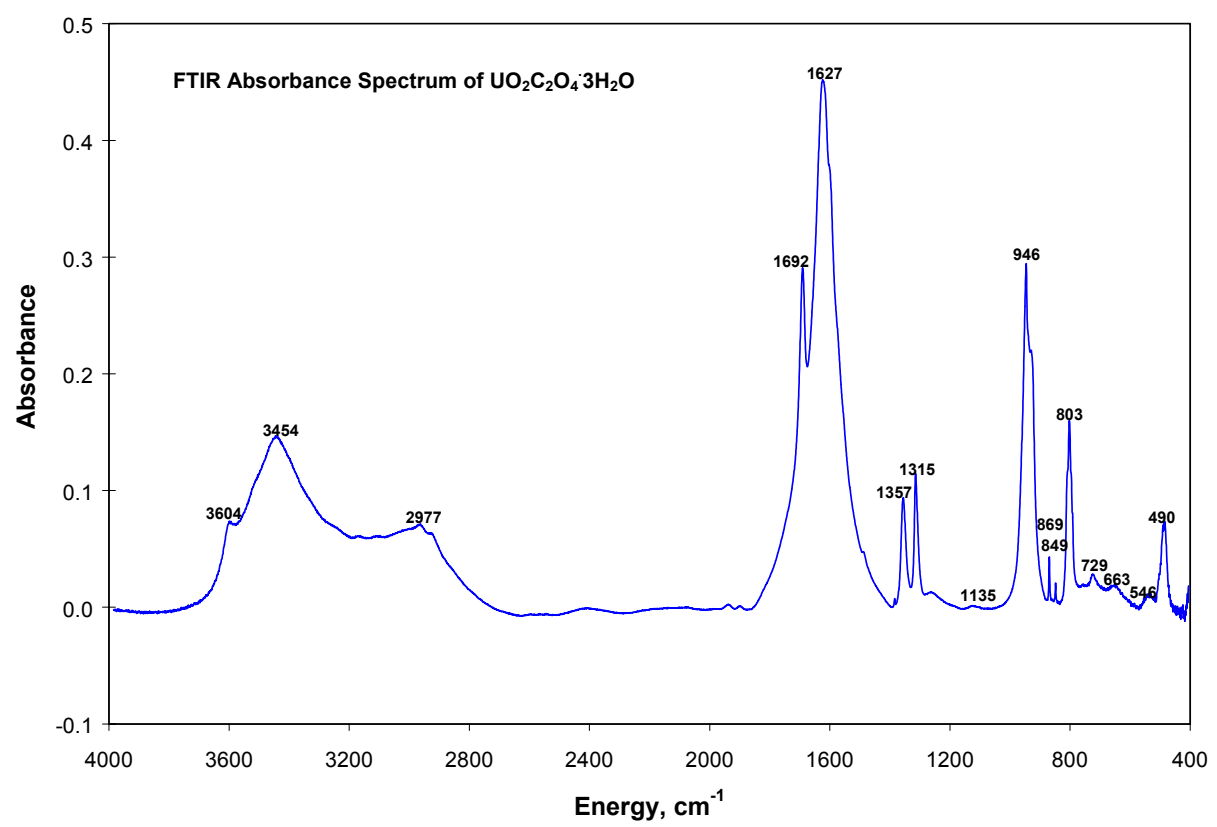

Figure 14. Infrared Spectrum of $\mathrm{UO}_{2} \mathrm{C}_{2} \mathrm{O}_{4} \cdot 3 \mathrm{H}_{2} \mathrm{O}$ Product

Table 3. Infrared Absorbance Bands of Uranyl Oxalate

\begin{tabular}{|c|c|c|}
\hline \multicolumn{2}{|c|}{ Frequency $\left(\mathrm{cm}^{-1}\right)$} & \multirow[b]{2}{*}{ Literature Assignment } \\
\hline Found & Literature & \\
\hline Not meas. & $257(s)$ & $v_{2}, \delta\left(\mathrm{UO}_{2}^{2+}\right)$ \\
\hline Not meas. & $379(m)$ & $v, \mathrm{r}\left(\mathrm{CO}_{2}\right)$ \\
\hline $490(\mathrm{~m})$ & $490(m)$ & $v_{3}, \delta(\mathrm{O}-\mathrm{C}-\mathrm{O}) ; v,(\mathrm{C}-\mathrm{C}=\mathrm{O})$ \\
\hline $546(w)$ & -- & \\
\hline $663(w)$ & $653(w)$ & $v, 1(\mathrm{H}-\mathrm{O}-\mathrm{H}) ; \mathrm{v},(\mathrm{O}-\mathrm{C}=\mathrm{O})$ \\
\hline $729(w)$ & $736(w)$ & \\
\hline $803(s)$ & $797(m)$ & $v_{12}, \delta(\mathrm{O}-\mathrm{C}-\mathrm{O})$ \\
\hline $849(w)$ & -- & \\
\hline $869(w)$ & $869(w)$ & $v_{1}, \mathrm{~s}\left(\mathrm{UO}_{2}{ }^{2+}\right)$ \\
\hline $946(v s)$ & $944(v s)$ & $v_{3}, \mathrm{a}\left(\mathrm{UO}_{2}{ }^{2+}\right)$ \\
\hline $1035(w)$ & $1060(w)$ & $v,(\mathrm{C}=\mathrm{O})$ \\
\hline $1315(\mathrm{~m})$ & $1314(\mathrm{~m})$ & $v_{11}, \mathrm{~s}(\mathrm{O}-\mathrm{C}-\mathrm{O})$ \\
\hline $1357(\mathrm{~m})$ & $1357(\mathrm{~m})$ & $v_{11}, \mathrm{~s}(\mathrm{O}-\mathrm{C}-\mathrm{O})$ \\
\hline $1627(v s)$ & $1623(v s)$ & $v_{9}, \mathrm{a}(\mathrm{O}-\mathrm{C}-\mathrm{O}) ; \mathrm{v},(\mathrm{C}=\mathrm{O}) ; v_{2}, \delta(\mathrm{H}-\mathrm{O}-\mathrm{H})$ \\
\hline $1692(v s)$ & -- & \\
\hline-- & $2322(w)$ & $\mathrm{CO}_{2}$ \\
\hline $2927(\mathrm{~m})$ & $2929(\mathrm{~m})$ & $v_{1}, \mathrm{~s}(\mathrm{OH}) ; v_{3}, \mathrm{a}(\mathrm{OH})$ \\
\hline $3454(s)$ & $3442(s)$ & $v_{1}, \mathrm{~s}(\mathrm{OH}) ; v_{3}, \mathrm{a}(\mathrm{OH})$ \\
\hline $3604(\mathrm{~m})$ & $3622(\mathrm{~m})$ & $v_{1}, \mathrm{~s}(\mathrm{OH}) ; v_{3}, \mathrm{a}(\mathrm{OH})$ \\
\hline \multicolumn{3}{|c|}{$\begin{array}{l}w \text { - weak; } m \text { - medium; } s \text {-strong; } v s-\text { very strong. } \\
v \text { - frequency; } \delta \text { - deformation, s- symmetric, a - antisymmetric, and } \mathrm{r}- \\
\text { rocking vibrations; } 1 \text { - libration. } \\
\text { Literature frequencies and assignments from Ribnikar and Trtica (1998). }\end{array}$} \\
\hline
\end{tabular}


The uranyl oxalate crystals also were characterized by DTA/differential scanning calorimetry (DSC) scans using 11.790 to $23.441 \mathrm{mg}$ samples. The scans were found to be consistent with published information (Bressat et al. 1963; Buttress and Hughes 1968; Tel et al. 1999). The thermal events of the present tests and results found in the technical literature for heating of uranyl oxalate in air are compared in Table 4.

The TGA scans were consistent with the thermal decomposition of uranyl oxalate trihydrate but sometimes complicated by loss of sample from the balance pan. The appearances of products from $500^{\circ} \mathrm{C}$ and $1000^{\circ} \mathrm{C}$ calcination of uranyl oxalate were practically identical by SEM (Figure 15), giving plate-shaped and possibly some rod-shaped crystals that did not sinter (fuse to form particles of apparent lower surface area) even at $1000^{\circ} \mathrm{C}$ treatment and having no SEM-visible porosity. The crystals were $\mathrm{U}_{3} \mathrm{O}_{8}$ in all cases, as shown by X-ray diffractometry (XRD), with some improvement in crystallinity at higher temperature, as shown by sharper diffraction peaks (Figure 25). Because the $500^{\circ} \mathrm{C}$ product calcine lost weight when heated to $1000^{\circ} \mathrm{C}$, transformation evidently was not complete at $500^{\circ} \mathrm{C}$.

To examine further the completeness of reaction, a moist uranyl oxalate filtercake approximately $3-\mathrm{cm}$ deep was calcined in an alumina $\left(\mathrm{Al}_{2} \mathrm{O}_{3}\right)$ crucible at plant conditions $\left(1000^{\circ} \mathrm{C}\right.$ for two hours). Samples from the calcine were examined by XRD to determine the completeness of conversion to $\mathrm{U}_{3} \mathrm{O}_{8}$ as a function of depth and thus exposure to air. Nearly all the calcined cake could be removed from the crucible in a single piece 1.5 diameter $\times 2.5 \mathrm{~cm}$ high but the material itself was porous and friable. Samples were taken from the top, middle, and bottom of the piece and mounted for XRD. As shown in Figure 16, $\mathrm{U}_{3} \mathrm{O}_{8}$ was the only product phase observed. In particular, no evidence was found for $\mathrm{UO}_{2}, \mathrm{UO}_{3}$, or other uranium oxide phases. Corundum $\left(\mathrm{Al}_{2} \mathrm{O}_{3}\right)$ was added during XRD sample preparation as an internal standard.

Moisture uptake studies on the $\mathrm{U}_{3} \mathrm{O}_{8}$ product calcined under loss on ignition conditions were performed using controlled humidity desiccators. The humidity was set using sulfuric acid solutions $\left(60 \mathrm{wt} \% \mathrm{H}_{2} \mathrm{SO}_{4}\right.$ for $18.8 \cong 19 \% \mathrm{RH}$ and $28 \mathrm{wt} \% \mathrm{H}_{2} \mathrm{SO}_{4}$ for $80 \% \mathrm{RH}$ [Weast 1976]). Duplicate tests were run, each with $\sim 3.5 \mathrm{~g} \mathrm{U}_{3} \mathrm{O}_{8}$ prepared by precipitation of uranyl oxalate, calcination at $500^{\circ} \mathrm{C}$, and then two hours' subsequent calcination at $1000^{\circ} \mathrm{C}$. The samples were loose powders and were not stirred during the moisture uptake tests. The tests were done in new alumina crucibles and a new blank (empty) crucible was run in parallel to monitor possible moisture uptake on the crucible itself. The moisture uptakes at 19\% RH after 48 hours, corrected for uptake by the empty crucible, and varied erratically between -0.005 and +0.015 $\mathrm{wt} \%$ and thus were essentially zero to the measurement accuracy.

Table 4. Thermal Analysis Results for Uranyl Oxalate Heating in Air

\begin{tabular}{|c|c|c|c|c|}
\hline \multirow{2}{*}{ Event } & \multicolumn{4}{|c|}{ Temperature $\left({ }^{\circ} \mathrm{C}\right)$} \\
\hline & Present Studies & Bressat et al. 1963 & Buttress and Hughes $1968^{(a)}$ & Tel et al. 1999 \\
\hline Endotherm & $74-82$ & monohydrate & $\sim 100$ & 100 \\
\hline Endotherm & 154-158 & 159 & $\sim 166$ & 170 \\
\hline Exotherm & $356-361$ & 367 & $360-400$ & 365 \\
\hline Exotherm & $\sim 530^{(\mathrm{a})}$ & -- & $\sim 548$ & -- \\
\hline Endotherm & $\sim 629^{(\mathrm{a})}$ & -- & $\sim 647$ & -- \\
\hline Ramp Rate & $5^{\circ} \mathrm{C} / \mathrm{min}$ & $5^{\circ} \mathrm{C} / \mathrm{min}$ & 1 or $6^{\circ} \mathrm{C} / \mathrm{min}$ & $10^{\circ} \mathrm{C} / \mathrm{min}$ \\
\hline
\end{tabular}



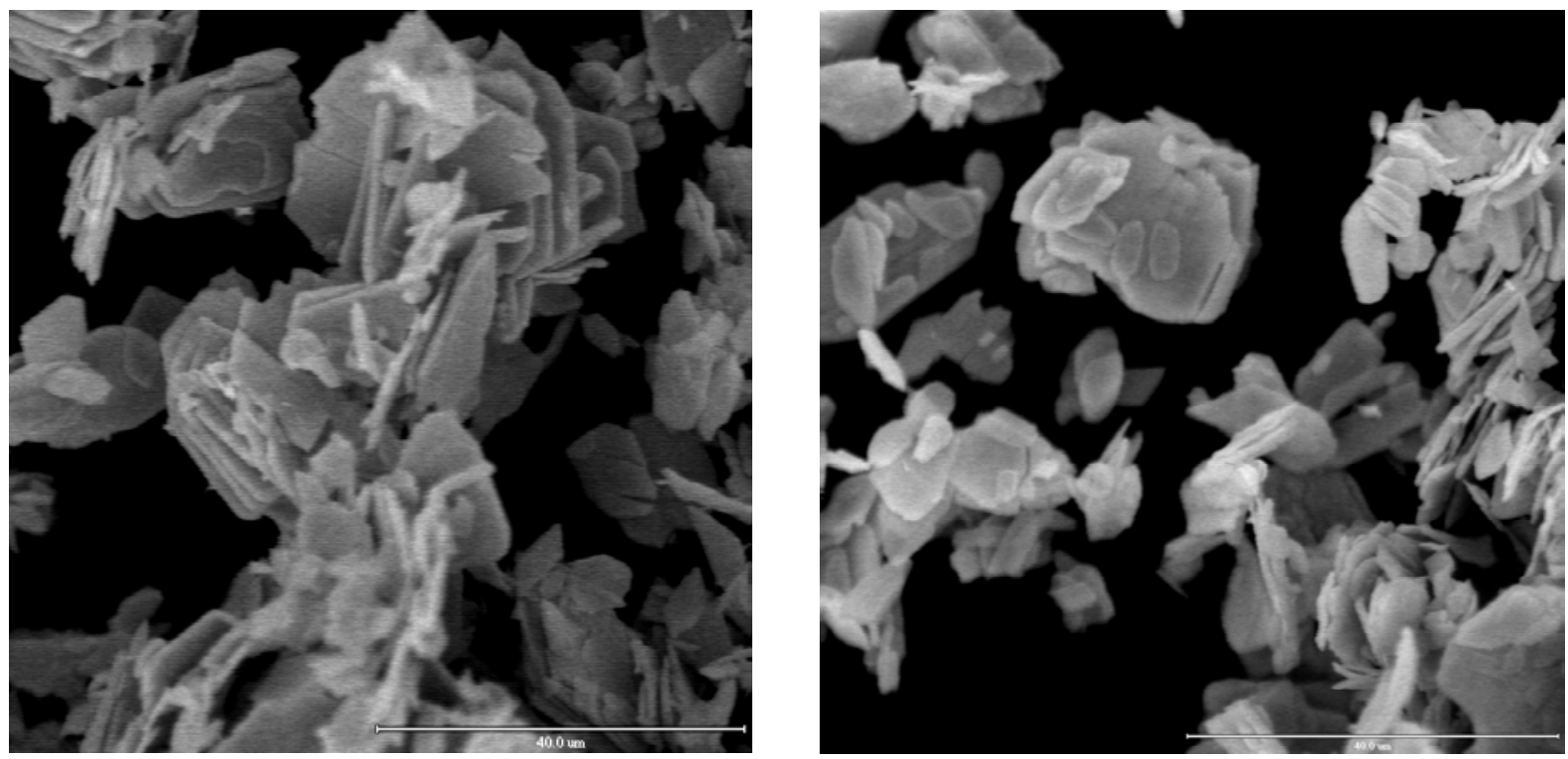

Figure 15. SEM Photomicrographs of $\mathrm{U}_{3} \mathrm{O}_{8}$ Product of Thermal Decomposition of $\mathrm{UO}_{2} \mathrm{C}_{2} \mathrm{O}_{4} \cdot 3 \mathrm{H}_{2} \mathrm{O}$ (left- $500^{\circ} \mathrm{C}$; right $-1000^{\circ} \mathrm{C}$; bars correspond to $40 \mu \mathrm{m}$ )

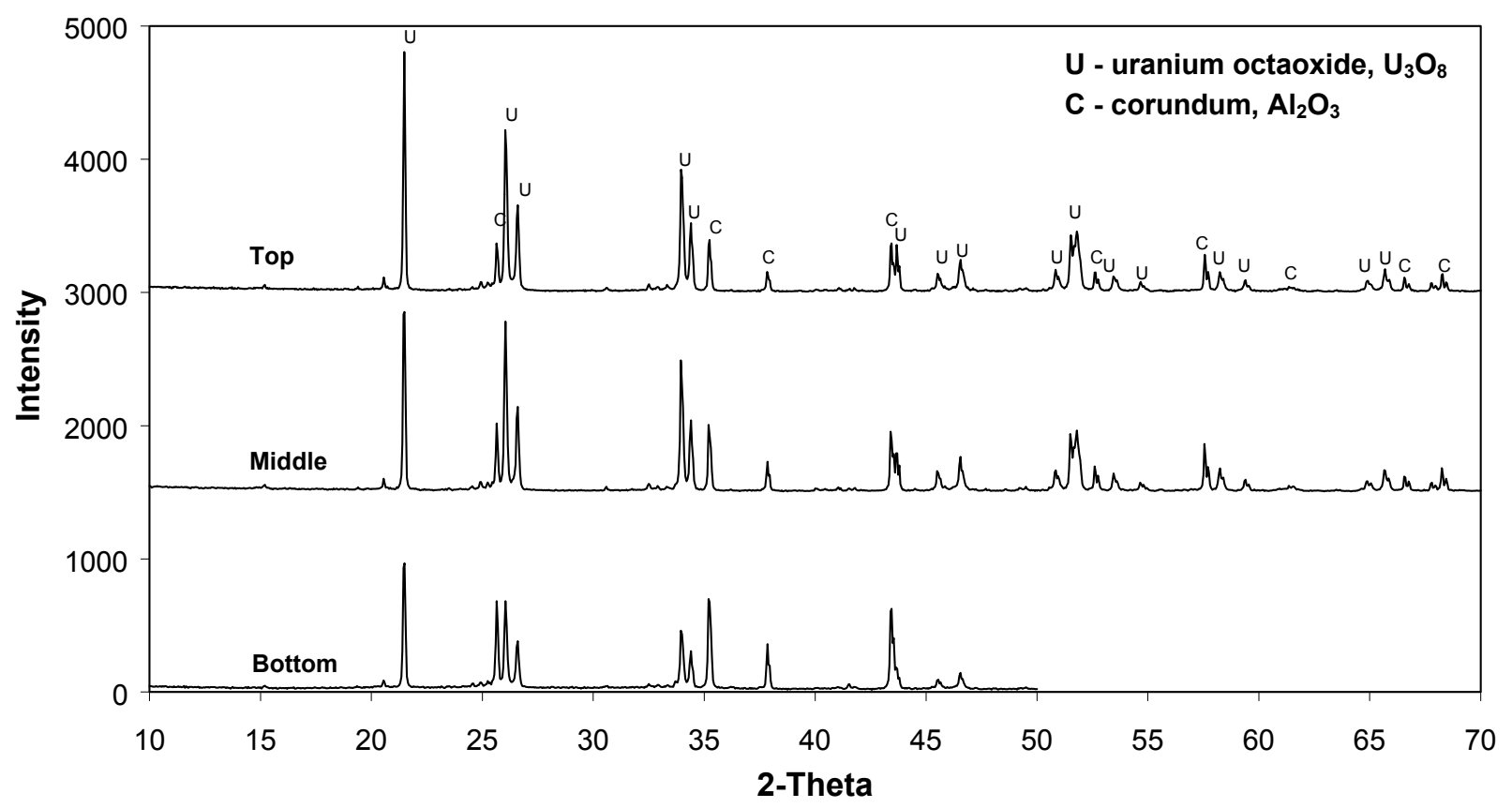

Figure 16. X-Ray Diffraction Scans of Products Taken at Various Depths in $1000^{\circ} \mathrm{C}$ Calcination of $\mathrm{UO}_{2} \mathrm{C}_{2} \mathrm{O}_{4} \cdot 3 \mathrm{H}_{2} \mathrm{O}$ Product in a Crucible 
This total variability is less than 0.001 grams and is negligible compared with the balance resolution of $\pm 0.0001 \mathrm{~g}$ for four weight measurements (before and after exposure to humidity for the empty and $\mathrm{U}_{3} \mathrm{O}_{8^{-}}$ bearing crucibles). Tests at $80 \% \mathrm{RH}$ also were performed for the same materials after their re-calcination at $1000^{\circ} \mathrm{C}$. Results at $80 \% \mathrm{RH}$ show moisture uptakes, corrected for the crucible blank, to be rapid (within a few hours) and leveling near $\sim 0.03 \mathrm{wt} \%$, well below the 0.5 -wt $\%$ moisture threshold. The moisture uptake results for the $19 \%$ and $80 \%$ RH are shown in Figure 17.

Tests were performed to monitor the moisture/weight uptake for $\mathrm{U}_{3} \mathrm{O}_{8}$ products prepared by $1000^{\circ} \mathrm{C}$ calcination of reagent-grade uranyl nitrate. To compare the test results with recent experiments at Oak Ridge National Laboratory (ORNL) (Icenhour et al. 2002), products from $650^{\circ} \mathrm{C}$ calcination of uranyl nitrate also were prepared. For completeness, similar experiments also were performed for products of $650^{\circ} \mathrm{C}$ and $1000^{\circ} \mathrm{C}$ calcination of uranyl oxalate. Thus, in the present testing, duplicate portions of uranyl nitrate were heated in alumina boats and then calcined to $1000^{\circ} \mathrm{C}$ to produce $\mathrm{U}_{3} \mathrm{O}_{8}$. Duplicate portions of $\mathrm{U}_{3} \mathrm{O}_{8}$ materials also were made by $650^{\circ} \mathrm{C}$ calcination of uranyl nitrate. Parallel two-hour $650^{\circ} \mathrm{C}$ and $1000^{\circ} \mathrm{C}$ calcinations of duplicate uranyl oxalate samples were performed in like manner. The respective nitrate and oxalate calcines were exposed to $80 \% \mathrm{RH}$ in closed chambers and the weight gains recorded as a function of time (Figures 18 and 19, respectively).

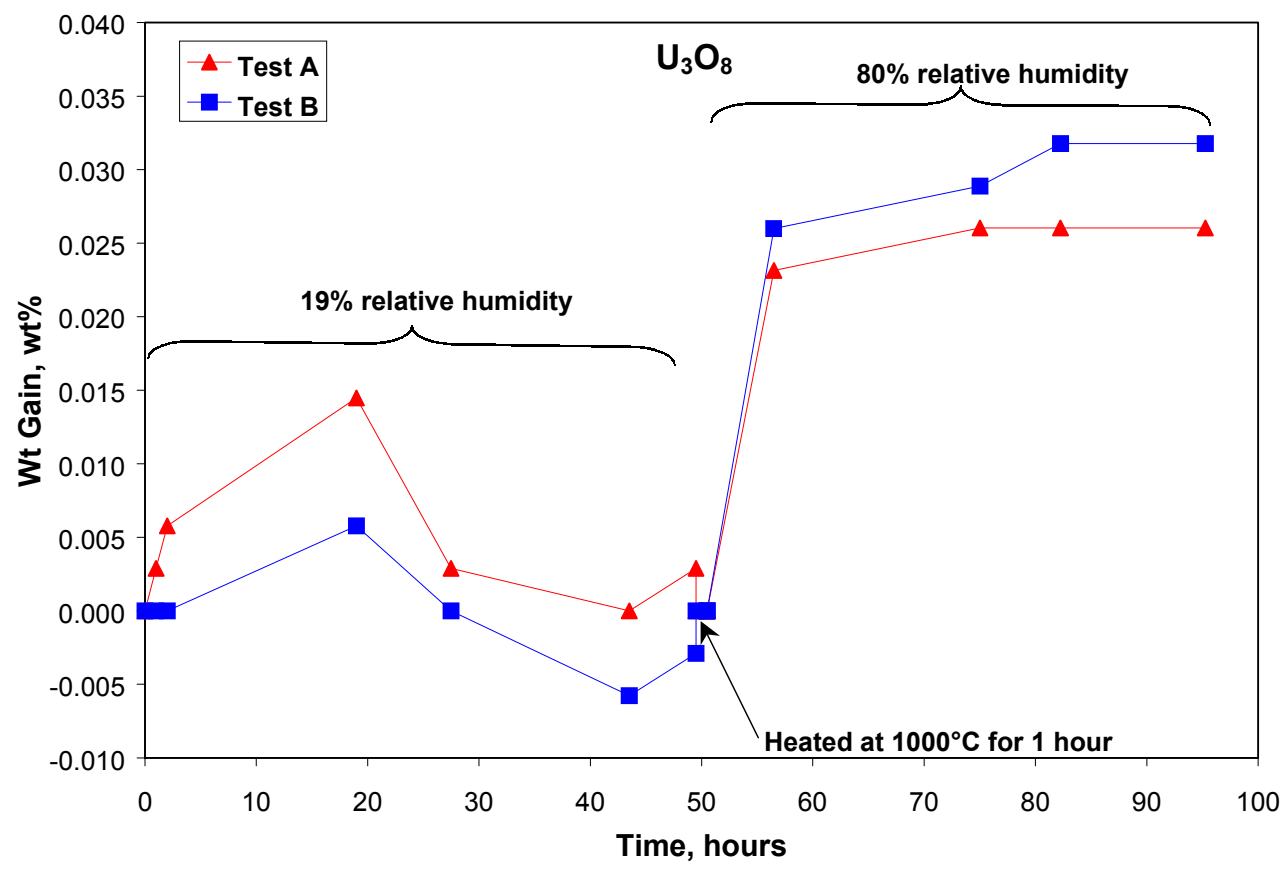

Figure 17. Moisture Uptake on $\mathrm{U}_{3} \mathrm{O}_{8}$ Prepared by $1000^{\circ} \mathrm{C}$ Calcination of Uranyl Oxalate as a Function of Humidity and Exposure Time 


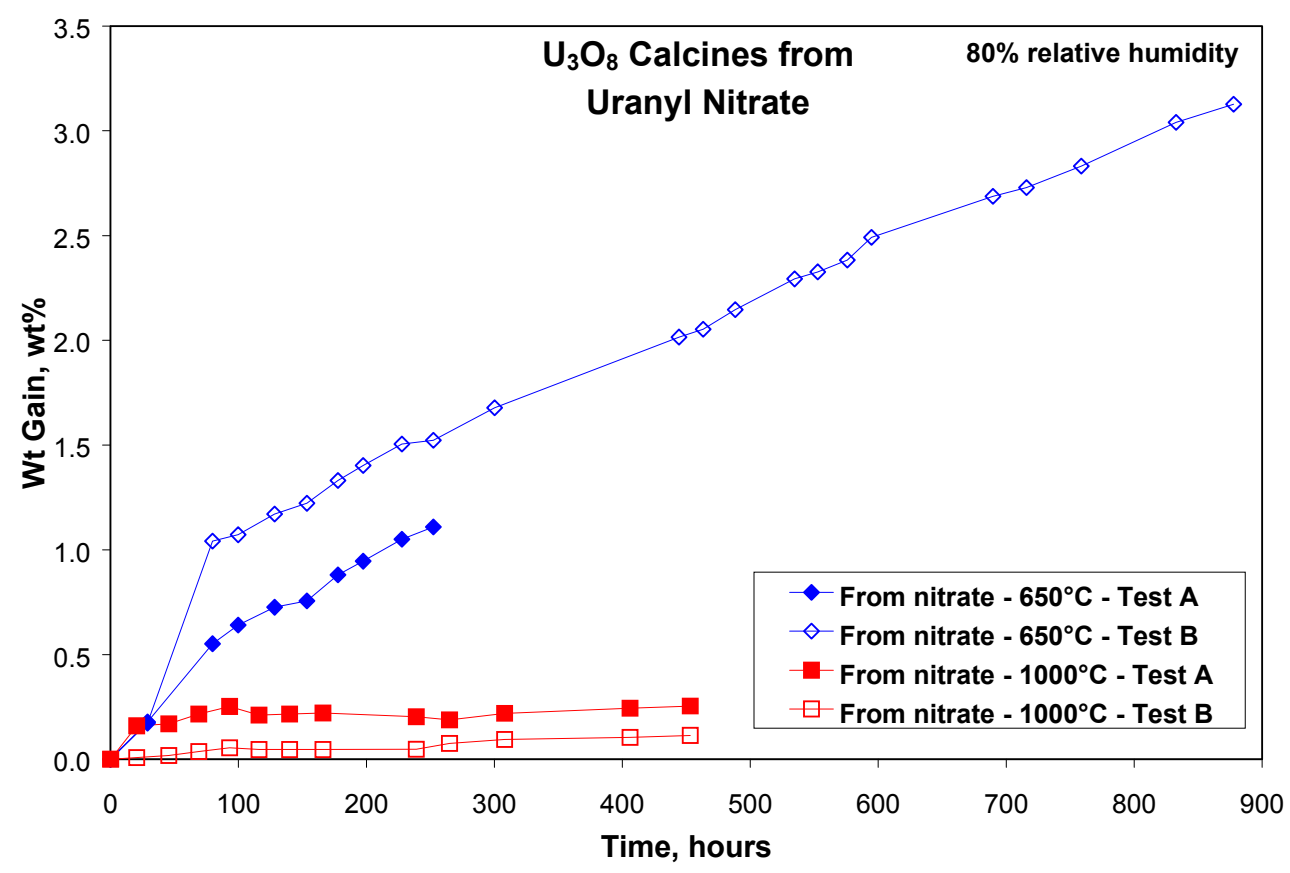

Figure 18. Moisture Uptake at $80 \% \mathrm{RH}$ on $\mathrm{U}_{3} \mathrm{O}_{8}$ Prepared by $650{ }^{\circ} \mathrm{C}$ and $1000^{\circ} \mathrm{C}$ Calcination of Uranyl Nitrate as a Function of Exposure Time

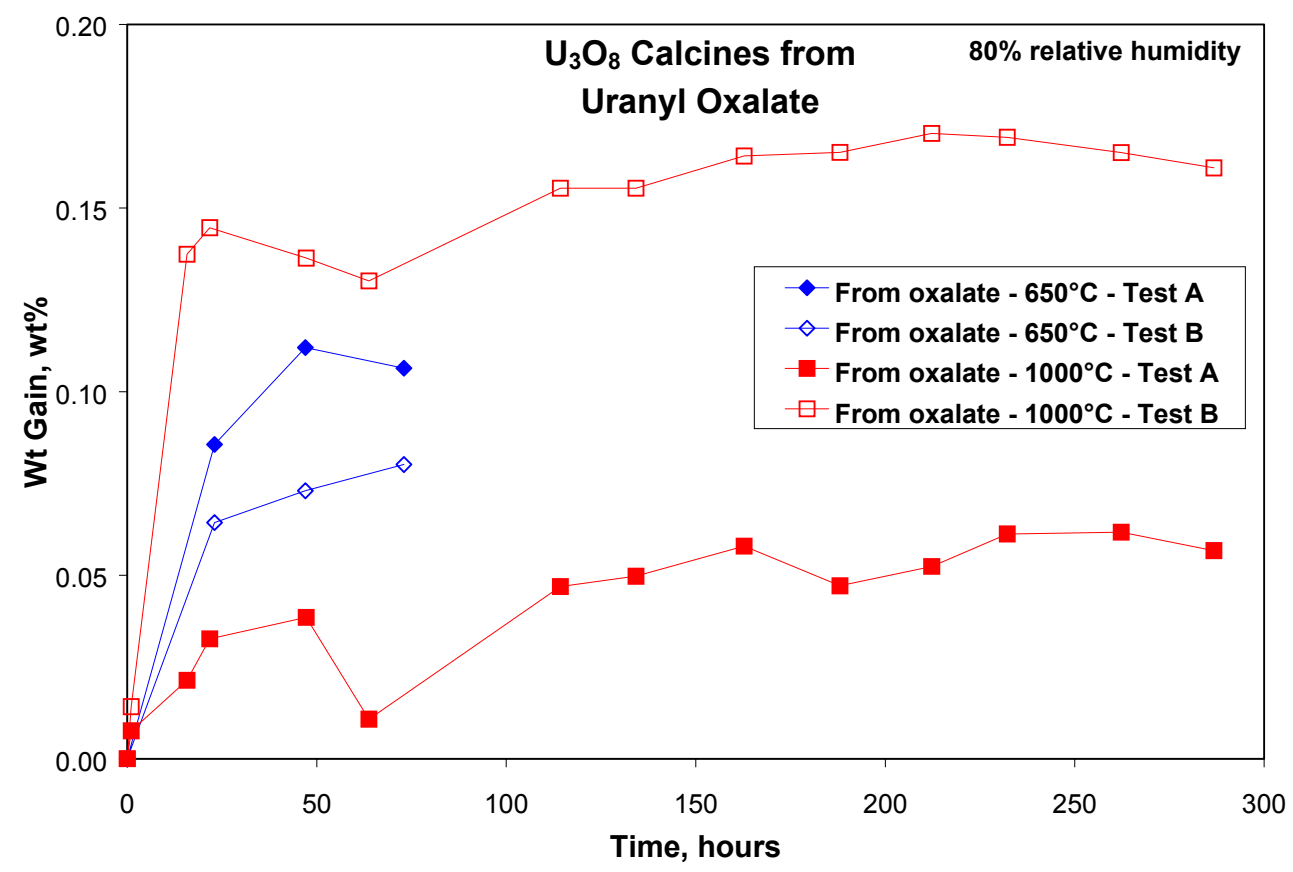

Figure 19. Moisture Uptake at $80 \% \mathrm{RH}$ on $\mathrm{U}_{3} \mathrm{O}_{8}$ Prepared by $650{ }^{\circ} \mathrm{C}$ and $1000^{\circ} \mathrm{C}$ Calcination of Uranyl Oxalate as a Function of Exposure Time 
As shown in Figure 18, the weight uptakes for the $\mathrm{U}_{3} \mathrm{O}_{8}$ products from $650^{\circ} \mathrm{C}$ calcination of uranyl nitrate increase monotonically through 36 days of exposure to $80 \% \mathrm{RH}$ air. After 12 days, the weight gains are about 1.1 and $1.5 \mathrm{wt} \%$ in the duplicate tests. The ORNL experiments (Icenhour et al. 2002) showed comparable behavior for a $\mathrm{U}_{3} \mathrm{O}_{8}$ material produced by overnight $650^{\circ} \mathrm{C}$ calcination of a $\mathrm{UO}_{3}$ intermediate product formed by $350^{\circ} \mathrm{C}$ thermal decomposition of uranyl nitrate hexahydrate salt. In the ORNL tests, a stirred 9-g sample of $\mathrm{U}_{3} \mathrm{O}_{8}$ prepared in this fashion and exposed to $97.5 \% \mathrm{RH}$ gained about $1.2 \mathrm{wt} \%$ after 12 days and about $9 \mathrm{wt} \%$ after 200 days. An otherwise-similar but stirred 2-g sample gained about $1.6 \mathrm{wt} \%$ in about 14 days. Over a 200-day period, another $\mathrm{U}_{3} \mathrm{O}_{8}$ sample (mass not stated) exposed to $70 \% \mathrm{RH}$ gained $4 \mathrm{wt} \%$; under otherwise similar conditions, a $\mathrm{U}_{3} \mathrm{O}_{8}$ sample also containing $5 \mathrm{wt} \% \mathrm{Gd}_{2} \mathrm{O}_{3}$ had similar weight gain. The ORNL studies thus showed that 1) the $650^{\circ} \mathrm{C}$-calcined $\mathrm{U}_{3} \mathrm{O}_{8}$ prepared by thermal decomposition of $\mathrm{UO}_{2}\left(\mathrm{NO}_{3}\right)_{2} \cdot 6 \mathrm{H}_{2} \mathrm{O} \rightarrow \mathrm{UO}_{3} \rightarrow \mathrm{U}_{3} \mathrm{O}_{8}$ is unstable to weight gain even when exposed to moist air for a few days and 2) the weight gain continues unabated for hundreds of days. The present test results concur with the ORNL findings and show that $\mathrm{U}_{3} \mathrm{O}_{8}$ prepared from $650^{\circ} \mathrm{C}$ calcination of uranyl nitrate weight increases continuously when exposed to humid (80\% RH) air.

In contrast, present testing shows low and relatively flat weight uptakes for products from $1000^{\circ} \mathrm{C}$ calcination of uranyl nitrate upon exposure to $80 \% \mathrm{RH}$ air. Even after 19 days of exposure, the weight uptakes in duplicate tests are 0.11 and $0.25 \mathrm{wt} \%$ for the $1000^{\circ} \mathrm{C}$-calcined uranyl nitrate products.

Results for $\mathrm{U}_{3} \mathrm{O}_{8}$ formed from calcination of uranyl oxalate also show low and comparable weight gains irrespective of calcination temperature (Figure 19). The $\mathrm{U}_{3} \mathrm{O}_{8}$ preparations from $1000^{\circ} \mathrm{C}$ calcination of uranyl oxalate achieved stable weight gains (of about 0.06 and $0.16 \mathrm{wt} \%$ for the two tests) in the first day and remained unchanged up to 12 days. Similar results were found for the oxalate products of $650^{\circ} \mathrm{C}$ calcination. These compare with $\sim 0.03 \mathrm{wt} \%$ observed in the prior tests for similar masses of uranyl oxalate calcine but exposed to a smaller surface area in a crucible (Figure 17).

To help understand the differences in weight uptake behavior, the $\mathrm{U}_{3} \mathrm{O}_{8}$ products of $650^{\circ} \mathrm{C}$ and $1000^{\circ} \mathrm{C}$ calcinations of uranyl nitrate were examined by SEM (Figure 20). These images, compared with images of the $1000^{\circ} \mathrm{C}$ product from uranyl oxalate (Figure 15; same magnification as in Figure 20), show an apparent higher porosity for the calcined uranyl nitrate and suggest that perhaps the high weight gains manifested by the $650^{\circ} \mathrm{C}$ uranyl nitrate products occur because of the high surface area. However, the $1000^{\circ} \mathrm{C}$ uranyl nitrate product, though of appearance similar to the $650^{\circ} \mathrm{C}$ product, had much lower moisture absorption.

Surface area measurements of all four $\mathrm{U}_{3} \mathrm{O}_{8}$ calcines were performed by BET gas uptake methods. Higher temperature calcination decreased surface area for both the uranyl nitrate and uranyl oxalate products. The uranyl nitrate product calcined to $650^{\circ} \mathrm{C}$ had a surface area of $3.1 \mathrm{~m}^{2} / \mathrm{g}$ while the $1000^{\circ} \mathrm{C}$ product had a surface area of $0.61 \mathrm{~m}^{2} / \mathrm{g}$. The uranyl oxalate products calcined to $650^{\circ} \mathrm{C}$ and $1000^{\circ} \mathrm{C}$ had surface areas of $1.1 \mathrm{~m}^{2} / \mathrm{g}$ and $0.059 \mathrm{~m}^{2} / \mathrm{g}$, respectively. The differences in surface area explain some but not all of the disparity in the moisture uptake results for the uranyl nitrate and oxalate calcine products.

Processing the CML solutions at the PFP will produce calcines from both uranyl oxalate and uranyl nitrate starting materials. The laboratory tests show that the highly fired $\mathrm{U}_{3} \mathrm{O}_{8}$-bearing $1000^{\circ} \mathrm{C}$ calcines to be produced from either of the uranyl salts should have low moisture uptakes. 

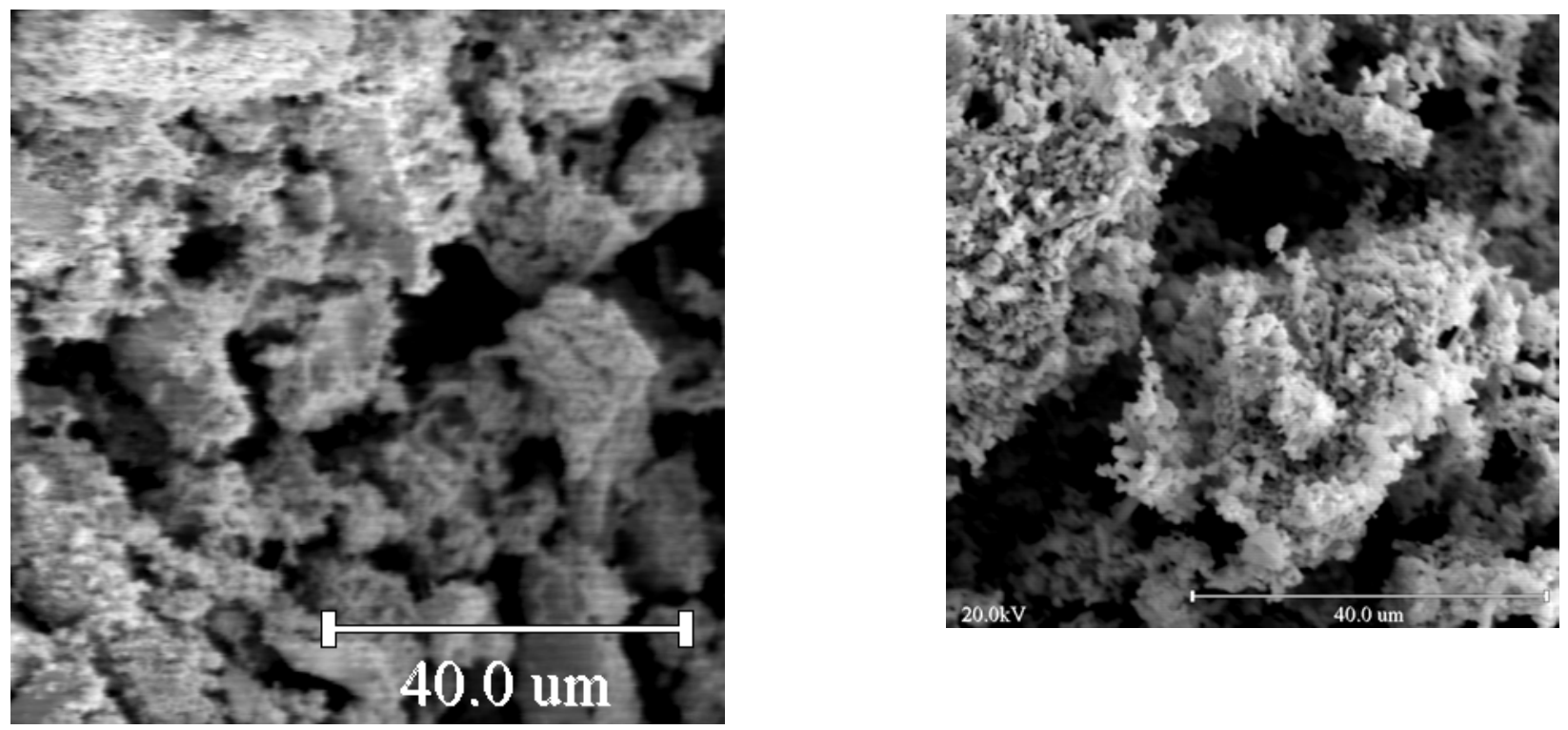

Figure 20. SEM Photomicrographs of $\mathrm{U}_{3} \mathrm{O}_{8}$ Products of Thermal Decomposition of $\mathrm{UO}_{2}\left(\mathrm{NO}_{3}\right)_{2} \cdot 6 \mathrm{H}_{2} \mathrm{O}$ (left $-650^{\circ} \mathrm{C}$; right $-1000^{\circ} \mathrm{C}$; bars correspond to $40 \mu \mathrm{m}$ )

However, thermodynamic analyses also suggest that exposure of the $\mathrm{U}_{3} \mathrm{O}_{8}$ to moist air should be limited because $\mathrm{U}_{3} \mathrm{O}_{8}$ is unstable to form either schoepite $\left[\left(\mathrm{UO}_{2}\right)_{8} \mathrm{O}_{2}(\mathrm{OH})_{12}\left(\mathrm{H}_{2} \mathrm{O}\right)_{12}\right]$ or metaschoepite $\left[\left(\mathrm{UO}_{2}\right)_{8} \mathrm{O}_{2}(\mathrm{OH})_{12}\left(\mathrm{H}_{2} \mathrm{O}\right)_{10}\right]$ in oxygen with condensing water. Thermodynamic calculations summarized below were performed using published standard free energies of formation, $\Delta \mathrm{G}_{\mathrm{f}}^{0}$ [Wagman et al. (1982) for $\mathrm{U}_{3} \mathrm{O}_{8}(-3369.7 \mathrm{~kJ} / \mathrm{mole})$ and liquid water $(-237.129 \mathrm{~kJ} / \mathrm{mole})$; Chen et al. (1999) for schoepite (calculated to be $-13609.2 \mathrm{~kJ} / \mathrm{mole})$; O’Hare et al. (1988) for metaschoepite $(-13096 \mathrm{~kJ} / \mathrm{mole})]$.

$$
\begin{array}{ll}
8 \mathrm{U}_{3} \mathrm{O}_{8}+4 \mathrm{O}_{2(\mathrm{~g})}+54 \mathrm{H}_{2} \mathrm{O}_{(\mathrm{l})} \rightarrow 3\left(\mathrm{UO}_{2}\right)_{8} \mathrm{O}_{2}(\mathrm{OH})_{12}\left(\mathrm{H}_{2} \mathrm{O}\right)_{12} & \Delta \mathrm{G}_{\mathrm{rxn}}=-1065.2 \mathrm{~kJ} \text { or }-133.1 \mathrm{~kJ} / \mathrm{mole} \mathrm{U} \\
8 \mathrm{U}_{3} \mathrm{O}_{8}+4 \mathrm{O}_{2(\mathrm{~g})}+48 \mathrm{H}_{2} \mathrm{O}_{(\mathrm{l})} \rightarrow 3\left(\mathrm{UO}_{2}\right)_{8} \mathrm{O}_{2}(\mathrm{OH})_{12}\left(\mathrm{H}_{2} \mathrm{O}\right)_{10} & \Delta \mathrm{G}_{\mathrm{rxn}}=-948.2 \mathrm{~kJ} \text { or }-118.5 \mathrm{~kJ} / \mathrm{mole} \mathrm{U}
\end{array}
$$

Limited laboratory studies confirm the thermodynamic interpretation and show that $\mathrm{U}_{3} \mathrm{O}_{8}$-type materials calcined from $\mathrm{UO}_{2}(\mathrm{OH})_{2}$ to relatively low temperatures can hydrate and oxidize in water-saturated air at $45-47^{\circ} \mathrm{C}$ (Urbanec and Sedláková 1963). The conversion of $\mathrm{U}_{3} \mathrm{O}_{8}$ to uranium oxide hydrate (various schoepites) also has been observed under aerated immersed conditions (Vochten et al. 1990).

Further characterization tests were performed to study the product formed by reaction of $\mathrm{U}_{3} \mathrm{O}_{8}$ with humid air. Samples of the $\mathrm{U}_{3} \mathrm{O}_{8}$ products formed by $650^{\circ} \mathrm{C}$ calcination of uranyl nitrate and $1000^{\circ} \mathrm{C}$ calcination of uranyl oxalate, and subsequently exposed to $80 \%$ RH for $\sim 400$ hours, were examined by XRD (Figure 21) and differential thermogravimetry (DTG) (Figure 22). Corundum, $\mathrm{Al}_{2} \mathrm{O}_{3}$, was added during XRD sample preparation as an internal standard. Both products' diffraction scans show primarily the expected $\mathrm{U}_{3} \mathrm{O}_{8}$ solid phase. In both cases, however, metaschoepite $\left[\left(\mathrm{UO}_{2}\right)_{8} \mathrm{O}_{2}(\mathrm{OH})_{12}\left(\mathrm{H}_{2} \mathrm{O}\right)_{10}\right]$ also was observed. Based on XRD peak heights, more alteration occurred with the uranyl nitrate product calcined at the lower $\left(650^{\circ} \mathrm{C}\right)$ temperature. 


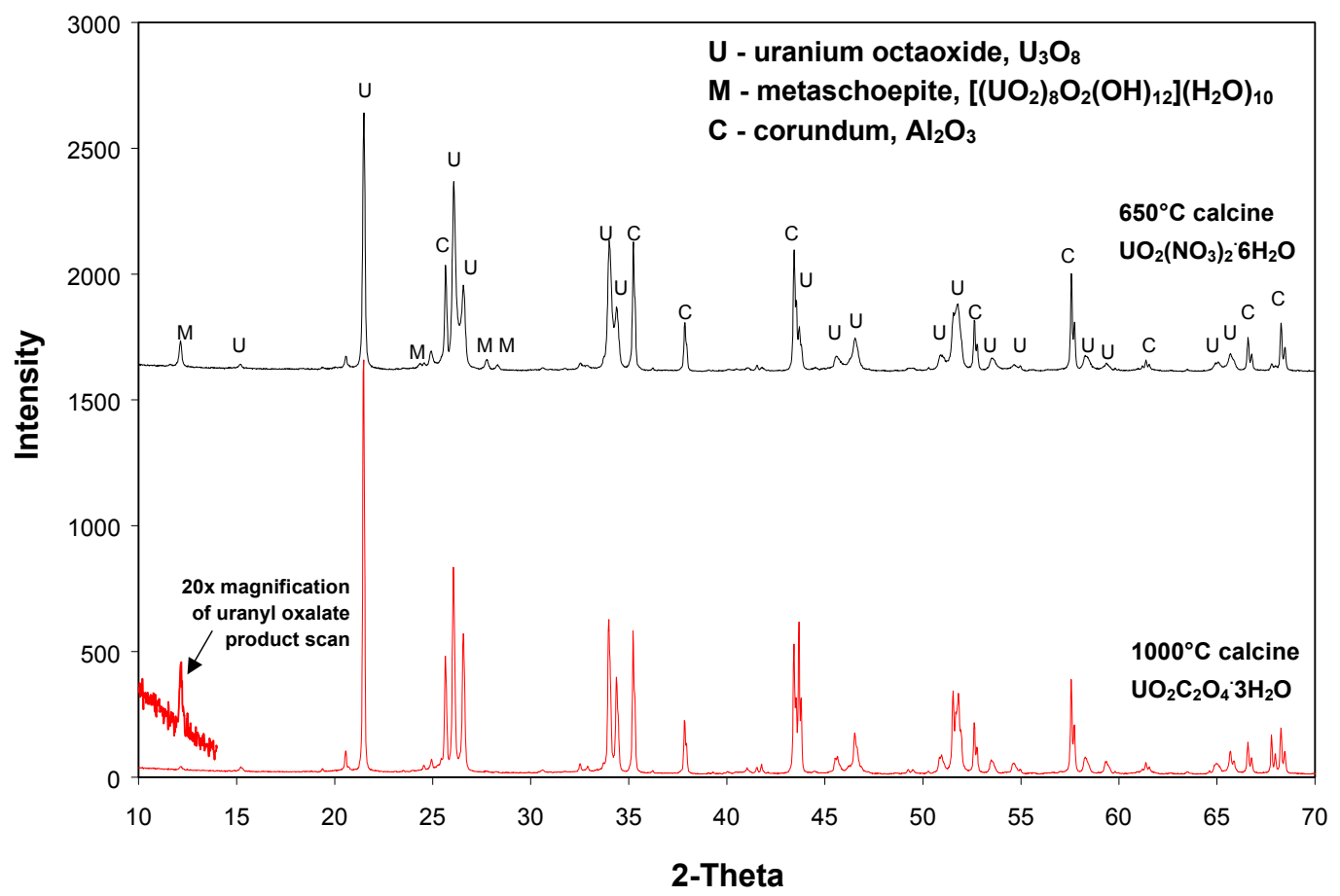

Figure 21. X-Ray Diffraction Scans of Products of $1000^{\circ} \mathrm{C}$ Calcination of $\mathrm{UO}_{2} \mathrm{C}_{2} \mathrm{O}_{4} \cdot 3 \mathrm{H}_{2} \mathrm{O}$ and $650^{\circ} \mathrm{C}$ Calcination of $\mathrm{UO}_{2}\left(\mathrm{NO}_{3}\right)_{2} \cdot 6 \mathrm{H}_{2} \mathrm{O}$ After $400 \mathrm{hr}$ Exposure to $80 \% \mathrm{RH}$ Air

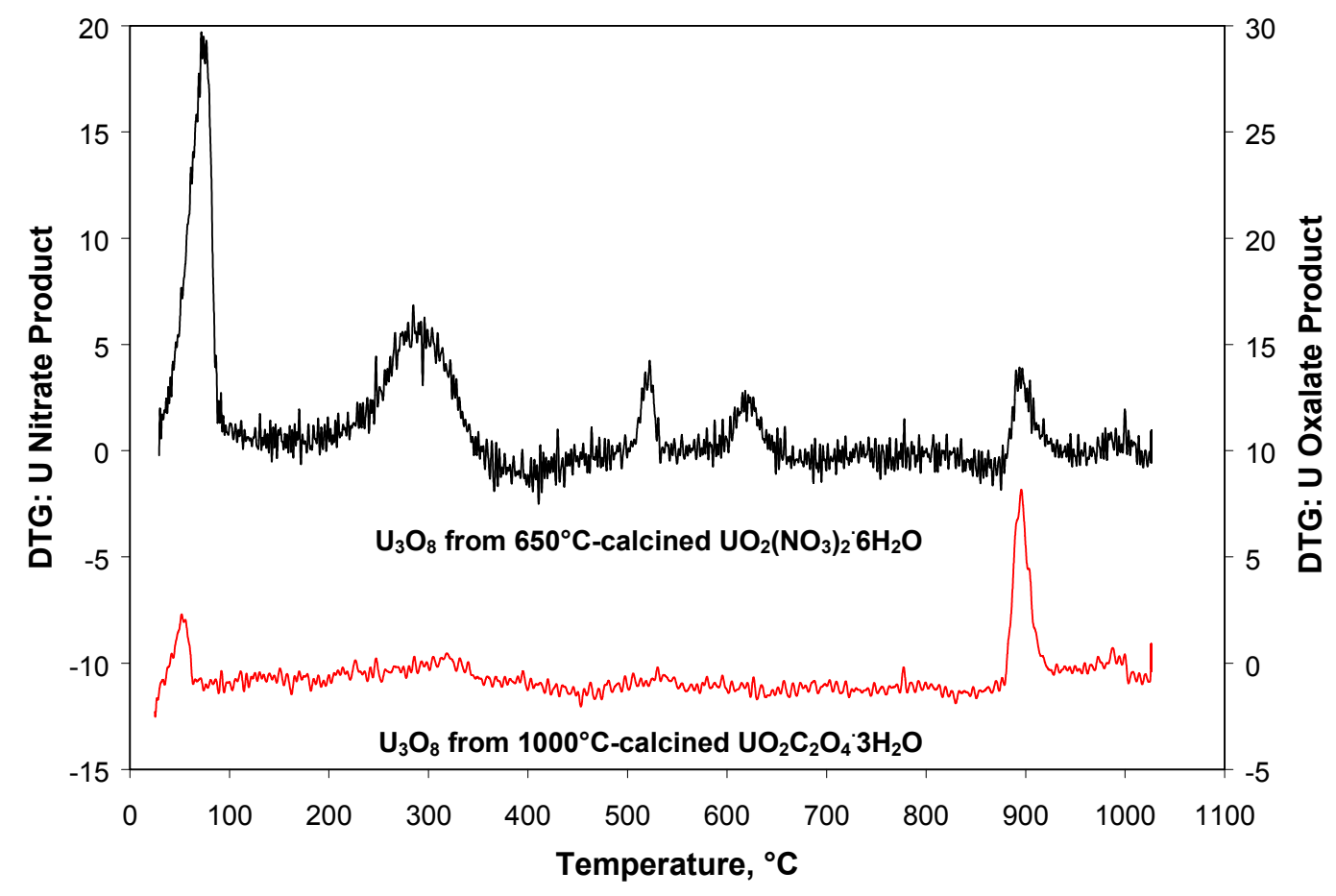

Figure 22. Differential Thermogravimetry of Products of $1000^{\circ} \mathrm{C}$ Calcination of $\mathrm{UO}_{2} \mathrm{C}_{2} \mathrm{O}_{4} \cdot 3 \mathrm{H}_{2} \mathrm{O}$ and $650^{\circ} \mathrm{C}$ Calcination of $\mathrm{UO}_{2}\left(\mathrm{NO}_{3}\right)_{2} \cdot 6 \mathrm{H}_{2} \mathrm{O}$ After $400 \mathrm{hr}$ at $80 \% \mathrm{RH}$ 
The DTG analyses confirm this interpretation, showing weight loss centered at $\sim 70^{\circ} \mathrm{C}$ due to metaschoepite decomposition and/or loss of physi-adsorbed water. The weight loss at $250-300^{\circ} \mathrm{C}$ represents conversion of dehydrated schoepite $\mathrm{UO}_{3} \cdot 0.8 \mathrm{H}_{2} \mathrm{O}$ to the hemihydrate $\mathrm{UO}_{3} \cdot 0.5 \mathrm{H}_{2} \mathrm{O}$ and then to anhydrous, amorphous $\mathrm{UO}_{3}$. At least one of the two peaks at $\sim 510$ and $\sim 650^{\circ} \mathrm{C}$ is from $\mathrm{UO}_{3}$ decomposition to form $\mathrm{U}_{3} \mathrm{O}_{8}$. The peak heights below $700^{\circ} \mathrm{C}$ are lower for the uranyl oxalate product and thus likely all arise from metaschoepite decomposition or loss of physi-adsorbed water.

Weight loss peaks occur at $900-920^{\circ} \mathrm{C}$ for both DTG scans. The weight losses correspond to reversible oxygen loss to the oxygen-deficient $\mathrm{U}_{3} \mathrm{O}_{8-\mathrm{x}}$ stoichiometry (Kolthoff et al. 1962 and citations therein; Vita et al. 1973; Weigel 1986) and are of similar height, consistent with their assignment to the predominant $\mathrm{U}_{3} \mathrm{O}_{8}$ phase. The reversibility of oxygen loss as temperature rises above $\sim 900^{\circ} \mathrm{C}$; comparable gain was demonstrated with cooling for a sample of the $\mathrm{U}_{3} \mathrm{O}_{8}$ product from uranyl oxalate calcination.

\subsection{Calcination and Moisture Uptake Studies of the Effects of Boric Acid and Gadolinium}

Boron and gadolinium are present in low concentrations in the CML solutions. The influences of boron (as boric acid) and gadolinium (as its nitrate salt) on the calcination and moisture uptake of CML products were studied in laboratory tests.

The boric acid $\left(\mathrm{H}_{3} \mathrm{BO}_{3}\right)$ present in the $\mathrm{CML}$ solutions is not expected to precipitate with any of the solution components and should only accompany the filtercake as part of the interstitial liquid. Upon heating, the boric acid would dehydrate to form free $\mathrm{B}_{2} \mathrm{O}_{3}$ and likely would fuse with the refractory $\mathrm{PuO}_{2}$ at the $1000^{\circ} \mathrm{C}$ temperature to form $\mathrm{B}_{2} \mathrm{O}_{3}-\mathrm{PuO}_{2}$ glass upon cooling. Because pure boric oxide is hygroscopic, significant uptake of moisture on cooling $\mathrm{B}_{2} \mathrm{O}_{3}$ or the prospective $\mathrm{B}_{2} \mathrm{O}_{3}-\mathrm{PuO}_{2}$ glass in humid atmospheres may occur and is a major cause for concern in stabilizing the CML solutions in the humid RMC glovebox line. Based on these considerations, the influence of $\mathrm{B}_{2} \mathrm{O}_{3}$ on the hygroscopicity of CML product calcines was studied.

Tests of moisture uptake on calcined boric acid were performed using $\mathrm{CeO}_{2}$ as a surrogate for $\mathrm{PuO}_{2}$. To be equivalent, the $\mathrm{Pu}: \mathrm{B}$ mole ratio of 45:1 was preserved for $\mathrm{Ce}: \mathrm{B}$ in the tests with the $\mathrm{CeO}_{2}$. On a gravimetric basis, this represents $0.00798 \mathrm{~g} \mathrm{H}_{3} \mathrm{BO}_{3}$ per gram $\mathrm{CeO}_{2}$. ${ }^{\text {(a) }}$

Calcined ceria $\left(\mathrm{CeO}_{2}\right)$, prepared by PFP scientists in the PPSL by precipitation and calcination of $\mathrm{Ce}$ (III) oxalate, was saturated with boric acid solution at mole concentrations comparable to and 1.5 times higher than the 1:45 B:Ce mole ratio concentrations representing unrinsed CML Pu oxalate filtercake. A blank test with water added also was run (i.e., tests were run at $0,0.022$, and 0.033 mole fraction boron). The three moist cakes, each with about 24 grams of ceria, were heated to dryness and then calcined at $1000^{\circ} \mathrm{C}$ for two hours in platinum crucibles.

The weight loss experienced by the samples upon $1000^{\circ} \mathrm{C}$ calcination under LOI conditions was recorded. Under LOI conditions, the samples were heated in a furnace at $150^{\circ} \mathrm{C}$ for two hours to drive off water, the furnace temperature ramped to $1000^{\circ} \mathrm{C}$ and held there for two hours, and the crucibles removed

(a) $\frac{1 \text { mole B }}{45 \text { mole } \mathrm{Ce}} \times \frac{\text { mole Ce }}{172.13 \mathrm{~g} \mathrm{CeO}_{2}} \times \frac{61.83 \mathrm{~g} \mathrm{H}_{3} \mathrm{BO}_{3}}{\mathrm{~mole} \mathrm{~B}^{2}}=0.00798 \mathrm{~g} \mathrm{H}_{3} \mathrm{BO}_{3} / \mathrm{g} \mathrm{CeO}_{2}$ 
from the furnace at $1000^{\circ} \mathrm{C}$ and placed directly into a desiccator. The desiccator was evacuated and the crucibles weighed when they reached room temperature.

The pure ceria sample lost $0.055 \mathrm{wt} \%$ upon calcination. The parallel samples with boric acid lost an additional increment of weight beyond that ascribed to the ceria. Thus, it was suspected that some fraction of the contained boron volatilized. The weight losses corresponded to $47 \%$ of the original boron (assayed as $\mathrm{B}_{2} \mathrm{O}_{3}$ ) in the case of the test with the expected interstitial boric acid concentration and $39 \%$ of the original boron in the case of test with 1.5 times the expected boric acid. Subsequent examination of the technical literature shows that boric acid can be steam-distilled from boiling aqueous solutions. That is, a boron compound, likely $\mathrm{HBO}_{2}$, has a significant vapor pressure in hot water vapor (Markovski1 1962). However, $\mathrm{B}_{2} \mathrm{O}_{3}$ itself melts at $430^{\circ} \mathrm{C}$ but does not boil until $2250^{\circ} \mathrm{C}$; therefore, any boric acid remaining after removal of water should not be lost by $1000^{\circ} \mathrm{C}$ heating.

The moisture uptake studies of the $\sim 2$-cm-deep calcined samples of $\mathrm{B}_{2} \mathrm{O}_{3}$-bearing $\mathrm{CeO}_{2}$ were performed in a humidity chamber controlled at $80 \% \mathrm{RH}$ using a $28 \mathrm{wt} \% \mathrm{H}_{2} \mathrm{SO}_{4}$ solution. The 2-cm depth corresponds to the approximate bed depth in process calcination boats with moisture uptake under tests at conditions plausible in the humid glovebox environment of the PFP RMC line, where thermal stabilization and packaging of the CML product oxalate is destined to occur. After about 60 hours of exposure at $80 \%$ $\mathrm{RH}$, the unstirred samples were re-calcined at $1000^{\circ} \mathrm{C}$ and exposed to $\sim 19 \% \mathrm{RH}$ (using $60 \mathrm{wt} \% \mathrm{H}_{2} \mathrm{SO}_{4}$ solution). The re-calcination restored the pure ceria sample to exactly its prior calcined weight. The samples with boron lost a small additional fraction of their boron (4 and $5 \%$ of their original boron for the 1 - and 1.5-fold boron tests to leave 49 and 55\%, respectively, of the original boron in the ceria bed) upon re-calcination.

The moisture uptake data are presented graphically in Figure 23. The moisture uptake on the pure calcined ceria at $80 \%$ RH was at apparent equilibrium after about one day and reached about $0.018 \mathrm{wt} \%$. The tests with boron added gained 0.038 and $0.054 \mathrm{wt} \%$, respectively, for the 1 - and 1.5 -fold expected boric acid loadings ( 0.022 and 0.033 mole fraction B). Even at this relatively high humidity, these moisture uptakes are well below the DOE-STD-3013 0.5-wt $\%$ moisture threshold. The moisture uptakes on the recalcined materials were all about $0.008 \mathrm{wt} \%$ at $19 \% \mathrm{RH}$. Though boron (likely as $\mathrm{B}_{2} \mathrm{O}_{3}$ ) increases the moisture-absorbing properties of ceria (the $\mathrm{PuO}_{2}$ surrogate), the enhancement observed in these tests does not jeopardize attaining the $0.5-\mathrm{wt} \%$ moisture threshold. The tests also showed that a significant fraction of the interstitial boric acid likely would be removed during hotplate drying by a steam-stripping mechanism. The boric acid did cause some cementation of the ceria particles so that the calcines formed chunky agglomerates. The agglomerates were not hard and could be crushed by slight finger pressure.

A quantity of gadolinium oxalate was prepared from a solution of the nitrate salt by shaking with a stoichiometric excess of oxalic acid in DI (distilled/deionized) water. The precipitate was washed with room temperature DI water, centrifuged, and decanted four times to remove interstitial salts. The solids then were heated to $1000^{\circ} \mathrm{C}$ for two hours to form $\mathrm{Gd}_{2} \mathrm{O}_{3}$ and weighed out into two platinum crucibles.

Weight uptake data on $\sim 1$-gram samples of the product $\mathrm{Gd}_{2} \mathrm{O}_{3}$, measured periodically during exposure to $80 \% \mathrm{RH}$ air (maintained by $19 \mathrm{wt} \% \mathrm{H}_{2} \mathrm{SO}_{4}$ ) in a closed chamber, show about $0.02-0.05 \mathrm{wt} \%$ gain after about two days of exposure (Figure 24). The weight gains remained constant for at least four days. 


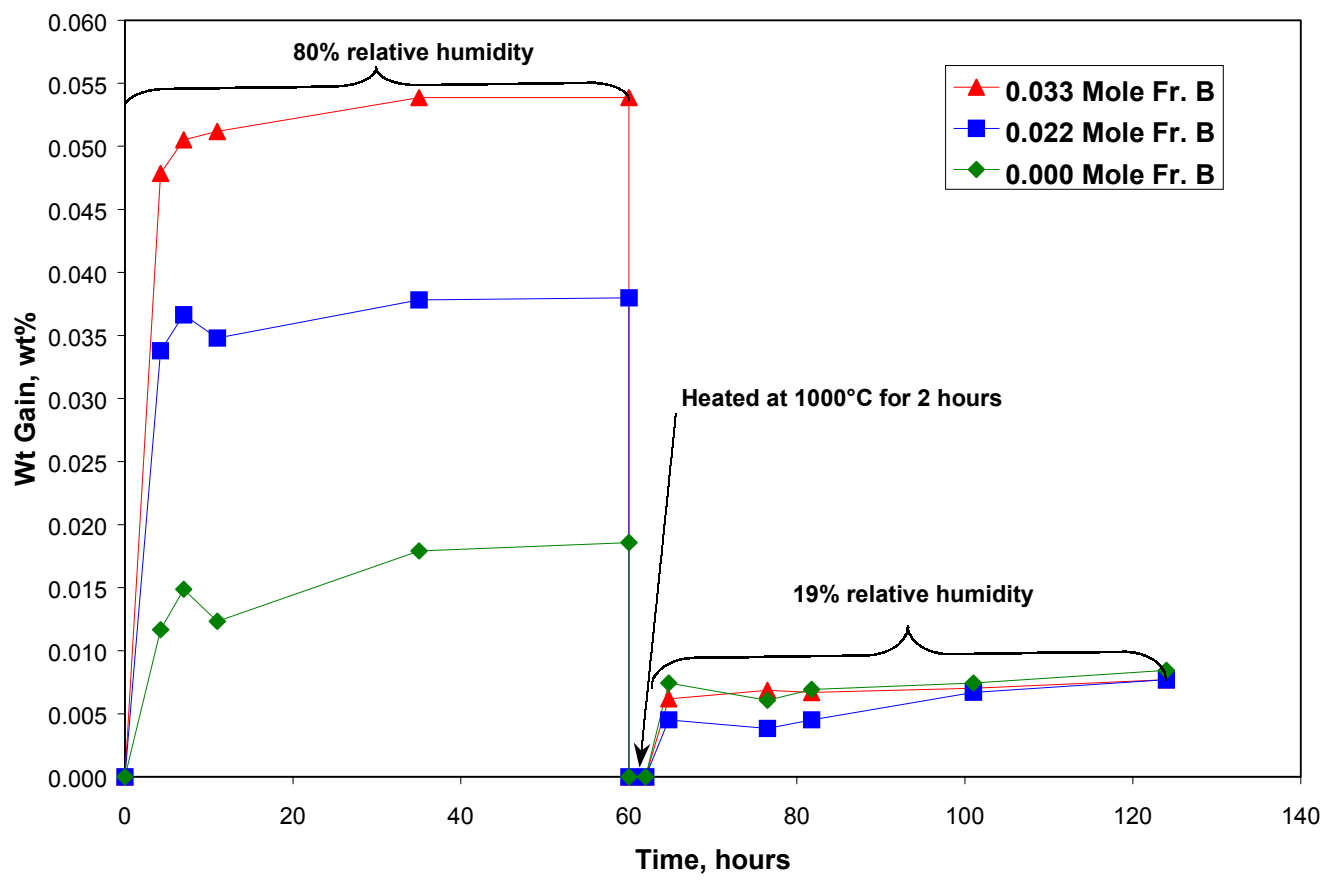

Figure 23. Moisture Uptake on Calcined $\mathrm{CeO}_{2}-\mathrm{B}_{2} \mathrm{O}_{3}$ as a Function of Humidity and Exposure Time

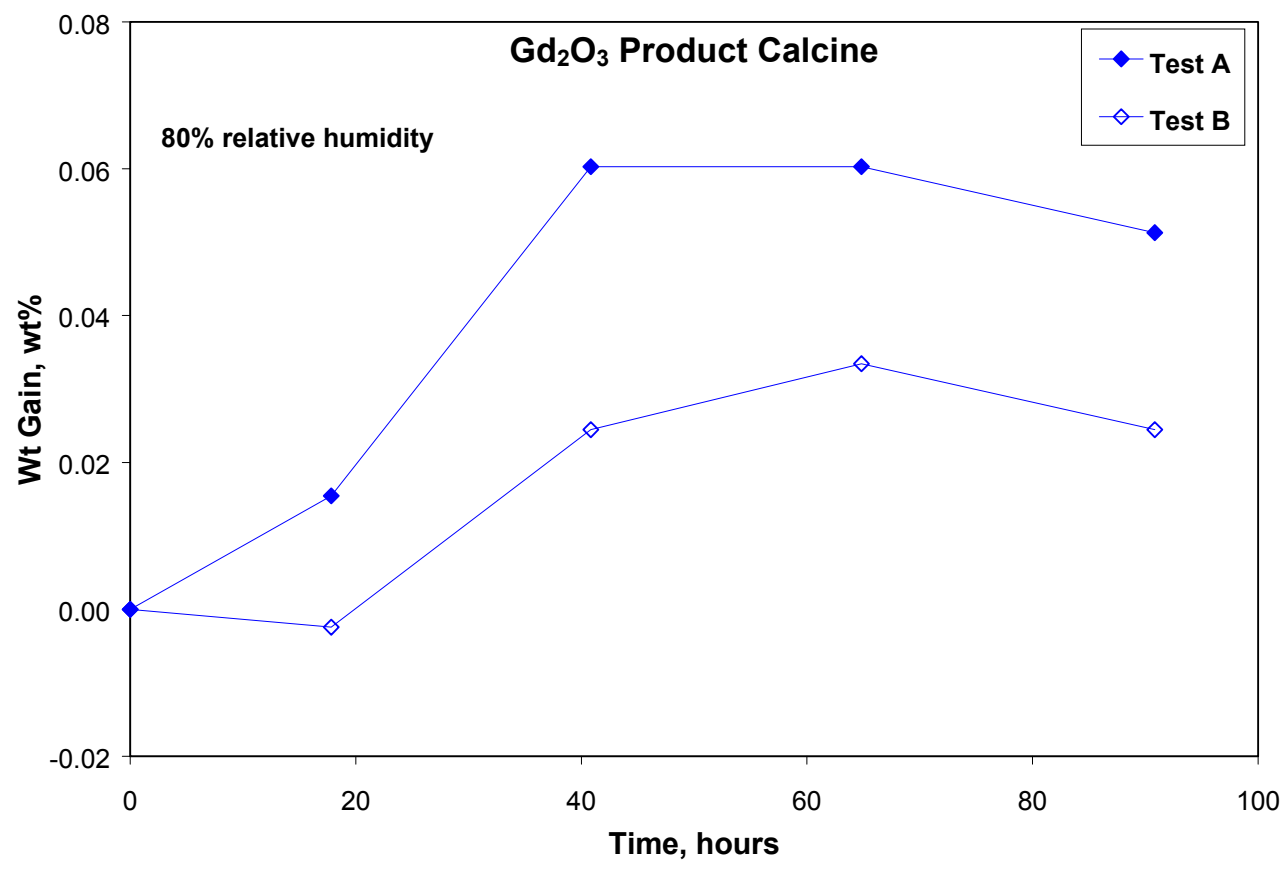

Figure 24. Moisture Uptake on Calcined $\mathrm{Gd}_{2} \mathrm{O}_{3}$ as a Function of Exposure Time 


\subsection{Tests of the Calcination and Moisture Uptake of Simulated CML Oxalate Precipitate Product}

The calcination and moisture uptake behaviors of products from precipitation of simulated CML oxalate were examined to determine the mutual influences of the plutonium and uranium constituents. These tests examined the effects caused by higher concentrations of uranium in the desired plutonium product and of the presence of boron and gadolinium.

Moist cake samples of $\mathrm{Pu}(\mathrm{IV})$ oxalate with interstitial uranyl nitrate solution (and some with uranyl oxalate solid) were dried and then calcined to $1000^{\circ} \mathrm{C}$ for two hours. The products then were examined by XRD. The unrinsed cakes were prepared by precipitating simulated dilutions of CML solutions (to $50 \mathrm{~g}$ $\mathrm{Pu} / \mathrm{L}$ and $112 \mathrm{~g} \mathrm{U} / \mathrm{L}$ in $1.14 \mathrm{M} \mathrm{HNO}_{3}$ ) with solid oxalic acid using 2.19:1, 2.62:1, and 3.50:1 oxalate:Pu mole ratios. The precipitation test conditions and results are described in the previous sections.

The cake products range from the nominal proposed, low acid concentration, plant precipitate products in which $\mathrm{Pu}$ precipitation is practically complete but no uranyl oxalate precipitation occurs (at 2.19:1 mole ratio) to product cakes containing $16 \%$ and $63 \%$ of the starting uranium in the precipitate (at $2.62: 1$ and 3.5:1 oxalate:Pu mole ratios, respectively) prepared under potential oxalic acid overdose conditions.

The XRD of the mixed plutonium-uranium oxide product calcines and of pure uranium oxides from calcination of uranyl oxalate at three different temperatures are compared in Figure 25. Together, the XRD scans show that $\mathrm{U}_{3} \mathrm{O}_{8}$ is the sole uranium-bearing phase formed after calcination though the detection limit

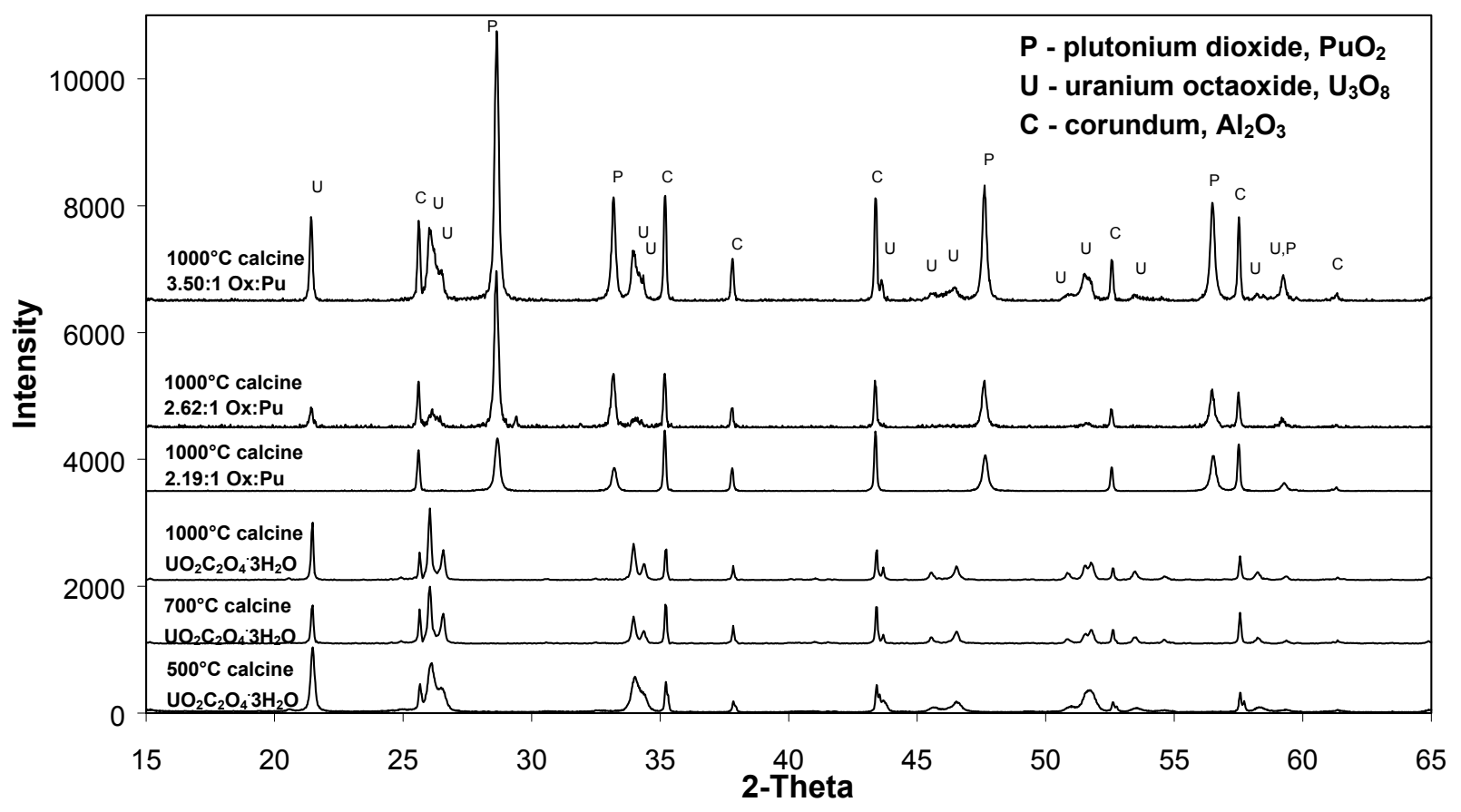

Figure 25. X-Ray Diffraction Scans of Mixed Pu/U Oxides Produced by $1000^{\circ} \mathrm{C}$ Calcination of $\mathrm{PuO}_{2}\left(\mathrm{C}_{2} \mathrm{O}_{4}\right)_{2} \cdot 6 \mathrm{H}_{2} \mathrm{O}$ and 500,700 , and $1000^{\circ} \mathrm{C}$ Calcination of $\mathrm{UO}_{2} \mathrm{C}_{2} \mathrm{O}_{4} \cdot 3 \mathrm{H}_{2} \mathrm{O}$ under Nominal Process Conditions 
by XRD is estimated to be only 5 to $10 \%$. For example, the plutonium-uranium product prepared at 2.19:1 oxalate:Pu mole ratio has only the sharp peaks corresponding to $\mathrm{PuO}_{2}$ and no peaks due to uranium phases.

Though the cakes were not rinsed and therefore contained uranium in the interstitial solution, no $\mathrm{U}_{3} \mathrm{O}_{8}$ or other uranium-bearing phase (e.g., $\mathrm{UO}_{2}, \mathrm{UO}_{3} \cdot \mathrm{H}_{2} \mathrm{O}$, and $\mathrm{UO}_{3} \cdot 2 \mathrm{H}_{2} \mathrm{O}$ ) was detected. The diffraction scans from the products from the 2.62:1 and 3.5:1 oxalate:Pu tests showed $\mathrm{U}_{3} \mathrm{O}_{8}$ with the $\mathrm{U}_{3} \mathrm{O}_{8}$ peak intensities increasing with increasing oxalate:Pu ratio (and thus uranyl oxalate concentration in the precipitate). Again, however, no $\mathrm{UO}_{2}, \mathrm{UO}_{3} \cdot \mathrm{H}_{2} \mathrm{O}$, or $\mathrm{UO}_{3} \cdot 2 \mathrm{H}_{2} \mathrm{O}$ was detected in the diffraction scans. The diffraction scans products from the calcination of $\mathrm{UO}_{2} \mathrm{C}_{2} \mathrm{O}_{4} \cdot 3 \mathrm{H}_{2} \mathrm{O}$ at 500,700 , and $1000^{\circ} \mathrm{C}$ show exclusively $\mathrm{U}_{3} \mathrm{O}_{8}$. Corundum was added during sample preparation to be an internal reference in all XRD mounts.

Moisture uptake studies also were performed for calcines from simulated CML solution. Two separate portions of oxalate filtercake from simulant CML solution were prepared at 2.25:1 and 2.75:1 oxalate:Pu ratio for moisture uptake studies. The precipitations were made from $1.5 \mathrm{M} \mathrm{HNO}_{3}$ solution containing boron and gadolinium at the nominal concentrations (see Table 2 for detailed solution compositions). Based on supernatant solution concentrations, the cake produced at the $2.25: 1$ ratio contained $\sim 4 \%$ of the uranium as an oxalate precipitate (i.e., $8.5 \mathrm{wt} \% \mathrm{U}_{3} \mathrm{O}_{8}$ in the calcine) and the $2.75: 1$ cake contained $\sim 27 \%$ of the uranium as precipitate (i.e., $39 \mathrm{wt} \% \mathrm{U}_{3} \mathrm{O}_{8}$ in the calcine). Uranium in the interstitial liquid would increase the $\mathrm{U}_{3} \mathrm{O}_{8}$ in the calcines to about 18 and $48 \mathrm{wt} \%$, respectively. Duplicate portions of moist cakes from each oxalate:Pu ratio, separated from the solution by centrifugation and decantation, were transferred to tare-weighed new alumina crucibles. The crucibles with contents were dried for several hours at $150^{\circ} \mathrm{C}$ and then heated to $1000^{\circ} \mathrm{C}$ for two hours. The crucibles with calcined materials were removed from the furnace at $\sim 800^{\circ} \mathrm{C}$ and allowed to cool under vacuum in a desiccator. A blank new empty crucible was run in parallel to monitor the behavior of the crucible itself. The quantities of calcine in the 2.25:1 oxalate:Pu tests were about $0.4-0.5$ grams each; the tests at 2.75:1 oxalate:Pu each had about 0.7 grams of calcine. The crucibles with contents were transferred to a desiccator controlled to $19 \% \mathrm{RH}$ with a $60 \mathrm{wt} \%$ sulfuric acid solution. The moisture uptakes on the unstirred but loose calcined $\mathrm{Pu} / \mathrm{U}$ oxides were monitored as a function of time for about two days. The crucibles with contents then were re-calcined to $1000^{\circ} \mathrm{C}$ for six hours (lab operations prevented earlier entry) and the moisture uptake experiment repeated in a desiccator controlled to $80 \%$ RH for seven days of contact time.

The results of the moisture uptake testing on the calcined CML products produced at nominal 2.25:1 and 2.75:1 oxalate:Pu ratios are depicted in Figure 26. The moisture uptakes at 19\% RH reached apparent steady state within a few hours and, at about 0.03 to $0.05 \mathrm{wt} \%$, are near the analytical detection limit and well below the $0.5 \mathrm{wt} \%$ threshold. The moisture uptakes at $80 \% \mathrm{RH}$ vary from 0.12 to $0.20 \mathrm{wt} \%$ after seven days of exposure and reach apparent equilibrium in a few hours. Within the measurement precision, moisture uptake apparently does not depend on the fraction of uranium in the $\mathrm{PuO}_{2}-\mathrm{U}_{3} \mathrm{O}_{8}$ mixtures.

Tests of the moisture uptake on two-hour $1000^{\circ} \mathrm{C}$ calcined simulated CML product were repeated starting with fresh preparations of the 2.25:1 and 2.75:1 oxalate:Pu precipitates. The calcines were prepared in alumina crucibles and again removed directly from the hot $\left(850-900^{\circ} \mathrm{C}\right)$ furnace and placed directly into a vacuum desiccator for cooling before weighing. About $0.36 \mathrm{~g}$ of the 2.25:1 calcine and $0.39 \mathrm{~g}$ of the 2.75:1 calcine were obtained. Moisture/weight uptakes on the unstirred loose solids then were monitored during exposure to $80 \% \mathrm{RH}$ as a function of time. As shown in Figure 27, about 0.08 and 0.20 wt $\%$ uptakes were observed through $\sim 37$ days of exposure with the greater uptake observed at the higher oxalate:Pu ratio (and thus higher uranium concentration). 


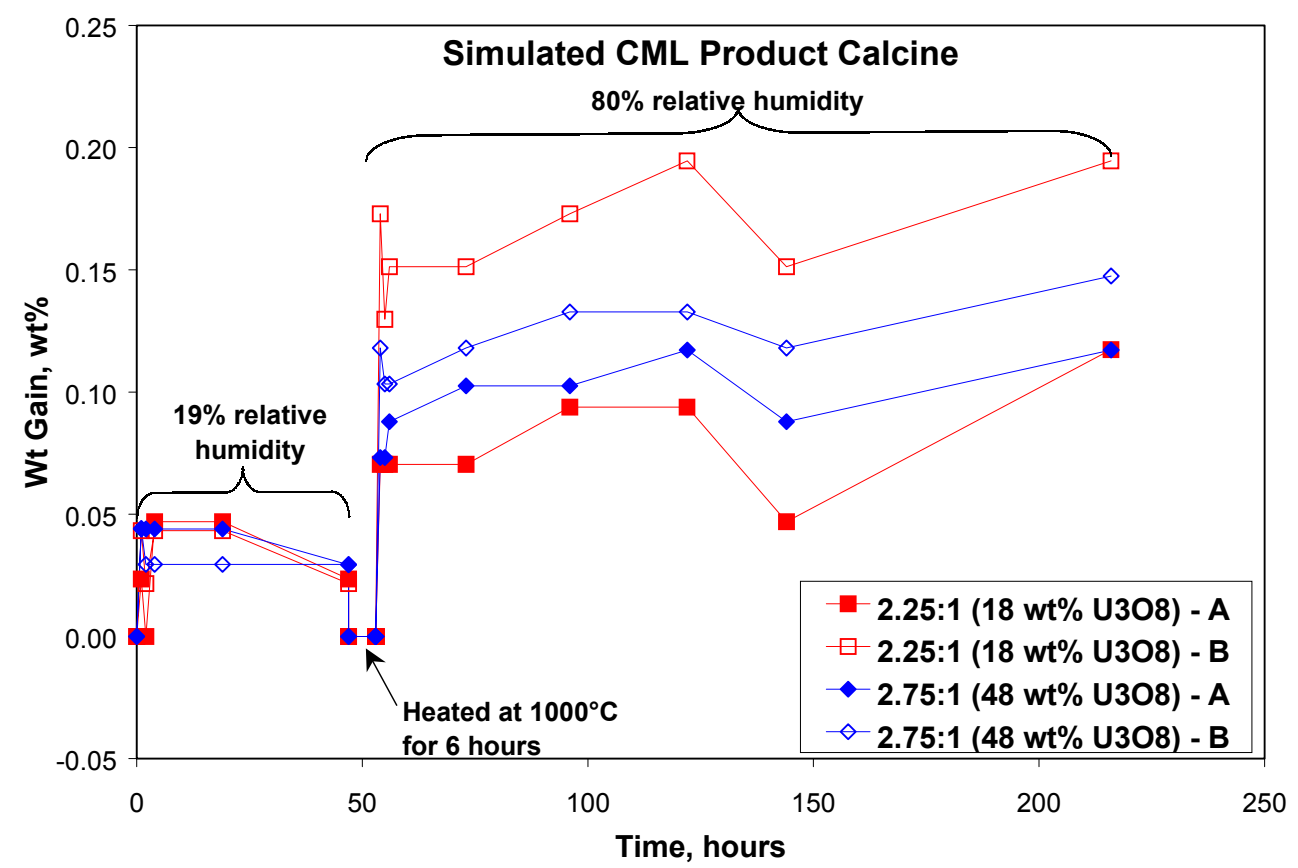

Figure 26. Moisture Uptake on Calcined Simulated CML Product Prepared at 2.25:1 and 2.75:1 Oxalate:Pu Ratio as a Function of Humidity and Exposure Time

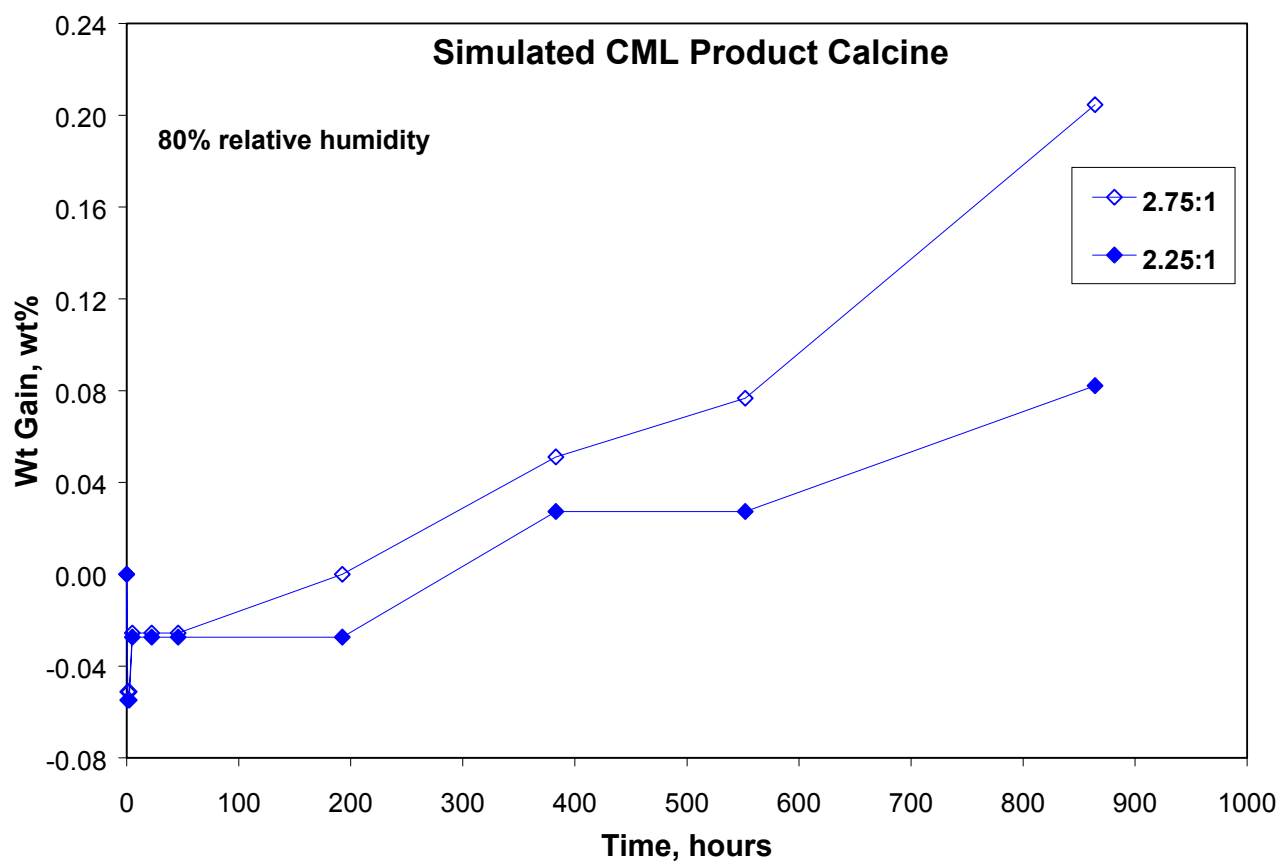

Figure 27. Moisture Uptake on Calcined Simulated CML Product Prepared at 2.25:1 and 2.75:1 Oxalate:Pu Ratio at $80 \% \mathrm{RH}$ as a Function of Exposure Time 


\subsection{Tests of the Calcination and Moisture Uptake of Genuine CML Oxalate Precipitate Product}

TGA and LOI measurements were made of oxide products prepared by calcination of oxalate precipitates from genuine CML solution. Three samples of oxide from genuine CML solution were prepared and analyzed for these tests.

Two of the oxides (called A and B) were prepared from a composite of 50-mL precipitation test products (results depicted in Figure 13). The starting solutions contained 20 to $40 \mathrm{~g} \mathrm{Pu} / \mathrm{L}$ and 60 to $110 \mathrm{~g}$ $\mathrm{U} / \mathrm{L}$ in 1 to $2 \mathrm{M} \mathrm{HNO}_{3}$. Because the oxalate:Pu mole ratios varied from 0.5:1 to 8:1 (with many of the tests at the higher ratios), the uranium concentrations in the precipitates were high. After the solutions from these tests were sampled, the solids were filtered, rinsed with water (wash volume approximately equal to the cake volume), and dried on a hot plate to constant weight. The dried solids were transferred to crucibles and calcined by two hours' heating to $1000^{\circ} \mathrm{C}$. The calcined solids were cooled in the furnace. A third oxide solid (called C) was prepared from a precipitation of $39 \mathrm{~g} \mathrm{Pu} / \mathrm{L}$ and $80 \mathrm{~g} \mathrm{U} / \mathrm{L}$. The oxalate:Pu ratio was $4: 1$ and the filtercake was not washed.

The PFP Analytical Laboratory assayed the samples for Pu concentration and LOI (Table 5). The exposure time is the period the calcined material was open to ambient glovebox air at 20 to $60 \% \mathrm{RH}$. Plutonium concentrations are $\sim 40 \mathrm{wt} \%$ for all three tests. Because the calcine product is a nearly pure mixture of $\mathrm{PuO}_{2}$ and $\mathrm{U}_{3} \mathrm{O}_{8}$, the uranium concentrations may be calculated by difference (results in Table 5). In all cases, LOI values are well below the $0.5-\mathrm{wt} \%$ threshold, even the material exposed for 57 days to ambient plant humidity.

Duplicate samples from the three test materials were analyzed using the PPSL's Netzsch TGA/MS to measure weight loss compared with water, carbon dioxide, and oxygen gas products. As shown in Figure 28 , the weight loss for sample A up to $1000^{\circ} \mathrm{C}$ was about $0.2 \mathrm{wt} \%$, but an additional $0.1 \mathrm{wt} \%$ loss occurred during the one-hour hold at $1038^{\circ} \mathrm{C}$. As shown by mass spectrometry (MS) (Figure 29), the weight loss during the $1038^{\circ} \mathrm{C}$ hold was not due to water or carbon dioxide. The water loss was highest at about $100^{\circ} \mathrm{C}$ and complete by $500^{\circ} \mathrm{C}$ while the carbon dioxide loss centered at about $350^{\circ} \mathrm{C}$ and was complete by $600^{\circ} \mathrm{C}$. The $\sim 0.1 \mathrm{wt} \%$ loss occurring above $800^{\circ} \mathrm{C}$ and during the subsequent one-hour high temperature hold was due to $\mathrm{O}_{2}$ generation (Figure 30), likely from the decomposition of $\mathrm{U}_{3} \mathrm{O}_{8}$ to $\mathrm{U}_{3} \mathrm{O}_{8-\mathrm{x}}$.

Table 5. Plutonium Concentrations, LOI, and TGA/MS for Oxide from Genuine CML Test Solutions

\begin{tabular}{|c|c|c|c|c|c|c|c|c|c|}
\hline \multirow{3}{*}{ Test } & \multirow{3}{*}{$\begin{array}{c}\text { Pu } \\
(w t \%)\end{array}$} & \multirow{3}{*}{$\begin{array}{c}\mathrm{U}, \\
(\mathbf{w t} \%)\end{array}$} & \multirow{3}{*}{$\begin{array}{c}\text { Exposure } \\
\text { Time } \\
\text { (days) }\end{array}$} & \multirow{3}{*}{$\begin{array}{c}\text { LOI } \\
(w t \%)\end{array}$} & \multicolumn{5}{|c|}{ TGA/MS (wt\%) } \\
\hline & & & & & \multicolumn{3}{|c|}{ TGA Weight Loss to } & \multirow{2}{*}{$\mathbf{H}_{2} \mathbf{O}$} & \multirow{2}{*}{$\mathrm{CO}_{2}$} \\
\hline & & & & & $600^{\circ} \mathrm{C}$ & $1000^{\circ} \mathrm{C}$ & $1 \mathrm{hr}$ at $1032^{\circ} \mathrm{C}$ & & \\
\hline \multirow{2}{*}{ A } & \multirow{2}{*}{37.5} & \multirow{2}{*}{48.7} & \multirow{2}{*}{57} & \multirow{2}{*}{0.12} & 0.086 & 0.20 & 0.35 & -- & -- \\
\hline & & & & & 0.081 & 0.20 & 0.34 & 0.13 & 0.10 \\
\hline \multirow{2}{*}{$\mathrm{B}$} & \multirow{2}{*}{43.6} & \multirow{2}{*}{42.9} & \multirow{2}{*}{2} & \multirow{2}{*}{0.04} & 0.150 & 0.25 & 0.44 & 0.19 & 0.11 \\
\hline & & & & & 0.152 & 0.24 & 0.45 & 0.20 & 0.11 \\
\hline \multirow{2}{*}{$\mathrm{C}$} & \multirow{2}{*}{36.3} & \multirow{2}{*}{49.9} & \multirow{2}{*}{1} & \multirow{2}{*}{0.06} & 0.114 & 0.24 & 0.37 & -- & -- \\
\hline & & & & & -- & -- & -- & 0.14 & 0.036 \\
\hline
\end{tabular}




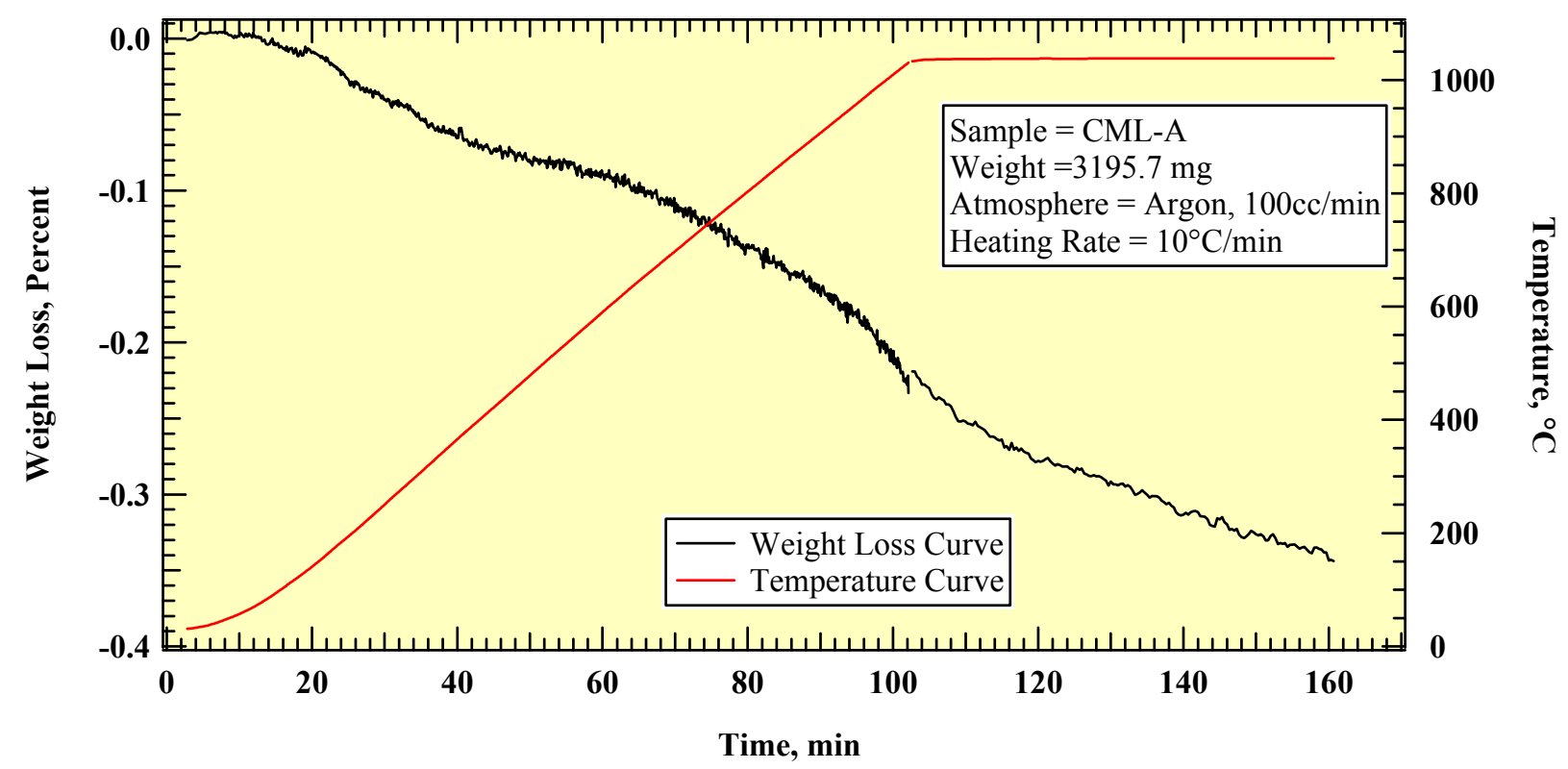

Figure 28. TGA of Genuine Calcined CML Product A

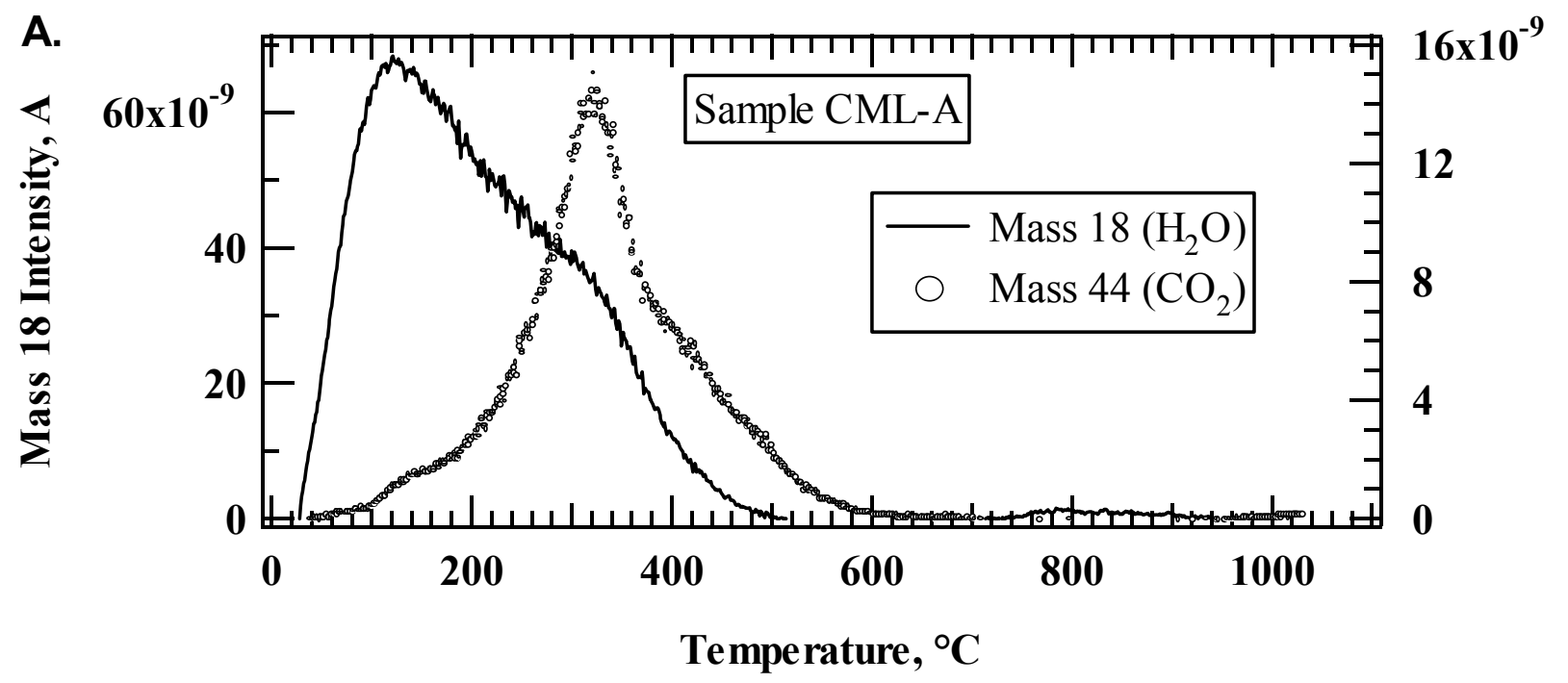

Figure 29. $\mathrm{MS}$ Analyses of $\mathrm{H}_{2} \mathrm{O}$ and $\mathrm{CO}_{2}$ from Genuine Calcined CML Product $\mathrm{A}$ 


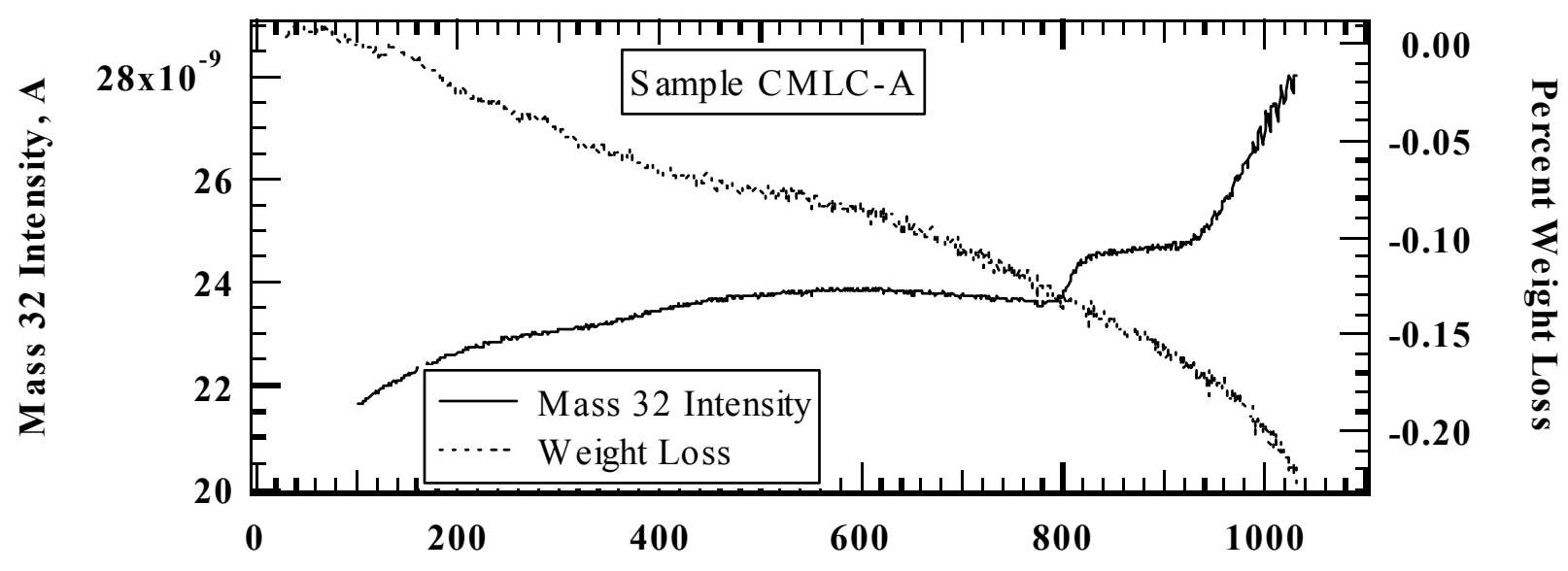

Tempe rature, ${ }^{\circ} \mathrm{C}$

Figure 30. MS Analysis of Oxygen from Genuine Calcined CML Product A

In summary, the TGA/MS data show that even with high uranium concentrations and prolonged exposure to glovebox humidity, water concentrations in calcined CML oxalate product were $0.2 \mathrm{wt} \%$ or lower and LOIs to $1000^{\circ} \mathrm{C}$ were $0.25 \mathrm{wt} \%$ or lower. The TGA/MS also showed that oxygen loss above $800^{\circ} \mathrm{C}$, likely from decomposition of $\mathrm{U}_{3} \mathrm{O}_{8}$ to a sub-stoichiometric composition, is significant. Under LOI conditions, this oxygen should be re-absorbed on cooling to reform the stoichiometric $\mathrm{U}_{3} \mathrm{O}_{8}$ and thus not further increase the moisture concentration value for DOE-STD-3013 purposes. However, monitoring total weight loss at the end of heating to $1000^{\circ} \mathrm{C}$ for any period of time will include losses incurred by the conversion of $\mathrm{U}_{3} \mathrm{O}_{8}$ to sub-stoichiometric $\mathrm{U}_{3} \mathrm{O}_{8-\mathrm{x}}$ and thus overstate the mass assumed due solely to water loss.

\subsection{Principal Findings from the Calcination and Moisture Uptake Testing}

The overall findings from the calcination and moisture uptake testing for CML solutions processing are summarized:

- Uranyl oxalate, a product of the reaction of oxalic acid with U(VI) nitrate solution, calcines to produce $\mathrm{U}_{3} \mathrm{O}_{8}$ both by itself and in the presence of calcining $\mathrm{Pu}(\mathrm{IV})$ oxalate. No evidence was found by XRD or thermal analysis (at an estimated 5\% detection limit) for other uranium oxide phases (e.g., $\mathrm{UO}_{2}$ or $\mathrm{UO}_{3}$ ) in the freshly prepared calcine.

- Moisture uptake by $1000^{\circ} \mathrm{C}$-calcined $\mathrm{U}_{3} \mathrm{O}_{8}$ under $19 \% \mathrm{RH}$ is essentially nil; it is $\sim 0.03 \mathrm{wt} \%$ at $80 \% \mathrm{RH}$ after two days of exposure at each condition using $~ 3.5$-g samples. However, extended exposure of $\mathrm{U}_{3} \mathrm{O}_{8}$ to moist air results in partial conversion to metaschoepite, a U(VI) oxide hydrate phase.

- The quantity of hygroscopic boric oxide found in the product calcine is decreased under conditions of hotplate drying, presumably due to stream stripping of boric acid.

- Moisture uptake by calcined $\mathrm{CeO}_{2}$ (used as an inert surrogate oxide) saturated with boric acid at zero, nominal, and 1.5-fold expected concentrations is indistinguishable and low (0.005 wt \%) under 19\% RH and is $\sim 0.015-0.055 \mathrm{wt} \%$ at $80 \%$ RH after five days' exposure at each condition for $\sim 24$-g samples. 
- Moisture uptake on pure samples of $1000^{\circ} \mathrm{C}$ calcined $\mathrm{Gd}_{2} \mathrm{O}_{3}$ prepared from $\mathrm{Gd}(\mathrm{III})$ oxalate precipitate is $\sim 0.02-0.05 \mathrm{wt} \%$ at $80 \% \mathrm{RH}$ after six days' exposure. The contribution of gadolinium oxide to the hygroscopicity of the CML product calcine therefore is expected to be negligible.

- Moisture uptake by $1000^{\circ} \mathrm{C}$-calcined $\mathrm{PuO}_{2} / \mathrm{U}_{3} \mathrm{O}_{8}$ produced at 2.25:1 and 2.75:1 oxalate:Pu ratios occurs within a few hours; it is $0.03-0.05 \mathrm{wt} \%$ at $19 \% \mathrm{RH}$. Subsequent tests at $80 \% \mathrm{RH}$ show 0.12 to $0.20 \mathrm{wt} \%$ uptake after seven days' exposure for these $\sim 0.5$-g samples. Again, rapid uptake to a constant weight is observed. Additional tests of similarly prepared $1000^{\circ} \mathrm{C}$-calcined oxide products from 2.25:1 and 2.75:1 oxalate:Pu ratios but exposed solely to $80 \% \mathrm{RH}$ show about $0.04 \mathrm{wt} \%$ uptake after 16 days.

- Results of LOI analyses of oxides produced by calcination of genuine rinsed CML solution oxalate precipitates range from 0.04 to $0.12 \mathrm{wt} \%$. The $0.12 \mathrm{wt} \%$ result was obtained for a sample exposed for 57 days to plant humidity. This material also was measured by TGA/MS of the off-gases. According to these more detailed measurements, the mass of water arising from this sample corresponds to $0.14 \mathrm{wt} \%$.

- LOI methods may be used to measure moisture concentrations of oxide products from CML nitrate solutions. However, care must be exercised in applying TGA to determine LOI in that weight losses occurring above about $900^{\circ} \mathrm{C}$ due to reversible oxygen loss from $\mathrm{U}_{3} \mathrm{O}_{8}$, contained in the calcine, to form sub-stoichiometric $\mathrm{U}_{3} \mathrm{O}_{8-\mathrm{x}}$ may cause (conservative) over-reporting of moisture concentration.

The moisture uptake studies all were conducted with small samples having relatively high surface-areato-volume ratios compared with plant materials in calcination process boats. Despite the small sample size, favorable calcination, moisture uptake, and LOI results were obtained. Therefore, it is suggested, conservatively, that calcination of oxalate products from CML feed solutions can be packaged under the RMC line humidity conditions $(<60 \% \mathrm{RH})$ provided that the time between the end of calcination and hermetic packaging of the product does not exceed three days. Though longer times between calcination and packaging may be tolerated, three days is an adequate interval between these process operations.

The results also showed that despite the favorably low moisture uptakes observed in the present tests, $\mathrm{U}_{3} \mathrm{O}_{8}$ is not stable indefinitely to humid air and can absorb water and oxidize to form metaschoepite. Therefore, prudence dictates that precipitation of the already unwanted uranium by disproportionate overdosing of oxalate to the CML solutions be limited to the extent practicable. 


\subsection{References}

Bernal S, FJ Botana, R Garcia, and JM Rodriguez-Izquierdo. 1987. "Behaviour of Rare Earth Sesquioxides Exposed to Atmospheric Carbon Dioxide and Water." Reactivity of Solids 4:23-40.

Bock R. 1979. A Handbook of Decomposition Methods in Analytical Chemistry, pp. 86-88. International Textbook Company, London.

Bressat R, B Claudel, and Y Trambouze. 1963. "Study of the Thermal Decomposition of Uranyl Oxalates and Uranium(IV) Oxalates." Bulletin de la Societe Chimique de France 3:464-470. Translation from French by ER Appleby, HW-TR-56, Hanford Atomic Products Operation, Richland, WA. See also discussion in "The Thermal Decomposition of Oxalate. A Review," D. Dollimore, Thermochimica Acta 117:331-363 (1987).

Brouns RJ and WW Mills. 1955. The Preparation of Primary Standard $U_{3} O_{8}$. HW-39767, Hanford Atomic Products Operation, Richland, WA.

Burney GA and JA Porter. 1967. "Solubilities of Pu(III), Am(III), and Cm(III) Oxalates." Inorganic and Nuclear Chemistry Letters 3:79-85.

Buttress GD and MA Hughes. 1968. "The Thermal Decomposition of Uranyl(VI) Oxalate." Journal of the Chemical Society (A) 8:1985-1989.

Chen F, RC Ewing, and SB Clark. 1999. "The Gibbs Free Energies and Enthalpies of Formation of U ${ }^{6+}$ Phases: An Empirical Method of Prediction.” American Mineralogist 84:650-664.

Chernyaev II. 1966. Complex Compounds of Uranium, p. 117 (Figure 71). Translation from Russian published by Israel Program for Scientific Translations, Jerusalem.

Curtis CE and JR Johnson. 1957. "Ceramic Properties of Samarium Oxide and Gadolinium Oxide; X-Ray Studies of Other Rare-Earth Oxides and Some Compounds." Journal of the American Ceramic Society 40(1):15-19.

DOE. 2000. Stabilization, Packaging, and Storage of Plutonium-Bearing Materials, DOE-STD-30132000, U.S. Department of Energy, Washington, DC.

Duval C. 1963. Inorganic Thermogravimetric Analysis, $2^{\text {nd }}$ edition, p. 666. Elsevier Publishing Company, Amsterdam.

Gel'man AD, AI Moskvin, LM Zaitsev, and MP Mefod'eva. 1962. Complex Compounds of Transuranium Elements, p. 96. Translation from Russian published by Consultants Bureau, New York.

Gmelin. 1974. Seltenerdelemente, Teil C1, "Sc, Y, La und Lanthanide." Gmelin Handbuch der Anorganischen Chemie, pp. 109 and 166, Springer-Verlag, Berlin (in German).

Greenwood NN and A Earnshaw. 1984. Chemistry of the Elements, p. 229. Pergamon Press, Oxford, UK. Greintz RM and DH Neal. Plutonium(IV) Oxalate Precipitation and Calcination Process for Plutonium Nitrate to Oxide Conversion. RFP-2602, Rockwell International, Golden, Colorado (Applied Technology).

Harmon KM and JF Facer Jr. 1953. The Precipitation of Plutonium(IV) Oxalate in Task I. HW-27563, Hanford Atomic Products Operation, Richland, WA. 
Harmon KM, BF Judson, WL Lyon, RA Pugh, and RC Smith. 1961. "Plutonium Reconversions." Chapter 11 in Reactor Handbook, $2^{\text {nd }}$ edition, Volume II, Fuel Reprocessing, SM Stoller and RB Richards, eds. Interscience Publishers, New York, p. 450.

Havel J. 1969. "Spectrophotometric Study of Complex Formation of Uranyl with Oxalic Acid." Collection Czechoslovak Chemical Communications 34:3248-3265.

Hindman JC. 1954. "Ionic and Molecular Species of Plutonium in Solution," pp. 349-350 in Chapter 9 of The Actinide Elements, G. T. Seaborg and J. J. Katz, editors, McGraw-Hill Book Company, New York.

Icenhour AS, LM Toth, and H Luo. 2002. Water Sorption and Gamma Radiolysis Studies for Uranium Oxides. ORNL/TM-2000/59, Oak Ridge National Laboratory, Oak Ridge, Tennessee.

Kolthoff IM, PJ Elving, and EB Sandell. 1962. Treatise on Analytical Chemistry, Part II, Analytical Chemistry of the Elements, Vol. 9, "U • The Actinides," pp. 74-76. Interscience Publishers, New York. Mandleberg CJ, KE Francis, and R Smith. 1961. "The Solubility of Plutonium Trifluoride, Plutonium Tetrafluoride, and Plutonium(IV) Oxalate in Nitric Acid Mixtures." Journal of the Chemical Society 1961:2464-2468.

Markovskiı̌ LY. 1962. “Oxygen Compounds of Boron.” Chapter V in Boron, Its Compounds and Alloys. GV Samsonov, LY Markovskiı̌, AF Zhigach, and MG Valyashko, translation published as AEC-tr-5032, U.S. Atomic Energy Commission, Washington, DC, and references therein.

Myers MN. 1956. Thermal Decomposition of Plutonium(IV) Oxalate and Hydrofluorination of Plutonium(IV) Oxalate and Oxide. HW-45128, Hanford Atomic Products Operation, Richland, WA.

O'Hare PAG, BM Lewis, and SN Nguyen. 1988. "Thermochemistry of Uranium Compounds XVII. Standard Molar Enthalpy of Formation at $298.15 \mathrm{~K}$ of Dehydrated Schoepite $\mathrm{UO}_{3} \cdot 0.9 \mathrm{H}_{2} \mathrm{O}$. Thermodynamics of (Schoepite + Dehydrated Schoepite + Water)." Journal of Chemical Thermodynamics 20:1287-1296.

Reas WH. 1949. "Identification of Plutonium(IV) Oxalate Complexes in Oxalic Acid Solution.” paper 4.9 in The Transuranium Elements, GT Seaborg, JJ Katz, and WM Manning (eds). National Nuclear Energy Series, IV-14 B, Vol. 1, McGraw-Hill, New York.

Ribnikar SV and MS Trtica. 1998. "Infrared Spectra of Uranyl Compounds in Alkali Halide Matrices: Oxalates and Acetates." Journal of the Serbian Chemical Society 63(2):149-157.

Sarver LA and PHMP Brinton. 1927. "The Solubilities of Some Rare-Earth Oxalates." Journal of the American Chemical Society 49:943-958.

Schmieder H and E Kuhn. 1972. "Automatische Kontrolle und Steuerung von Aufarbeitungsprozessen für Kernbrennstoffe durch Spektralphotometrie und Leitfähigkeitsmessung." Chemie-Ingenieur Technik 44(3):104-111 (in German).

Tel H, M Bülbül, M Eral, and Y Atlaş. 1999. "Preparation and Characterization of Uranyl Oxalate Powders." Journal of Nuclear Materials 275:146-150.

Urbanec Z and L Sedláková. 1963. "Phase Changes in the Reaction of an Oxide of Composition Between $\mathrm{UO}_{3}$ and $\mathrm{UO}_{2.67}$ with Water Vapor." UJV-940/63, Institute of Nuclear Research, Czechoslovak Academy of Science, ̌̌zž, Czechoslovakia (in Czech); abstracted in Nuclear Science Abstracts 18(23):41377 (1964) and Chemical Abstracts 62:10060e (1965); see also Gmelin Handbuch der Anorganischen Chemie, Uran, Teil C2, 1978, "Oxide $\mathrm{U}_{3} \mathrm{O}_{8}$ und $\mathrm{UO}_{3}$. Hydroxide und Oxyhydrate sowie Peroxide," p. 119, SpringerVerlag, Berlin (in German). 
Vita OA, CR Walker, and E Litteral. 1973. "The Gravimetric Determination of Uranium in Uranyl Nitrate." Analytica Chimica Acta 64:249-257.

Vochten R, E De Grave, and H Lauwers. 1990. "Transformation of Synthetic $\mathrm{U}_{3} \mathrm{O}_{8}$ into Different Uranium Oxide Hydrates." Mineralogy and Petrology 41:247-255.

Wagman DD, WH Evans, VB Parker, RH Schumm, I Halow, SM Bailey, KL Churney, and RL Nuttall. 1982. "The NBS Tables of Chemical Thermodynamic Properties - Selected Values for Inorganic and $\mathrm{C}_{1}$ and $\mathrm{C}_{2}$ Organic Substances in SI Units." Journal of Physical and Chemical Reference Data 11 (Supplement 2).

Weast RC, ed. 1976. Handbook of Chemistry and Physics, p. E-46, 57 $7^{\text {th }}$ Edition. CRC Press, Cleveland.

Weigel F. 1986. "Uranium." Chapter 5 in The Chemistry of the Actinide Elements, $2^{\text {nd }}$ edition, JJ Katz, GT Seaborg, and LR Morss, eds, pp. 266-267. Chapman and Hall, London.

Weigel F, JJ Katz, and GT Seaborg. 1986. "Plutonium." Chapter 7 in The Chemistry of the Actinide Elements, $2^{\text {nd }}$ edition, JJ Katz, GT Seaborg, and LR Morss, eds, pp. 567-569. Chapman and Hall, London. 